


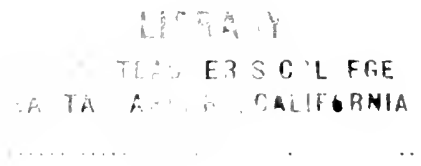






\section{THE FOUNDATIONS AND NATURE OF VERSE}




\section{COLUMBIA UNIVERSITY PRESS}

SALES AGENTS

NEW YORK

LEMCKE \& BUECHNER

30-32 West 27th Street

LONDON

HUMPHREY MILFORD

Amen Corner, E.C.

Shanghai

EDWARD EVANS \& SONS, LTD. 30 North Szechuen Road 


\title{
THE FOUNDATIONS \\ AND NATURE OF VERSE
}

\author{
BY \\ CARY F. JACOB, M.S., Ph.D.
}

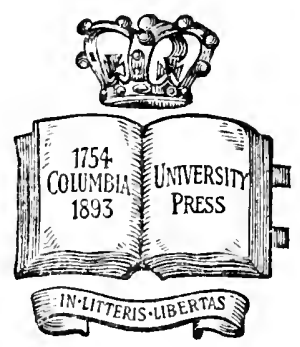

丹2etw 翼otk

COLUMBIA UNIVERSITY PRESS.

1918

All rights reserved 
Copyright, 1918

By Columbia University Press

Printed from type, February, 1918 


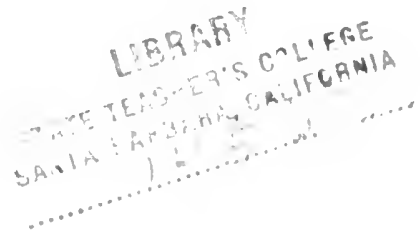

\section{FOREWORD}

OUT of the seeming chaos of conflicting opinion that has enveloped the study of English prosody, order at last begins to evolve itself. The deplorable lack of agreement among prosodists as to the very fundamentals of their science has led the sceptically inclined to a not unjustifiable questioning with regard to the propriety of dignifying as science the mass of writing concerned with phenomena about the nature of which so great an amount of uncertainty has prevailed and still prevails. That, through a long period of years and with ever increasing earnestness and skill, a large number of scholars have kept untiringly at work upon the solution of prosodic problems, is of itself occasion for encouragement and for congratulation, not for discouragement. The most remarkable aspect of the situation, when one considers the rather crude methods of investigation that have until comparatively recently been the only ones possible, is that from so marked a disparity of opinion as has prevailed an astonishingly large amount of truth has been brought to light. Almost every one who has approached the subject in a spirit of conscientiousness, and not of mere slavish imitation, has been able to contribute something of value to the gradually increasing quota of knowledge, even though in many instances his contribution has seemed to be at variance with the precepts of all established schools.

The chief difficulty has lain in the unusual breadth of the field. Too frequently each writer has fixed his atten- 
tion exclusively upon those particular acres which could be seen from his own little rise. Where the range of vision has been sufficiently broad to include the areas covered by other inquirers, they have formed themselves into a school and have taken up the cudgel against all who did not see as they saw. This type of partizanship has led to great activity; but it has not always made for open-mindedness. Often it has been the means of obscuring more truth than it has revealed. The time has now come when quite a number of prosodists are prepared to see that the light does not rest exclusively within the keeping of any individual or of any one group. Facts can be brought together, sometimes from the most unpromising sources, and their correlation so established as to effect a synthesis that does not involve a compromise. This can be accomplished more readily by a qualitative than by a quantitative method of procedure, - not so much by a tabulation of data as by a judicious weighing of the facts already at hand.

"The use of prosody," says Professor J. B. Mayor, "1 "is to supply a technical language by which to describe each specimen of verse brought before us, to distinguish the different kinds of verse, and to establish a type of each, with reference to which existing varieties may be compared, and finally to state the laws of composition which have been observed by those whom the world recognizes as poets. Then from this we may draw practical rules of art for the use of the poet or the reader." Fortunately, the poets before beginning to write have never waited for the prosodists to formulate the rules of poetic art. Guided by the verse of their predecessors and by their own good taste, they have written. It has remained for the prosodist to reformulate his rules time and time again in order that they might meet the demands of an ever broadening ${ }^{1}$ Transactions of the Philological Society, 1873-4, p. 624. 
conception of art. Where the rules have not been sufficiently elastic, the rules, and not the verse, have had to go by the board. The function of the prosodist is to describe and to interpret, - not to make rules, but to say what rules the poets seem to have followed. As critic he can praise or condemn, - not, however, on the ground of preeedent, but upon the more comprehensive basis of whether or not a given production follows the natural and artistic trend of its genus.

"In a subject like prosody," Professor Mayor continues, "there is danger of confused treatment, arising from its connection with history on the one hand and astheties on the other. There are thus three views which may be taken of it: [first,] . . the purely scientific, or logical; secondly, the historical, which brings in the succession of time, and traces the growth of one form out of another; thirdly, the æsthetic, or subjective, which adds criticism to statement of fact, and points out beauties and defects in the various metres, or in the manner in which they have been handled. It is of great importance that the first view should be kept clear of the other two, that an antiquarian yoke, for instance, should not be laid upon the readers and the writers of the present, and their verses be denied to be metrical at all, or else twisted and mangled to suit the usage of five centuries ago; just as the modern sentence might be condemned as ungrammatical because it could not be explained on antiquarian views of syntax."

In my attempt to avoid most effectively the pitfalls into which so many prosodists have stumbled, I must say at once, that, although I consider both the historical and the æsthetic methods of the highest importance and of indispensable value in establishing a comprehensive view of the subject, and that, although I shall use them wherever they can make plainer the path I have chosen, never- 
theless, it is the purely scientific, or logical, method I purpose to follow, (1) because it offers the most satisfactory solution of a large number of existing problems; (2) because, in consequence of recent investigations by psychologists and physicists, much invaluable material is for the first time available, which must be interpreted upon some broad, general principle before it can influence our conception of the poetic principle; (3) because, through the application of the results of these experiments to prosodic problems, quite a number of questions which until now have been in abeyance can at last be answered definitely and, I hope, finally; (4) because, unless certain facts are placed before them at this time, the workers in the fields of historical and æsthetic prosody may find themselves in need of knowledge, a lack of which may occasion them considerable delay in solving their own particular problems.

I do not pretend to present any fact hitherto unknown. Whatever value this contribution may have, rests, I believe, in the bringing together of a large body of material until now undigested. Many of the propositions herein set forth are the result of independent conclusions reached at a time when there was only my own judgment to support them. Since experimental psychology has now given validity to these opinions, I do not hesitate to present them as facts and to add in their support the weight of such other authority as I have been able to collect.

I regret that it is impossible for me to publish at this time a complete bibliography of the enormous number of books, pamphlets, and magazine articles relating to the prosodic problem. Such a bibliography would be a volume in itself. I am glad, however, to be able to append to this dissertation a few works containing full, though not complete, references to the important contributions to the subject. If the drudgery of others whose interest shall tempt 
them to rework the ground I have covered can thus be lightened in any wise so as to give them more time for constructive thought upon vital issues, I feel that they, too, will recognize the debt of gratitude due the compilers of these bibliographies.

UNIVERSITY OF VIRGINIA,

CARY F. JACOB

June 1, 1917 



\section{CONTENTS}

Foreword . . . . . . . . . . . . . . v

I. INTRODUCTION . . . . . . . . . . . . . . . 1

II. NoIse and Tone . . . . . . . . . . . . . . . \&

III. PITCH . . . . . . . . . . . . . . . . . . . 12

IV. Tone Quality . . . . . . . . . . . . . . . . 38

V. The Quality of Vowel Sounds. . . . . . . . 43

VI. IN'TENSITY . . . . . . . . . . . . . . . . . . . 61

VII. Genetic Aspects of Rhtтhi . . . . . . . . 65

VIII. Thü . . . . . . . . . . . . . . . . 80

IX. Rhythi Defined . . . . . . . . . . . . . . . 95

X. Duration . . . . . . . . . . . . . . . . 103

XI. Accent . . . . . . . . . . . . . . . . . . . 122

XII. The Phrase: its Nature and its Length . . . 144

XiII. Rhyme and the Line: their Relation to the Phrase . 160

XIV. The Structure of the Foot: Accent, Duration, and

Pitch in the General Process of Time Srnthesis . 168

XV. The Content of the Phrase. . . . . . . . . . . 193

XVI. The Rhythi of Prose . . . . . . . . . . . . . . 199

XVII. Scansion . . . . . . . . . . . . . . 211

XVIII. SummarY . . . . . . . . . . . . . . . . 213

Appendix (Bibliography) . . . . . . . . . . . 219

INDEX . . . . . . . . . . . . . . . 221 


$$
\text { - }
$$




\section{THE FOUNDATIONS AND NATURE OF VERSE}

\section{CHAPTER I}

\section{INTRODUCTION}

So thoroughly accustomed to the use of print are we that years of our lives are spent in silent enjoyment of its message without our once being impressed by the complexity of the act we are performing. ${ }^{1}$ We lose sight entirely of the difficulty with which we first learned to associate sound with symbol and symbol with sound. And what of our first attempts to read without pronouncing the words aloud? What of the days and days spent in preliminary whispering before we finally succeeded in suppressing every muscular movement except those of the lips? But in time these, too, were overcome; and the silent association of sound and symbol passed from the field of the automatic to that of the reflex, so that through the medium of the eye the mind was finally capable not only of hearing and interpreting the unspoken sounds but also of shading them with every degree of intensity, duration, and pitch. After this stage has been reached, it does not require an unusual endowment of imagination to carry us a step or two farther until even the facial expressions and the gestures accompanying the words of the speakers present themselves

'Walter Fenno Dearborn: "The Psychology of Reading," Archives of Psychology, Science Press. 
to us; and we are able to grasp simultaneously both the complexities of an exciting situation and the nicest subtleties of character and of motive, - all without our raising our eyes from the page or uttering one sound. Add to this, particularly in the case of verse, the conscious enjoyment of the beauties of rhythm and of vowel and consonant combinations and correspondences, which, aside from the ideas which they convey, give to the words themselves a peculiar fascination; and the occasion for wonder is anything but decreased.

Even in the face of such an accomplishment as this, however, we are no little surprised and just a bit incredulous on being told, that, without the aid of an instrument or even of his voice, a well-trained musician can enjoy the harmonies symbolized by the lines and dots of an orchestral score. Such a feat seems almost impossible. Still, as between the reading of print and the reading of music, the latter is the less remarkable accomplishment. Certainly it involves for the musically endowed much less tax upon either the imagination or the powers of interpretation than the reading of print involves for the ordinary man. The comparative infrequence of our meeting with any one able to interpret a musical score as readily as he can interpret the written page is due to the fact that only a very few persons ever have occasion to become as entirely familiar with the sounds of the different musical instruments, or even with those of any one instrument, as practically every one has of becoming with the speech sounds themselves, if not with the speech symbols. The processes involved in the interpretation of the one set of symbols are exactly those involved in the interpretation of the other; and, if the two were equally familiar, the musically inclined might stretch himself in his easy chair for the enjoyment of an evening of Beethoven quite as fre- 
quently as the man of literary tastes now spends his time with Shelley or with Wordsworth.

Although prose or verse or music may be read and enjoyed without the intermediary voice as interpreter, I do not suppose any one doubts, that, because the mind is able to supply through the imagination its own instrument of sound production, prose or verse or music is not essentially and completely an appeal to the intelligence and the emotions through the muscular sense or through the sense of hearing. ${ }^{1}$ It is quite possible to exchange ideas by other means than the medium of sound. Witness the sign language of the dumb. Under certain conditions, a fire on a mountain top, a grouping of different colored flags, or even postures of the body can convey their message quite as effectively as if words were employed. It is only when the ideas to be expressed have become highly complex in character that so delicate and varied a system of communication as is language need be employed, or that sounds, which in the early periods of our history as a race were of the most rudimentary nature, may develop into the medium of expression for our most exalted emotions. Serving at the one extreme the purposes of our common, daily needs, as the ideas to be expressed become more and more emotionalized, words may be combined to meet the respective exigencies of prose, ${ }^{2}$ oratory, street cries, ${ }^{3}$ verse, song-

${ }^{1}$ Wilhelm August Ambrose: "The Boundaries of Music and Poetry" (G. Schirmer, New York, 1903), pp. 127-138.

Harry Porter Weld: "An Experimental Study of Musical Enjoyment," Amer. Journal of Psychol., 1912, XXIII., pp. 245-308.

Christian A. Ruchmick: "The Rôle of Kinæsthetics in the Perception of Rhythm," Amer. Journal of Psychol., 1913, XXIV.

${ }^{2}$ F. von Andrian: "Some Results of Modern Ethnology," Correspondenzblatt der deutschen Gesellschaft für Anthropologie, Ethnologie, und Urgeschichte, 1894, No. 8, p. 71. I do not agree with this writer in thinking that the development of prose followed that of verse.

${ }^{3}$ William Gardner: "The Music of Nature." 
speech, ${ }^{1}$ intoning, ${ }^{2}$ recitative, ${ }^{3}$ chanting, ${ }^{4}$ and vocal music, ${ }^{5}$ until, finally, at the other extreme, having become void of all significance as language, syllables may find use in giving tone quality to the voice in its more or less ambitious flights into the realm of pure music. The same sounds which at breakfast enable us to order eggs and toast may in other combinations when falling from the lips of Maud Adams move us to laughter or to tears, or may transport us into the land of the invisible when used by Alma Gluck in the soarings of a florid Italian aria or in her adaptation to the voice of such a purely instrumental composition as Raff's "Élègie." All who are familiar with the sermonizing of the negro exhorter must have noticed how, with the rise of emotional intensity, he passes from singsong to shouting, and finally, without interruption, to the rocking melody of a spiritual in the burden of which intellectual significance may be entirely lacking. ${ }^{6}$ A similar use of meaningless syllables is common in the burdens of folk-songs and popular ballads of nearly all peoples. ${ }^{7}$ It should be

'Billert: "Japanische Musik" in Reissm. Mend. Lexicon, 5th vol., p. 368.

2 Jacobsthal: "Musikalische Bildung der Meistersänger" in Haupt's Zeitschrift für deutsches Alterthum, XX, $80 \mathrm{ff}$.

${ }^{3}$ Richard Wallaschek: "Primitive Music" (Longmans, London, 1893), pp. 180-186.

${ }^{4}$ Theodor Baker: "Über die Musik der Nordamerikanischen Wilden," p. 47.

'F. B. Gummere: "The Beginnings of Poetry" (Macmillan, 1901), Chapters II, through V.

${ }^{6}$ H. E. Krehbeil: "Afro-American Folk Song" (G. Schirmer, N. Y.) Guessfelt, Falkenstein, Pechuël-Loesche: "Die Loango Expedition," p. 76. I am familiar with the life of the negroes of Virginia, of which state I am a native, and in three sections of which I have lived consecutively for many years.

${ }^{7}$ Richard Wallaschek: "Primitive Music," pp. 170-172. Numerous examples can be found in F. J. Child's "English and Scottish Popular Ballads." For a satisfactory example see page 344 of the Houghton Mifflin Company's edition of 1904. 
clear, therefore, that the capacity for this infinity of expression rests in the human voice just as certainly as an equal capacity for the perception of these sounds rests in the ear, and that both music and poetry have at their disposal the medium of sound for suggesting or inducing emotions, - that is, for "sympathetic induction of emotion," as William McDougall very aptly phrases it. ${ }^{1}$ Thus poetry and vocal music, because they make use of words, can attain effects far more definite than those possible to pure music. ${ }^{2}$ By means of words, for instance, the progress of a fight can be followed in detail. Without words, a warlike emotion would be the nearest approach to the concrete which the same music could arouse. Yet, with words or without them, the pleasure derived from art is subjective. Though excited by the work of art, it is in oneself and of oneself. ${ }^{3}$ The appeal is to the primal nature of man. The sublimation may be so complete that the origin of the emotion may be lost sight of; but a careful investigation will invariably show that the primitive instinct of struggle against environment and the pervading urge of sex furnish the psychological basis for the material with which the tonal arts must deal. Love, hate, triumph, despair, joy, sorrow, awe, fear, - one and all from the shadow-land of psychic awakening, - are the emotions which arise most vividly at the seductive lure of sound.

It is not my purpose, however, to treat of the physiological effect of sound upon the ear or of its xsthetic value when heard. I can mention them only in passing; yet mention them I must. Otherwise it might be thought

1 "Social Psychology" (John Luce and Co., Boston, 1911), p. 92.

${ }^{2}$ Harry Porter Weld: "An Experimental Study of Musical Enjoyment," Amer. Journal of Psychol., XXIII., April, 1912, pp. 245-308.

3 J. Donovan: "From Lyre to Muse," p. 87. 
that I am attempting to account upon a strictly physical basis for all the phenomena of the tonal arts. When the last word as to the physical structure and form has been said, the hitherto incalculable factor of the psychological capacity for the appreciation of art must be taken into consideration. Yet, for the purposes of this inquiry, it must be granted that the ear does hear and that it does find pleasure in such sounds as through the ages have furnished the material for art. ${ }^{1}$ Fortunately, the fundamental phenomena of the subject lie within the range of experience common to civilized and even to savage man, so that the physiological psychologist has been able to work out in his laboratory answers to the most important questions which suggest themselves. Not until these have been exhausted need there be any dispute relative to matters of taste; but, whenever taste is involved, whatever the ears of men of artistic temperament do not condemn in the purely physical structure of a composition must be pronounced at least passable art. All that can not be established through the ear must remain unsolved. Therefore, for the time being, as my interest is neither antiquarian nor æsthetic, I must address myself primarily to those who are interested in the physical structure of verse.

Certain phenomena are common to prose, verse, and music. Wherein and to what extent the three are dissimilar can be shown to be the result of slightly different uses made of the same physical material, so that the separate forms are exhibited as arising from the same phenomena through the combination in varying degrees of their several constituent parts. Prose will be seen to grade almost imperceptibly into verse, verse into song, and song into

${ }^{1}$ Henry T. Moore: "The Genetic Aspects of Consonance and Dissonance," Psychological Monographs, Vol. XVII., No. 73 (Psychological Review Co., Lancaster, Pa.). 
pure music. Indeed, there is often much discussion as to with which of two art forms a certain production should rightly be classed. For my part, however, I can see no reason why any one need puzzle himself with the drawing of over-nice distinctions. The boundaries of the three forms are much too ill-defined to admit of one's making a clean-cut partition. Yet, lest my attitude on this point be misunderstood, I hasten to say that I do not think the highest art ever results from a form which is not clearly and definitely on one side of the marches. 


\section{CHAPTER II}

\section{NOISE AND TONE}

ALL sound is the result of vibration. First, there is the vibration of the body in which the sound originates; second, the vibration of some medium (normally the atmosphere) which transmits the sound; and, third, the vibration of the nerves of the ear of the person who perceives the sound. Sound, therefore, may be defined as "the sensation resulting from the action of an external stimulus on the sensitive nerve apparatus of the ear"; ${ }^{1}$ yet for present purposes it is better to restrict the meaning of the term so as to have it designate, not the resulting sensation, but rather the vibrations originating in the sounding body itself, because to these are due all the peculiarities which are felt as characteristic of any sound or combination of sounds.

Art does not make use of all kinds of sounds. It selects only those capable of coördination by the ear, - that is, only those which are musical. It is well, therefore, in analyzing sounds to divide them into two classes. Those of the first class are called noises; those of the second, tones.

"Noise and tone are merely terms of contrast, in extreme cases clearly distinct, but in other instances blending; the difference between noise and tone is one of degree. A simple tone is absolutely simple mechanically; ${ }^{2}$ a musical tone is more or less complex,

${ }^{1}$ Dayton Clarence Miller: "The Science of Musical Sounds," p. 2 (Macmillan, 1916).

${ }^{2}$ It is the result of vibration back and forth like that of a pendulum when allowed to swing freely in its are. 
but the relations of the component tones, and of one musical sound to another, are appreciated by the ear; noise is a sound of too short duration or too complex in structure to be analyzed or understood by the ear.

"The distinction sometimes made that noise is due to nonperiodic vibration while tone is periodic, ${ }^{1}$ is not sufficient; analysis clearly shows that many so-called tones are non-periodic ... , and it is equally certain that noises are as periodic as some tones. In some instances noises are due to ehanging period, producing the effeet of non-periodicity; but by far the greater number of noises which are continuous are merely complex and apparently irregular, their analysis being more or less difficult.

"The ear, through lack of training or from absence of suitable standards for comparison or perhaps on account of fatigue, often fails to appreciate the charaeter of sounds and, relaxing the attention, classifies them as noises." 2

Just here let me emphasize a fact which I shall have occasion to reiterate, sometimes to the extent of tediousness, yet which cannot be too much dwelt upon if an accurate conception of the nature of the phenomena under consideration is to be obtained. As with noise and tone, so with all forms of art in which sound is employed, - there is no clear-cut line of demarkation between them. There are musical noises and unmusical tones. Art may employ both, provided the choice be made with circumspection. Differences in sounds are matters of degree, not of inherent differences of nature, so that, although I have said that art selects only those sounds capable of coördination, I do not wish to make the impression that sounds, which under ordinary circumstances would be considered as noises (such as the clacking of bones or the beating of the tambourine), may not be capable of coördination in some partic-

1 Periodic means recurring at regular intervals of time.

2 Dayton Clarence Miller: "The Science of Musical Sounds," pp. 21-22. 
ular, and, therefore, have their artistic uses, or that sounds which are coördinate, say in pitch (such as the regular vibrations of very, very low organ pipes), may not affect the ear so disagreeably as to be regarded as noises unfit for artistic purposes. In fact, it is impossible to exclude noise completely from even the purest musical sounds. The buzzing due to the friction of the bow as it is drawn across the strings of the violin, the glottal catch preceding the pronunciation of some vowels, ${ }^{1}$ and the hissing sound of the letter $s$, to mention only a few instances, are cases in point, presented at this time merely by way of illustration. We may begin, therefore, by excluding all sounds popularly considered as noises, and from now on confine our attention strictly to tones.

Any sound possessing continuity and definiteness to such a degree as may be appreciated by the ear is called a tone. All tones are characterized in four ways, - according (1) to pitch or frequency, (2) to quality or tone color, (3) to loudness or intensity, and (4) to duration or length. Upon pitch, quality, intensity, and duration depends every distinguishing feature of tonal art which has a physical basis. Their combination into various tonal and temporal units is a

1Fred Newton Scott: "Vowel Alliteration in Modern Poetry," in Modern Language Notes, Dec., 1915, Vol. XXX., pp. 233-237. The note at the bottom of page 237 is of importance:

"L. P. H. Eijkman's 'Notes on English Prosody' in Dic Neuen Sprachen, xvii, 443, and Daniel Jones's comment, Ibid., p. 571. Eijkman and Jones agree that the glottal catch is not uncommon in normal English speech, and the former quotes the letter written by Lloyd Viëtor in 1894 (Viëtor, Elemente d. Phonetik, paragraph 30, Ann. 5): 'I have not noticed any special substitution of glottal catch, for a dropped $h$; but I do notice that clear beginning, sometimes forcible enough to be called glottal catch, exists largely in English in certain positions, e.g. (a) when another vowel, especially a very similar vowel, precedes; (b) when a strong emphasis is intended. A speaker laboring under suppressed passion uses unconsciously the clear beginning."' 
psychological process. The use made by the mind of the phenomena thus presented to it is the result of subjective elements that need not be considered until after each of these purely physical components has first been dealt with in turn.

When pitch has been explained, I shall attempt to show to what artistic purposes it may be put and why the mind accepts some pitches and refuses others. Then, quality and intensity must undergo like manner of treatment. Finally, the all-important question of time and of temporal relationships will have to be disposed of. For, not until these four elements are understood as they are employed in their general aspects by prose, verse, and music, will it be possible to focus the discussion upon the specific problems of verse. 


\section{CHAPTER III}

\section{PITCH}

"The pitch of a sound is that tone characteristic of being acute or grave which determines its position in the musical scale; an acute sound is of high pitch, a grave sound of low pitch. Experiment proves that pitch depends upon a very simple condition, the number of complete vibrations per second; this number is called the frequency of the vibration." 1

The sound produced by a tuning fork is the result of simple, pendular vibrations set up in two metal bars. In string instruments, - such as the violins, the guitar, the piano, etc., - the sound is due to the vibration of the strings. Under the general title wind-instruments may be classed flutes, oboes, clarinets, horns of all kinds, the pipe-organ, the human voice, etc. In all instruments of this latter type the sound is the result of vibration induced in a stream of air, either by directing it against a sharp edge (as in the flute and the flute-pipes of the organ), or by causing it to set in motion an elastic tongue or reed (as in some of the pipes of the organ, in the oboe, and in the clarinet). In all wind-instruments it is necessary that the air be confined in a resonance chamber of some description, such as that furnished by the tube of the clarinet. Otherwise the tones are lacking in strength or in agreeableness or in both. For the production of voice sounds, two elastic, membranous bands, called the vocal cords, attached to the walls of the larynx, are drawn across the

${ }^{1}$ D. C. Miller: "Science of Musical Sounds," p. 26. 
trachea until their free edges meet. Between these edges air from the lungs passes, causing the cords to vibrate. The voeal cords have the power of thickening, flattening, shortening, or of vibrating in whole or in part, according as the sound to be produced is high or low. The rate of their vibration, of course, determines the pitch emitted. The buecal and nasal cavities furnish the necessary resonance ehamber. ${ }^{1}$

Some instruments, notably the piano and the pipe-organ, can produce only those pitches to which they are tuned. Others, like the violin and the human voice, have at their disposal an infinite variety of pitches, limited, of course, by the number of vibrations possible within the range of any particular kind of instrument. Though an exceedingly sensitive ear is capable of perceiving as continuous sounds with frequencies as low as six or eight and as high as twenty thousand or even thirty thousand, the sounds available for artistic purposes range in frequeney from about sixteen to $4,138 .^{2}$ The compass of the singing voice is from sixty for a low bass to about thirteen hundred for a very high soprano. The speaking voice is still further restricted.

"It is evident that the passage from one pitch to another must be made in one of two ways. Either the pitch of a sound changes suddenly from the initial state to the final state, in such a way that at no moment does the sound rest at, or pass through, any intermediate degree of pitch; or the pitch changes gradually in the direction of the final degree of pitch, that is, either upward or downward, and so passes through every possible intermediate degree but rests at none (portamento tones). These are the only two

${ }^{1}$ A very clear, popular description of the organs of speech is to be found in the "Encyclopedia Britannica" under Voice.

${ }^{2}$ Physicists vary in their findings with regard to range of musical audibility. I am quoting from the experiments of Dr. Rudolph Koenig, which were conducted with unusual care. 


\section{THE FOUNDATIONS AND NATURE OF VERSE}

ways in which a sound emanating from one and the same instrument can pass from one pitch to another. They may be compared to stepping and gliding. In the one case the intermediate space is leaped over, in the other it is traversed." 1

In ancient Greek music the unit of division was originally the tetrachord; in medieval music it was the hexachord. In modern music it is the octave. Within these limits the tone successions are arranged in various scales. The successive tones of a scale are called degrees. They are usually numbered from the first, or starting-tone, called the keynote, or key-tone, from below upward. The smallest interval allowed among the Chinese is a whole tone. The smallest in modern musie is a half tone. ${ }^{2}$ Among the Persians quarter tones are allowed.

"For rougher measurements, then, we are justified in assuming as a unit whatever interval we find most convenient for the purpose. The size of the interval will, of eourse, depend on the nature of the music concerned. Thus, in Hindu music the octave is regarded as consisting of twenty-two intervals (çrutis), such that nine of them make a fourth and thirteen a fifth, and consequently four make the major Whole-tone. In Javanese music five approximately equal intervals compose the octave. But ancient Greek music, like modern European music, recognizes an octave of twelve nominally small intervals of which five make up the Fourth and seven the Fifth and two the Tone, which is their difference. They are, however, unlike in this, that, while in modern music no in-

${ }^{1}$ Charles W. L. Johnson: "Musieal Piteh and the Measurement of Intervals among the Ancient Greeks" (Johns Hopkins University dissertation), p. 17.

2 This does not mean that the modern ear can not diseriminate as to intervals smaller than the half tone. Consult, C. E. Seashore: "The Measurement of Pitch Diserimination: A Preliminary Report" (Psychological Monograph, Vol. XIII., 1910); and T. F. Vance: "Variation in Piteh Diserimination" (Psychological Monographs, 1914, of the University of Iowa Studies in Psychology, VI). 
terval differing very widely from the twelfth part of an octave or some multiple thereof is used, in ancient Greek music on the contrary, the existence of various periods of Quarter- and Thirdtones (equal to one-half and two-thirds the Semi-tone respectively) is well attested. For this reason the Tone is perhaps a better unit of rough measurement than the Semi-tone." 1

In modern music when the scale is pure, the frequencies of tones that are a whole tone apart bear to each other the ratio 8:9. The frequencies of tones a half tone apart are to each other as 24:25 (from $\mathrm{C}$ to $\mathrm{C}$, for instance) or as 15:16 (from $\mathrm{D}$ b to $\mathrm{C}$ ). The ear, however, is not as exact in its measurements as it is usually conceived to be, so that modern music rarely employs a pure scale, but is satisfied with approximations. It makes use of a tempered scale, - that is, a scale in which only very few of the sounds employed bear to each other the actual mathematical ratios found in the pure scale. The method of modern musical notation takes into account only whole tones and half tones. Any degree of sound involving less than a half tone can not be represented by it.

The elasticity of sounding bodies capable of producing tones is such that the bodies vibrate not only as wholes but also in their aliquot parts. The law of their vibration was first definitely formulated by G. S. Ohm of Munich, and is known as Ohm's Law of Acoustics. D. C. Miller gives the following very convenient statement of this law:-

"All musical tones are periodic; the human ear perceives pendular vibrations alone as simple tones; all varieties of tone quality are due to particular combinations of a larger or smaller number of simple tones; every motion of the air which corresponds to a

${ }^{1}$ Charles W. L. Johnson: "Musical Pitch and the Measurement of Intervals among the Ancient Greeks," p. 39. 
complex musical tone or to a composite mass of musical tones is capable of being analyzed into a sum of simple pendular vibrations, and to each simple vibration corresponds a simple tone which the ear may hear." 1

For instance, a violin string at the same time that it vibrates throughout its length, divides itself into halves, thirds, quarters, fifths, etc., each fractional part emitting its own tone simultaneously with the sound of the fundamental, the tone emitted by the vibration of the full length of the string. The tones resulting from the vibration of these fractional parts of the string are variously known as harmonics, overtones, upper partial tones or more briefly partials. Koenig prefers to call them sounds of subdivision, as expressing their nature more exactly than any of the preceding terms. I find it more convenient, however, to speak of them simply as partials. The fractions of the string naturally vibrate with greater frequencies than the full length string. Beginning with the frequency of the fundamental tone, their frequencies are proportional to the series $1,2,3,4,5,6,7,8$, etc. Although only such tones as are one or more octaves ${ }^{2}$ from the fundamental are in perfect tune with it in our modern scale, the diagram which follows expresses as accurately as is possible by means of musical notation the partials of the fundamental $\mathrm{C}_{2} \cdot{ }^{3}$

1 "The Science of Musical Sounds," p. 62.

2 The octave is "a tone of the eighth diatonic degree above or below a given tone; the next higher or lower reduplicate of a given tone." "The Century Dictionary and Cyclopedia."

${ }^{3}$ This diagram is taken from page 64 of D. C. Miller's "The Seience of Musieal Sounds." "The notes on the staff represent the scale tones which are nearest to the overtones." The line a gives the number of the partials. The line $c$ gives the names of the notes. The line $b$ gives the frequencies according to the tempered scale. The line $d$ gives the frequencies according to the pure scale. The fundamental $\mathrm{C}_{2}$ is chosen purely as a matter of convenience. 


\section{Figure I}

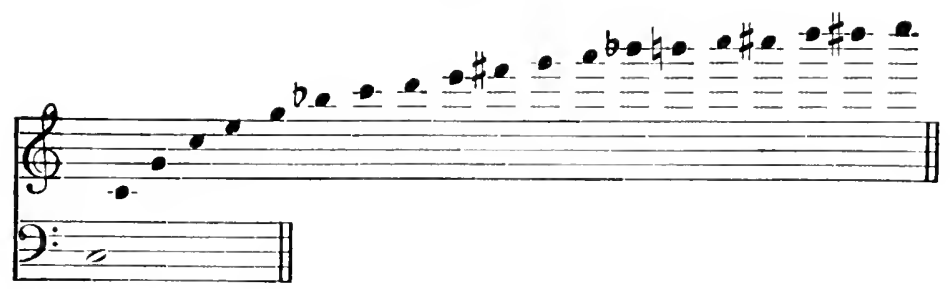

(a) $\begin{array}{llllllllllllllllllll}1 & 2 & 3 & 4 & 5 & 6 & 7 & 8 & 9 & 10 & 11 & 12 & 13 & 14 & 15 & 16 & 17 & 18 & 19 & 20\end{array}$

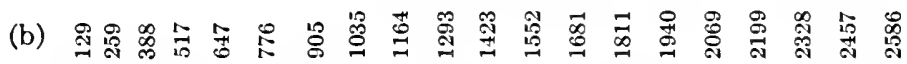

(c) $\mathrm{C}_{2} \mathrm{C}_{3} \mathrm{G}_{3} \mathrm{C}_{4} \mathrm{E}_{4} \mathrm{G}_{4} \mathrm{Bb}_{4} \mathrm{C}_{5} \mathrm{D}_{5} \mathrm{E}_{5} \mathrm{G}_{b_{5}} \mathrm{G}_{5} \mathrm{G}_{\mathrm{H}_{5}} \mathrm{Bb}_{5} \mathrm{~B}_{5} \mathrm{C}_{6} \mathrm{C}_{\mathrm{H}_{6}} \mathrm{D}_{6} \mathrm{D}_{6} \mathrm{E}_{6}$

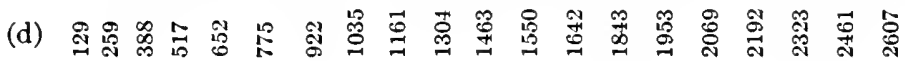

The interval from the fundamental to the first partial is an octave; from the fundamental to the second partial, an octave and a fifth; from the fundamental to the third partial, two octaves; from the fundamental to the fourth partial, two octaves and a major third; and so on. Some of the still higher partials are not at all agreeable when prominent. For this reason Koenig objects to their being called harmonics.

What is true of the vibration of the violin string is true of the strings of all string instruments, and equally true of all wind-instruments, especially the voice. Of course, in the case of wind-instruments it is the vibration of a column of air which is thus subdivided.

The reason why the sounds of the partials are not familiar as such to our ears is that their sounds are normally very faint. In order that their presence may become audible, some mechanism to aid in the analyzing of the tone is usually necessary, though acute ears can easily detect the more prominent partials. 
Upon the system of natural relationships furnished by these partials modern European music is based. Other scales than ours likewise make use of them, but to a more limited extent.

The mathematical ratios which the tones of the pure scale bear to the tonic, or tone upon which any scale is built, are given in the following diagram.

\section{Figure II}

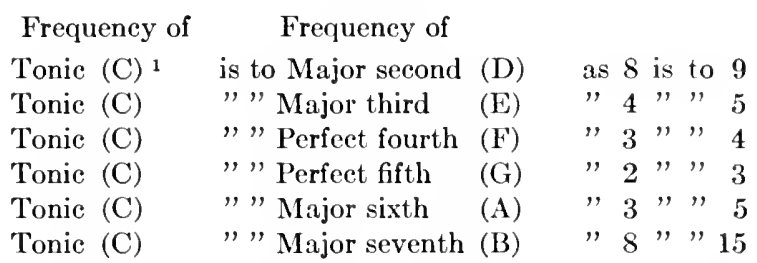

If, now, I start with $\mathrm{C}_{-1}$ as having a frequency of $16,{ }^{2}$ the frequency of $\mathrm{G}_{-1}$ will be 24 ; that of $\mathrm{E}_{-1}, 20$. Suppose that I next take $\mathrm{Gr}_{-1}$ as my tonic. The perfect fifth of that scale is $\mathrm{D}_{0}$. Its pitch will be to that of $\mathrm{G}_{-1}$ as $2: 3$, and will have a frequency of 36 . Now, using this $D_{0}$ as a tonic, its perfect fifth is $A_{0}$ with a frequency of 54 . Treating this $A_{o}$ in the same manner, $E_{1}$, its perfect fifth, will have a frequency of 81 . The same $E_{1}$ in the scale of $C$, from which we started, has a frequency of 80 . On the piano or the organ, these tones are one and the same, though the $\mathrm{E}_{1}$ in the key of $\mathrm{C}$ has a frequency of 80 and $\mathrm{E}_{1}$ in the key of $A$ has a frequency of 81 . A diagram may help to make this clearer.

${ }^{1}$ I have used $\mathrm{C}$ as tonic merely for convenience of illustration. Any other tone might have served just as well.

${ }^{2}$ What pitch shall be used as a standard is purely arbitrary. Different pitches have been used at different times. International Pitch is really 16.17. For rough measurements it is just as well to drop the fraction. 
Figure III
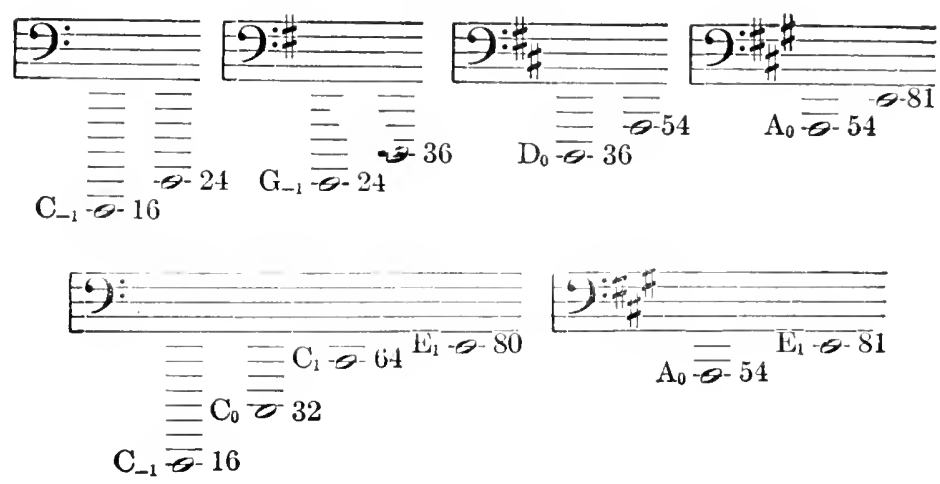

Finally, the point is reached where $B$ 茾, which on the piano is the same as $\mathrm{C}$, is almost half a tone higher than $\mathrm{C} .{ }^{1}$ Obviously, then, with scales built upon exact mathematical proportions, it is impossible to pass from some keys to some others. As the ear will accept as true intervals which are not true, ${ }^{2}$ Johann Sebastian Bach (1685-1750) suggested that the pure scale be altered in such a way as to distribute among all the tones of all the scales the discrepancy which is most apparent between the keys of $\mathrm{B}$ and $\mathrm{C}$. This slight changing of the pitch of each tone is known as tempering the scale, and the resulting scale as the tempered scale. It is this scale which is in use today. Although very few

1 J. P. N. Land says in "Recherches sur l'histoire de la Gamme Arabe," Actes du $6^{\text {me }}$ Congr. Intern. des Orientals, part ii, sect. 1, p. 37: "Arabian lutenists use seventeen notes within the octave. They distinguish between sharps and flats; and their diatonic scales would show such a difference as that which exists between the scales of $B$ whereas with us the difference is only theoretical."

${ }^{2}$ W. VanDyke Bingham: "Studies in Melody," p. 21, par. 11. (Psychological Monographs, Vol. XII., No. 3. Jan., 1910, Review Publishing Co., Lancaster, Pa.) 
persons would notice the fact, the octaves are the only intervals which are exactly in tune. However, what has been lost in accuracy and brilliancy of pitch is made up for by greater facility in passing from one key to another, or modulating, as it is called. Thus it has come about that even upon instruments of fixed intonation, like the piano and the organ, it is now possible to produce all the keys of both the major and the minor modes.

To say that modern music employs tones exhibiting the mathematical ratios expressed in the following table is to state a fact; but in this instance the fact offers no clue to the why or the wherefore. It gives no explanation of our preference of one pitch to another or of one set of pitches to another set, nor of how or why, during the process of

\section{Pure Tempered}

\begin{tabular}{|c|c|c|}
\hline Prime or unison.... (C to $\mathrm{C}, \mathrm{F}$ to $\mathrm{F})$ & $1: 1$ & $1: 1$ \\
\hline Augmented prime... (C to $\mathrm{C} \#, \mathrm{~F}$ to $\mathrm{F} \#)$ & $24: 25$ & \\
\hline Minor second...... (C to $\mathrm{D} b, \mathrm{~F}$ to $\mathrm{G} b)$ & $15: 16\}$ & $1: 2 \overline{12}$ \\
\hline Major second......(C to $\mathrm{D}, \mathrm{F}$ to $\mathrm{G})$ & S:9 $(9: 10)$ & $1: 2 \frac{1}{6}$ \\
\hline Augmented second.. (C to $\mathrm{D} \#, \mathrm{~F}$ to $\mathrm{G} \#$ ) & $64: 75\}$ & \\
\hline Minor third........ (C to $\mathrm{E} b, \mathrm{~F}$ to $\mathrm{A} b)$ & $5: 6$ & $1: 2 \frac{1}{4}$ \\
\hline Major third....... (C to $\mathrm{E}, \mathrm{F}$ to $\mathrm{A})$ & $4: 5$ & $1: 2 \frac{1}{3}$ \\
\hline Perfect fourth..... (C to $F, F$ to $B b)$ & $3: 4$ & $1: 2 \frac{5}{12}$ \\
\hline Augmented fourth. $(\mathrm{C}$ to $\mathrm{F}=\mathrm{F}$ to $\mathrm{B} b)$ & $32: 45(18: 25)$ & \\
\hline Diminished fifth.... (C to $\mathrm{G} b, \mathrm{~F}$ to $\mathrm{C} b)$ & $45: 64(25: 36)$ & \\
\hline Perfect fifth........ (C to G, F to $\mathrm{C})$ & $2: 3$ & $1: 2 \frac{7}{12}$ \\
\hline Augmented fifth.... (C to $\mathrm{G} \#, \mathrm{~F}$ to $\mathrm{C} \#)$ & $16: 25$ & 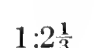 \\
\hline Minor sixth....... (C to $\mathrm{A} b, \mathrm{~F}$ to $\mathrm{D} b)$ & $5: 8$ & \\
\hline Major sixth.......(C to $\mathrm{A}, \mathrm{F}$ to $\mathrm{D})$ & $3: 5$ & $1: 2 \frac{3}{4}$ \\
\hline Augmented sixth... (C to $A$ 光, F to $D=)$ & $128: 225$ & $1: 2$ \\
\hline Minor seventh.....(C to $\mathrm{B} b, \mathrm{~F}$ to $\mathrm{E}$ ? $)$ & $9: 16(5: 9)$ & 1.2 \\
\hline Major seventh.....(C to $\mathrm{B}, \mathrm{F}$ to $\mathrm{E})$ & $8: 15\}$ & $1: 2 \frac{11}{2}$ \\
\hline Diminished octave. . (C to $\mathrm{C}^{\prime \prime} b, \mathrm{~F}$ to $\left.\mathrm{F}^{\prime} b\right)$ & $135: 256$ & $1: 2 \overline{12}$ \\
\hline Octave........... (C to $\mathrm{C}^{\prime}, \mathrm{F}^{\prime}$ to $\left.\mathrm{F}^{\prime}\right)$ & $1: 2$ & $1: 2$ \\
\hline
\end{tabular}


selection, as well as after it has taken place, the phenomenon of pitch finds use in melody. Modern ears agree that certain successions and combinations of pitches are pleasant, others unpleasant. Some may prefer a given tone a little sharp or a little flat; ${ }^{1}$ but, in the main, what one ear will accept, all will accept. How does it happen, then, that such a ratio of frequencies of pitches as that presented above is the particular series in which we find most satisfaction? The physicist was the first to attempt an answer to this question. Both the psychologist and the anthropologist have since attacked the problem, each from his own point of view; but it is probable, that, even after both have had their say, the complete explanation has not yet been found.

Almost every one has noticed, that, when two tuning forks are not quite in unison, a peculiar throbbing, pulsating effect is experienced in the ears. These pulsations are known as beats. "The more closely the forks agree, the slower are the beats. When complete unison is attained, they disappear. With increased difference of pitch on the other hand, the rapidity of the beats increases until they come too fast to be distinguished. The result is then discord." 2 Beats are due to the combining of sound waves from two vibrating bodies at one moment to strengthen and at the next to annul each other. If, for example, two tuning forks, one vibrating 255 times a second and the other 256, are sounding simultaneously, they will give rise to one beat each second, because once in each second the

${ }^{1}$ Professor Max Meyer in "Contributions to a Psychological Theory of Music," University of Missouri Studies, 1901, I., 1-80, has worked out very carefully the ratios which his ear prefers. See also C. Stumpf and M. Meyer, "Maassbestimmungen über die Reinheit consonanter Intervalle," Zeits. f. Psychol., 1898, 18, 321.

2 E. L. Nichols: "Outlines of Physics" (Macmillan, 1907). 
two wave-systems will coincide and produce a maximum sound, and once they will be half a wave-length apart and the sound will disappear. "When the beats are few, the separate pulsations are easily detected. When the beats are many, the ear does not perceive the separate pulses, and instead the sensation is that of a third tone, which is as distinct and as musical as the two generating tones, and which has a frequency equal to the difference in the frequencies of the two generators; that is, its frequency is equal to the number of beats if such beats could be heard. This tone is called a beat-tone." 1

Only sounds of such frequencies, then, as will combine without producing beats can furnish the tonal basis for the construction of a scale like ours. Such a basis is offered by the major triad, - that is, a chord consisting of the tonic, the major third, and the perfect fifth. These, it should be observed, are the first partials of any fundamental. They do not produce beats, because the ratios of their frequencies, being simple numbers, are such, that, although the sound waves first reinforce and then tend to lessen each other, they never annul each other, but are absorbed in the same uniformly progressing wave crest and trough of atmosphere.

Physically the relation of tones probably depends upon to what extent the upper partials of two tones coincide. Tones which have but a distant relation to each other, however, are often closely related to a third tone, and then, particularly if they are associated in some melodic series, may acquire a close relationship. This, together with the fact that two tones are often felt to be related merely because of their nearness to each other, is sometimes made to account for the association in the same scale of such beat-

${ }^{1}$ D. C. Miller: "The Science of Musical Sounds," p. 183. See also, Zahm: "Sound and Music," pp. 322-340 (Chicago, 1892). 
producing intervals as the tonic and the major second or the tonic and the major seventh. ${ }^{1}$

It must not be thought, however, that in the construction of the diatonic scale there was involved any such conscious process as I have described. ${ }^{2}$ The building of the scale must have been a matter of gradual accretion through ages and ages, though I suppose that its origin might possibly be conceded to lie in the sex cries of the anthropoid animal. ${ }^{3}$ "At the very bottom of the process of development," says Hubert H. Parry," "are those savage howls which have hardly any distinct notes in them at all. Many travelers record such things, and try to represent them in the European musical stave. For instance, the natives of Australia are described by a French traveler as beginning a howl on a pitch note and descending a full octave in semitones." Parry, however, does not believe this to be an accurate description of the process, "as a downward scale of correct semitones is beyond the powers of any but very highly trained singers. In all such cases the process must have been a gliding of the voice up or down, without notes that were strictly defined either in relation to one another or to any general principle."

Whatever may have been the very first step in the process is not of vital concern to my argument, however. For it is a mere matter of theory that can be passed over in

${ }^{1}$ Hermann von Helmholtz: "Sensations of Tone," p. 256 and p. 350. (Translated by A. J. Ellis, second English edition, London, 1885.)

Geza Révész: "Zur Grundlegung der Tonspsychologie" (Veit und Co., Leipzig, 1913).

${ }^{2}$ Henry T. Moore: "The Genetic Aspects of Consonance and Dissonance."

${ }^{3}$ Charles Darwin: "Descent of Man," 2d ed., p. 299 and p. 358. To me in these cries appears to lie the origin of language rather than of music. See Richard Wallaschek: "Primitive Music," pp. 240-259.

4 "The Art of Music," p. 53. 


\section{THE FOUNDATIONS AND NATURE OF VERSE}

consideration of the fact that savages in all parts of the globe, where they have music involving the use of tones at all, usually fix upon a monotone above and below which their voices rise and fall to other pitches of more or less definiteness. ${ }^{1}$ 'This rude singing may or may not involve the use of words; but in no instance are rhythmic movements of the body and rhythmic accompaniment on some instrument of percussion lacking, so that for man the process seems to be from rhythm to melody. Birds, as well as numerous animals, employ sounds that are musical; but nowhere in the animal kingdom except with man is the unifying principle of rhythm present. The instinct for race preservation gives rise to communal action. Among savages those tribes which are most in the habit of engaging in mimic warfare and mimic hunts are invariably the dominant tribes. Practice in concerted rhythmic movement fits them to act together in the struggle against their neighbors and against nature. Without some unifying element, concerted action is impossible. This element is first found in rhythm. Later a unit tone is fixed upon, and to this tone other tones are graclually added. Frequently this unit tone is that of the drum upon which they are in the habit of beating. As soon as a pipe of any kind is added to their orchestra, the foundation for the building of a scale is prepared. Pipes can produce only certain tones. Therefore, the voice gradually settles to the use of those tones produced by the pipes. Wallaschek is probably right in ascribing to the limitations enforced by the

${ }^{1}$ Mary Eugenia and Adams William Brown: "Musical Instruments and their Homes," pp. 242-243.

Theodor Baker: "Úber die Musik der Nordamerikanischen Wilden," pp. 18-19.

Lewis H. Morgan: "The League of the Ho-dé-no-san-nee, or Iroquois" p. 289. 
use of instruments the origin of a regular scale. ${ }^{1}$ In the first stages of musical development savages are not at all particular about what these pitches shall be. With increase of mechanical skill in constructing their pipes, they begin to show a tendency toward selection, until finally a scale of some kind is built up. This seems to me a logical explanation, especially when attention is called to a similar process in the development of modern music. The limitations set by the pianoforte and the pipe-organ have forced us to adopt a modified scale with which most ears are at least tolerably well satisfied, especially if they have never heard the pure scale. The tendency, however, is always toward the avoidance of those tones which, when sounded in unison, produce beats.

As the result of hearing the same tones together repeatedly, the mind begins to associate the sounds and to regard them as related. Conscious art begins. The individual musician takes the place of communal production of music. Through special skill he is able to stand apart from the crowd, yet at the same time to draw the community together in a bond of unified emotion. Once the function of musician has become specialized, progress is rapid; but it never moves more rapidly than the mind of the community is able to assimilate the added tones and to find pleasure in them. Finally, there appears a Bach or a Wagner, who through the power of genius is strong enough to force upon his generation his own standards of tone. At first opposition is tremendous. The new combinations are felt to be unrelated, disagreeable, noisy. Repeated hearings render them familiar, pleasing, musical. And so progress continues. But it is progress brought about, first, by restriction to a unit, and, then, by the gradual addition of other sounds to this unit and their coördination with it and with

${ }^{1}$ Richard Wallaschek: "Primitive Music," pp. 156-159. 
one another. Whether the introduction of new tones and new combinations of tones be fortuitous or deliberate, the advance in communal rsthetic appreciation must be either simultaneous with each addition or must lag so slightly behind that the musician may not be altogether without an audience. For the audience can never be entirely lacking, even though at times it appears to have been restricted to only the musician himself. Both speech and music have always been, and must continue to be, communal in essence. They exist because of the desire of the individual to communicate to others his ideas and his emotions and to share theirs with them.

In the triangular controversy carried on by Darwin, ${ }^{1}$ Spencer ${ }^{2}$ and Wallaschek, ${ }^{3}$ as to the origin of music, several points called attention to by Wallaschek seem to be so pertinent that I cannot refrain from quoting them here:-

"Whereas Mr. Spencer . . . seems to think that musical modulation originates in the modulations of speech, I maintain that it arises directly from the rhythmical impulse. . . . Even admitting the present reciprocity of influence in both music and speech, I doubt that such is the origin, and that for several reasons.

I. "We find even in the most primitive state of culture a sort of recitative, side by side with a kind of music, in which the rhythm alone plays a leading part, and with songs, the words of which are perfectly meaningless or at least can not be understood by the tribe in question. ${ }^{4}$ In such circumstances it is obviously impos-

${ }^{1}$ Charles Darwin: "The Deseent of Man," ii, pp. 68-74.

${ }^{2}$ Herbert Spencer: "On the Origin and Funetion of Music."

${ }^{3}$ Richard Wallaschek: "Primitive Musie," pp. 237-259.

${ }^{4}$ Theodor Baker: "Über die Musik der Nordamerikanisehen Wilden," p. 7.

Lewis H. Morgan: "League of the Ho-dé-no-san-nee, or Iroquois," p. $2 \mathrm{ff}$.

Krehbiel in "Afro-American Folk Songs" says that the meaningless words employed in the songs of the American negroes are in many 
sible for the musical modulations to have taken rise from the spoken modulations, since there is no genuine speech in the case. Among savages primitive vocal music reveals in many cases no connection with language, but is simply a succession of musical sounds sung by the voice. ...

II. "Primitive music can not have evolved from modulations of the voice in emotional speech, as the most primitive music is in so many cases no modulation of tone but merely a rhythmical movement in one tone. . . .

III. "Speech expressed in song does not develop at the same rate as speech itself; on the contrary, the intellectual importance of singing declines with the higher development of language. Examples of a word changing its meaning with a different vocal inflection are only to be met with in primitive language. . . .

IV. "Music is the expression of emotion, speech the expression of thought. If we assume that music originates in, and is developed from, speech, we must also assume that emotion is developed from thought. It may be that in the adult human organism particular emotions do arise in this way, but it is not true of emotions generally. Moreover, many cases of aphasia prove that an expression cannot be emotional and intellectual at the same time, the one kind of expression arising in and spreading through different parts of the brain and nervous system from those occupied by the other. ${ }^{1}$ It may be, however, that in a very primitive stage of mental development thought and emotion have not yet become clearly differentiated... I think then that music and speech did not arise the one from the other, but that both arose from (or together with) an identical primitive stage in one of their common elements. Hence it happens that inquiring into the origin of music

cases vestiges of songs formerly sung in Africa, the ear retaining the sound of the words though their meaning has been forgotten. Meaningless words used as padding seem to be common to all ballad literature.

${ }^{1}$ Richard Wallaschek: "Über die Bedeutung der Aphasie für den musikalischen Ausdruck," Viertelj. f. Musikwissenschaft, VII., Heft i, Jahrg., 1891; and "Das musikalische Gedächtnis bei Katalepsie, im Traum, in der Hypnose," Viertelj. f. Musikwissenschaft, VIII., Heft iii. Jahrg., 1892. 
we necessarily come into contact with the primitive language, and in inquiring into the origin of speech we come into contact with primitive music, or, more correctly speaking, with the corresponding sounds. Primitive human utterance, using sound metaphors and onomatopœia in order to make itself intelligible, may resemble primitive musical tones; yet nevertheless an early separation of distinct tones and indistinct sounds seems to have taken place, not as transition from the one as prior to the other as succeeding, but as a divergence from a primitive state which is, strictly speaking, neither of the two. . . It is just this power of uttering, no matter what, that enables it [the human child, or, what amounts to the same thing, the savage] in course of time to evolve a faculty both for singing and speaking. . . . It is as difficult to tell whether a primitive utterance is sufficiently developed to be called musical as to know whether it can properly be called language or not. This perhaps is the reason why Mr. Darwin and Mr. Spencer do not agree on the question as to which comes first, music or language. 'Spencer,' said Darwin, 'comes to an exactly opposite conclusion to that at which I arrived. He concludes, as Diderot did formerly, that the cadences used in emotional speech afford the foundation from which music has developed, whilst I conclude that musical notes become firmly [I should rather say, possibly] associated with some of the strongest passions an animal is capable of feeling.' I think Darwin's mistake in the sentence here quoted lies in his speaking of music, instead of musical sounds, i.e., sounds which come to be used later in music." 1

Some of even the most rudimentary songs do contain words; but the words are lacking almost entirely in significance, and at best are hardly more than the monotonous repetition of a single phrase or of a very short sentence. The intellectual element is so negligible as to be of no consequence except in showing that germination is already in process. Music and verse continue to develop in a single trunk, until, with the further strengthening of the intellec-

${ }^{1}$ Richard Wallaschek: "Primitive Music," pp. 251-255. 
tual fiber, the tree begins to fork; yet never do the two main branches separate so widely that their twigs are not everywhere most inseparably interlaced. Speech brought under rhythmic control ${ }^{1}$ may result either in music or in verse, according to the degree of prominence now assumed by a second factor, - melody.

The problem of melody has received special attention at the hands of four psychologists, - Fritz Weinmann, ${ }^{2}$ Theodor Lipps, ${ }^{3}$ Max Meyer, ${ }^{4}$ and W. Van Dyke Bingham. ${ }^{5}$ "Into the determination of the total psychosis of melody," pitch, time rhythm, tempo, tone-color, and intensity must all enter. A change in any one of these will alter the effect of the melody in some degree; yet the determining factor is so predominantly a matter of pitch that the problem resolves itself into a discussion of how a series of discreet tonal stimuli can arouse that feeling of unity upon which Bingham lays so much emphasis in the following definition:-A melody is "a succession of musical sounds which is felt to constitute an asthetic unity, a unity toward the establishment of which pitch relations of the successive tones contribute." 6

1 With Verrier's contention ("Essai sur les principes de la métrique anglaise," III., p. 71, 4 Rue Bernard, Palissy, Paris, 1910) that the origin of verse is to be found neither in the rhythm of work nor in the rhythm of dancing, but in the prose "segments" of everyday conversation, I do not agree at all.

2 "Zur Struktur der Melodie," Zeits. f. Psychol., 1904.

3 "Zur Theorie der Melodie," Zeits. f. Psychologie, 1902; also his "Psychologisches Studien," 2te Aufl., 1905, and "Grundlegung der Aesthetik," 1903.

4 "Unscientific Methods in Musical Esthetics," Journal of Phil. Psy., and S. M., 1904; also "Elements of a Psychological Theory of Melody," Psych. Rev., VII., 1900.

5 "Studies in Melody," Psychological Monographs, Vol. XII., No. 3, Jan. 1910, Whole Number 50, Psychological Review, Review Publishing Co., Lancaster, Pa.

'W. VanDyke Bingham: "Studies in Melody," p. 5. 
Weinmann, Lipps, and Meyer differ with one another and with Lipps as to what constitutes a melody; yet, after all, the difference is not irreconcilable. Lipps and Weinmann limit their conception of melody to such rsthetic tonal units as subordinate the constituent elements to a single dominating tonic. This excludes all melodies which are lacking in tonality, and automatically places in the center of attention only modern diatonic European music. Meyer opposes this idea of a dominant tonality. To him a melody is a unity because we experience relationship between the tones. However, he uses relationship in the technical, musical sense of the word, - that is, only such tones as bear to each other the same ratio as is borne to each other by a fundamental, and any one of its several partials are regarded as related. ${ }^{1}$

"The matter of prime importance," however, says Bingham, " "is, of course, to realize that by whatever names they may be called, we are confronted with three different phenomena-relationship, phrase- or period-unity, tonality - which, no matter how intimately they may prove to be bound together, are nevertheless in introspection clearly distinguishable, and must not be confused." For the sake of clearness, therefore, it is better to regard a melody as "a succession of musical sounds which is felt to constitute an asthetic unity." Any smaller or less completely developed group of musical sounds should not be thought of as a melody, but as a melodic fragment, if the pitches are definite,

${ }^{1}$ Following the example of Bingham, wherever the word is used in this teehnical sense, I shall write it in italies. When it is not so written, it is being used in the popular understanding of that term. In the latter sense two tones are said to be related to eaeh other beeause they have frequently been heard together, or beeause one is felt to be higher or lower than the other.

2 "Studies in Melody," p. 3. 
or as a primitive melody, ${ }^{1}$ if the pitches are uniform or random or indefinite. Speech tunes are melodies of the random, indefinite, or primitive type." "Indeed," to quote Bingham again, "the infinite variety of delicately expressive inflections which enrich our spoken intercourse must be recognized as based upon pitch relations of this 'indefinite' kind. The gross difference between the rising interrogative inflection and the falling assertatory is the most obvious example of this type of melodic relationship. The mental effects produced by mere rise in the pitch have been described by Meyer in terms of effects upon the attention." 3

"A rise in pitch causes the hearer's attention to become strained, and the more so, the steeper the ascent, if I may use this expression. A fall in pitch, on the other hand, causes a relaxation of attention, a cessation of mental activity. ... The same strain and relaxation of attention is to be found in music. The normal end of a mental process is, of course, characterized not by strained, but by relaxed attention; for strained attention means continued mental activity. It is natural therefore that a melody ends with a falling inflection." ${ }_{4}$

"If one carefully examines different melodic intervals to discover whether there may not be still other types of relation, he will probably disclose to himself a phenomenon which has received much attention at the hands of certain writers. He will notice that many melodic intervals exhibit a peculiar character which shows itself as a tendency for us to prefer one of the two tones as an end-tone. The interval of a minor third, whose tones have the

${ }^{1}$ Good examples are instanced by B. I. Gilman in "Hopi Songs," Jour. of Am. Ethnol. and Archeol., 1905, 5, 14 and 224. I have heard these Indians sing.

2Sidney Lanier: "The Science of English Verse," pp. 251-279 (Charles Scribner's Sons, New York, 1907).

3 "Studies in Melody," pp. 10-11.

"Max Meyer: Amer. Jour. Psych., 1903, 14, 456. 
vibration ratio of 5:6, possesses no such attribute: one acquiesces indifferently in either as the upper or the lower final tone. Neither tone has any very positive characteristics about it. Not so, however, with the perfect fifth $(2: 3)$. If one hears it as an ascending interval, he is dissatisfied, uneasy, and under more or less tension until he hears the first tone over again. But if it is a descending fifth which he hears, there is acquiescence, satisfaction, repose, and no desire to hear the second tone a second time. One may say that one of these tones stands to the other in relationship of 'tonic,' or end-tone. This aspect of musical intervals will be called by the present writer their melodic trend." 1

A consideration of melodic trend gives rise to the Law of the Return, which is: Where other things are equal, it is better to return to any starting point than not to return. It seems to be impossible for us to construct an organic, melodic whole unless we have become habituated to the tone successions. To enjoy them we must be able in some measure to anticipate them. Further, we show (1) a decided "preference for lower tones as such for end-tones (phenomenon of the falling inflection), (2) a preference for the return of the first tone as an end-tone, (3) preference for the expected ending (if one knows that a given tone is to be the last, its arrival may be sufficient to arouse the feeling of finality quite apart from the operation of any other factors), and, finally (4) preference for an end on one of the tones of the tonic chord - and especially the tonic itself - of the suggested tonality." 2

"The closing tone institutes a response which is not wholly a new reaction but which is, on the contrary, the completion of an act already in progress. The feeling of finality arises only when the completion of the act issues in a muscular relaxation which is a dying out of balanced tensions. The facts regarding 1 "Studies in Melody," pp. 10-11.

${ }^{2}$ W. Van Dyke Bingham: "Studies in Melody," p. 41. 
those finality effects which are due to the falling infleetion also coincide with such a view. Rise in pitch is not merely a result of inereased tension of the vocal apparatus: it likewise produces inereased muscular tension in the hearer. A falling inflection at the elose consequently serves to hasten the relaxation process which marks the eompletion of the melody.

"Finally, a motor theory of melody makes possible an unambiguous statement of the nature of melodie relationship. Two or more tones are said to be related when there is community of organized response. Unrelated pitehes fall apart beeause each demands its own separate attentive act of adjustment; but with related tones the attitude which appears as a response to the first is a preparation for the response to the seeond and is completed, not destroyed, by that response. The feeling of relationship is the feeling that arises when the tones elicit reactions which are in some measure common. When, on the other hand, the first tone calls up one set of associates and establishes a certain attitude or organization of ineipient tendeneies, while the second tone tends to eall up a set of associates and establishes an attitude which is at variance with the first, there ean be no adequacy of coördinated response and the feeling of relationship is prevented from arising." 1

The feeling of relationship is due to both sensory and associative forces. Consonance results from sounds that require a relatively simple response on the part of the ear to stimuli which are more or less similar, or even identical. One race, one age, and even the same individual undergo constant change in ability to associate, amplify, and organize sounds. Constantly hearing a certain succession of pitches develops the ability to recognize them and to respond to them, so that they finally come to be felt as related.

"The unity, then, which marks the difference between a mere succession of discrete tonal stimuli and a melody, arises not from ${ }^{1}$ W. Van Dyke Bingham: "Studies in Melody," p. 86. 
the tones themselves; it is contributed by act of the listener. When tone follows tone in such a manner that the hearer can react adequately to each, when the response to the successive members of the series is not a series of separate or conflicting acts but rather in each instance only a continuation or further elaboration of an act already going forward, then the tones are not felt as discrete, separate, independent, but as related to each other. And when, finally, the series of tones comes to such a close that what has been a continuous act of response is also brought to a definite completion, the balanced muscular resolution gives rise to the feeling of finality, and the series is recognized as a unity, a whole, a melody." 1

As I shall show later, rhythm, time, tempo, tone-color, and intensity are common to both speech and music. They differ from each other primarily in this: The singing voice uses only such tones as are capable of combination into scales and of employment in melodies; the speaking voice does not confine itself to any set or sets of tones, but employs all or any of the degrees of vibration that can be produced within the limits of its range.

For such small degrees of pitch as are utilized by the speaking voice, there is no system of notation; ${ }^{2}$ nor can one ever be devised. How can it be possible to represent systematically sounds that are themselves lacking in any unifying principle such as furnishes the basis for music? As far as pitch is concerned, there is no mathematical relationship of one pitch to another. Hence, there can be for the speaking voice no possibility of combining tones

${ }^{1} \mathrm{WW}$. Van Dyke Bingham: "Studies in Melody," p. 87.

2 Dr. Rush in "The Philosophy of the Human Voice" uses a system that answers for practical purposes of elocution. John R. Scott ("The Technique of the Speaking Voice") employs the Rush method; but with neither man is absolute accuracy of pitch intended. Consult also, John Walker ("The Melody of Speaking") and Saran ("Melodik und Rhythmik Zueignung Goethes"). 
in any such manner as that made use of by harmony in music. In speech but one voice can sound at a time. The moment two or more voices begin to sound, unless they are either in unison or an octave apart, only noise and confusion can result. Harmony, as that term is applied to music, is independent of either melody or rhythm. It is the result of a simultaneous combination of related tones, as those tones are employed in chords. Since for the speaking voice there is no system of related tones, there can be no possibility of constructing chords.

Of rhythm, melody, and harmony, harmony is the last phase to begin development in the evolution of the musical life of a people; and harmony in the strict sense of that word is possible to only such musical systems as have passed the early stages of the primitive. In saying this, I am perfectly aware that the ancient Greeks knew something of harmony and made use of it in their instrumental music, ${ }^{1}$ that the Egyptians were acquainted with the diatonic scale probably as early as 3000 B.c., ${ }^{2}$ and that today savages from every quarter of the globe, especially the negroes of Africa, show some skill in their employment of harmony. ${ }^{3}$ In fact, quite a number of the negro tribes display a very highly developed sense of harmony, and are capable of deriving the greatest pleasure from melodies and harmo-

${ }^{1}$ Rudolph Westphal: "Die Musik des Griechischen Alterthumes," p. 24.

2 Sir John Gardner Wilkinson: "Ancient Egyptians," vol. 3, p. 487.

${ }^{3}$ Theodor Baker: "Über die Musik der Nordamerikanischen Wilden."

Carl Stumpf: "Lieder der Ballakula Indianer," in Viertelj. $f$. Musikw., vol. ii., p. 416.

Hubert Howe Bancroft: "The Native Races of the Pacific States of North America."

David Livingston: "Missionary Travels and Researches in South Africa," p. 293. 
nies far in advance of anything with which they have previously been familiar. ${ }^{1}$ However primitive these tribes may be in other particulars, in their appreciation of music they have passed the primitive state; yet even though some of them make free use of both major and minor modes, ${ }^{2}$ there is no such complexity of interweaving harmonies as modern European music has developed. Their harmonies, like their melodies, are simple, rudimentary. Even at this, their music is far in advance of that of the Chinese and other Oriental peoples, who exceed them greatly in culture, ${ }^{3}$ and immeasurably in advance of that of some of the tribes immediately surrounding them. Relatively speaking, therefore, any tribe or people possessing a well-defined scale and a tolerable ear for harmony has risen above the nether confines of the musically primitive; and with them, as with us, it is possible to make a distinction between their music and their verse, even where the two art forms may sometimes overlap.

The development of music in this, as in all particulars, is in line with general evolutionary principles. From perfectly indefinite pitches, the tendency is toward pitches of more and more definite character, until in the end only those pitches which bear to a tonic tone certain mathematical ratios are employed. It is progress from indefi-

1 John W. D. Moodie: "Ten Years in South Africa."

${ }^{2}$ Friedrich Ratzel: "Völkerkunde," p. 516.

Richard Francis Burton: "The Lake Region of Central Africa."

William Marsden: "The History of Sumatra," p. 196.

${ }^{3}$ Michael Symes: "Embassy at Ava" in Pinkert. Collect., vol. ix., p. 485.

Hector Berlioz: "A travers chants."

Ida Laura Pfeiffer: "The Latest Travels of I. P.," p. 119.

T. A. van Aalst: "Chinese Music."

Ernst Faber: "The Chinese Theory of Music."

Billert: "Japanische Musik." 
niteness and incoherence of structure toward definiteness and coherence. Speech, on the contrary, has made no advance. Though the tendency in the rendering of verse is to use a much more sustained tone than for prose, nevertheless, even for verse, both the prevailing tone and the other sounds associated with it are absolutely unfixed. They are related only in so far as one sound is recognized as higher or lower than another. The moment speech sounds begin to take on definiteness and coherence of pitch, however, they are moving toward the establishment of a tonality. This tonality once recognized, it is only a matter of how far the definition of melody may be legitimately stretched in order to have it include the transition products. 


\section{CHAPTER IV}

\section{TONE QUALITY}

BY far the most difficult problem of acoustics has been that presented in answer to the question: To what are differences in tone quality - or tone-color, as it is frequently called-due? Why should any note ( $\mathrm{A}_{4}$ for instance) when played on the piano have a different sound when played on the violin or when sung?

Many eminent physicists, fascinated by the complexity of the subject, have taxed their powers in attempting its solution; yet for a long time the lack of agreement among them was the occasion for much doubt as to the validity of the results obtained by any one. Uniformity was expeeted where uniformity does not exist. Almost every experimenter lost sight of a fact familiar to all musicians, - namely, that no two instruments, even of the same kind, have exactly the same sound. This is equally true of the violin, the piano, or any other instrument; but the difference is particularly noticeable in the case of the human voice. Who, if suddenly stricken with blindness, would fail to recognize by the sound of their voices the individual members of his family? And there, as a rule, the difference is at a minimum. With no two instruments, then, exactly alike in quality, the difficulty of investigation becomes at once apparent, especially when it is remembered how crude the instruments for analyzing tones must at first of necessity have been. Only within the last few years 
have discoveries and inventions in other fields made possible the constructing of apparatus sufficiently sensitive to assure accurate results. Today, however, although many problems are still in need of further elucidation, certain facts, I think, may be regarded as definitely established. ${ }^{1}$

It will be remembered that, as a part of Ohm's Law of Acoustics, it was stated (1) that "every motion of the air which corresponds to a complex musical tone is capable of being analyzed into a sum of pendular vibrations, and [(2) that] to each simple vibration corresponds a simple tone which the ear may hear." These separate, component tones have been designated as partials, the partial of lowest frequency being the fundamental. It sometimes happens that one of the upper partials is so predominant as almost to obscure the fundamental. This Clarence Wilson Hewlett ${ }^{2}$ found to be the case for the G-string of all good violins, in the intensity of the second partial (first overtone) being contained from 90 to 100 per cent of the total intensity of the string. In bells the prominence of the upper partials is still more noticeable. Sometimes the pitch is characterized by a subjective beat-tone, although no actual physical tone of this pitch may be present.

The investigations of Hermann von Helmholtz led him to believe that the quality of a tone is entirely dependent upon the number and relative strength of its several partials. ${ }^{3}$

${ }^{1}$ The most recent, as well as the most authoritative, popular book on this subject was published in 1916 by Dayton Clarence Miller. He has succeeded in photographing sound waves and in measuring the curves thus obtained. I have adopted his explanation of tone quality.

2 "Analysis of Complex Sound Waves," p. 367 (Johns Hopkins University dissertation; also published in Physical Review, XXXV.,. 1892, pp. 359-372). See also P. H. Edwards in Physical Review, XXXII., 1911, pp. 23-37.

3 "Sensations of Tone." 
Koenig ${ }^{1}$ argued that another factor, phase, ${ }^{2}$ might also affect the quality of a sound; but Lindig ${ }^{3}$ showed that this could take place only when one sound wave interfered with another. M. G. Lloyd and P. G. Agnew, ${ }^{4}$ working together, demonstrated that differences of phase in the partials do not affect the quality of the tone. Winkelman, ${ }^{5}$ Barton, ${ }^{6}$ Miller, ${ }^{7}$ and others are also in entire agreement with Helmholtz, so that the weight of authority undoubtedly rests on his side. Miller, however, thinks that, when beat-tones are present, the beat-tone may have an additional influence never before fully appreciated.

Although beat-tones are purely subjective, the ear hears them just as distinctly as if they were real partials; and their presence helps to determine the tone quality of many instruments and perhaps also of the voice. Beats and beat-tones I have already defined. To this I must add an illustration. $\mathrm{C}_{6}$ (frequency 2046) and $\mathrm{D}_{6}$ (frequency 2304) when sounded together produce a third tone of the pitch $\mathrm{C}_{3}$ (frequency 256). This latter tone, although having no physical existence, affects the ear just as if it were

1 "Quelques Expériences d'Acoustique."

${ }^{2}$ Phase is the "particular value, especially at the zero of time, of the uniformly varying angular quantity upon which a simple harmonic motion, or a simple element of a harmonic motion, depends." - "Century Dictionary and Cyclopedia."

${ }^{3}$ Annalen der Physik, X, 242-269 (1903).

${ }^{4}$ Bulletin of the Bureau of Standards, VI., 255-263 (1909).

5 "Akustik," pp. 268-278, in "Handbuch der Physik," 2 Aufl. Leipzig, 1909, Bd. II., "Akustik" by F. Auerbach.

6 "Text-Book of Sound," pp. 605-607 (London, 1908).

7 "The Science of Musical Sounds;" Physical Review, XXVIII., 151 (1909); Science, XXIX., 471 (1909); Proceedings of the British Association for the Advancement of Science, Dundee (1912), p. 419; Engineering, London, XCIV., 550 (1912); Proceedings of the Fifth International Congress of Mathematicians, Cambridge (1912), II., pp. 245-249. 
a real sound. As yet it is uncertain how much importance to attribute to beat-tones; still, they must be taken into consideration. Although I shall not mention them again, it should not be thought that I am unaware of their presence or that I deliberately choose to pass them by. Too little is known about them to justify the positing of any further statement than that they are present as a component in determining the tone quality of some instruments. ${ }^{1}$

Pitch, then, depends upon the number of complete vibrations per second of the sounding body; quality, upon the peculiar kind, or form, of motion which the body undergoes in vibrating.

A tone as it originates in the sounding body is frequently very faint, sometimes even disagreeable. The unsupported tone of a tuning fork is of the first type; the squeaky sounds produced by the vibration of the reed in the mouthpiece of the clarinet are of the second. In order that the intensity of the tone may be increased and that the vibrations may be sent forth furnished with sufficient brilliance to make them pleasing, it is necessary that instruments be provided with some mechanical device constructed especially for this purpose. The part of the instrument in which the sound is produced is spoken of as the generator; the part which increases the intensity and brilliance, as the resonator. A tuning fork must be mounted upon a box if its tone is to be audible beyond a few feet. The body of the violin is the chief source of its resonance. The soundboard acts as resonator for the piano. The cavities of the mouth and the nose serve in the capacity of resonators for the sounds generated in the larynx. In addition to increasing the volume of a sound, resonators have still another function. As has been mentioned already, not all the partials of a given fundamental are pleasing. These

${ }^{1}$ Zahm: "Sound and Music," pp. 322-340. 
disagreeable sounds a well constructed resonator will suppress, and at the same time bring into prominence those which are agreeable. ${ }^{1}$ Although the resonator cannot give out any tone not received as the result of vibrations in the generator, nevertheless, it determines the proportions in which the fundamental and its component parts shall reach the ear. The tone quality of the pianoforte is rich and full, because all partials except the lower, agreeable ones are carefully obliterated, while the latter are well supported. The tone of the tuning fork can never be anything except thin, no matter how the fork is mounted, because the tone itself is lacking in partials. Its tone is the simplest and purest of all musical sounds; yet this very simplicity and purity makes it monotonous, and, therefore, unsuited for use as a musical instrument. To be of value musically a tone must possess character and distinction. It must have a personality of its own. This differentiating quality of sound is undeniably a question of partials, or overtones. Vowel quality, however, presents aspects both peculiar and difficult. As vowels are of the utmost importance in all considerations of prosody, every phase of the phenomena connected with them must be investigated at some length. First in order must come the matter of vowel quality.

${ }^{1}$ A resonating cavity may give inharmonic partials dependent upon the elasticity of its walls. See "Science of Musical Sounds," p. 181. 


\section{CHAPTER V}

\section{THE QUALITY OF VOWEL SOUNDS}

WiLLIS (1829) was the first to attempt an explanation of vowel quality. Since his day no branch of acoustics has been more extensively investigated than has the subject of vowels; yet nowhere has there been a greater disparity of results obtained. Although no single opinion as to the cause of vowel quality has prevailed, in general, two distinct theories have developed. Into these, individuals have introduced such modifications as the results of their several investigations have seemed to justify.

The physicist, however, has not been the only one attracted to the vowel problem. The physiologist, the vocalist, and the philologist have each taken a hand, with results so different and so highly specialized that a synthesis of their various methods and findings seems well-nigh impossible, nor is one necessary. In fact, I believe it to be highly undesirable. A great part of the confusion both in conception and in terminology found in the writings on prosody today is due to a mixing of these methods. The terms long and short, high and low, for instance, have played havoc in being bandied back and forth among physiologists and vocalists and philologists. Therefore, I shall make no attempt to formulate a genetic or a physiological definition of the term vowel. To do so would be like presenting the shape, size, material, and construction of an organ pipe as a definition of its tone. ${ }^{1}$ Given these

${ }^{1}$ See Lloyd's maps of the mouth cavity when set for the production of different vowels: Proc. Roy. Soc. Edin., March, 1898. 
factors the tone can be produced, of course; but what concerns us here is the tone itself. What are its constituents? What possibilities do vowels present for artistic purposes? - these are the questions which I shall attempt to answer.

All physicists are now agreed that a vowel consists of a cord tone and one or more upper partials made prominent through reinforcement in the resonance chambers of the buccal and nasal cavities or in the buccal alone. The division of opinion is with regard to the relation of the larynx, or cord, tone to the resonance tones. Willis maintained the mouth tone to be independent of the cord tone, yet of a fixed, characteristic pitch. ${ }^{1}$ Wheatstone ${ }^{2}$ (1837) and Grassmann $^{3}$ (1854) extended this theory. Donders ${ }^{4}$ (1864) found the cavity of the mouth to be tuned to different pitches for different vowels. The opinions of these three men gave rise to what is called the fixed-pitch theory. Helmholtz ${ }^{5}$ (1862-1877) further enlarged this view. His theses are $(a)$ that the vowel sounds are different from the sounds of most musical instruments essentially in the fact that the strength of their partials depends not only upon the number of the upper partial, but above all upon its actual pitch; (b) that, as the voice rises or falls, the mouth must also change its tone in order to be able to extend its resonance to a considerable degree, the range of accommodation extending in the musical scale over as much as a fifth above and below the tone of maximum resonance. This

${ }^{1}$ Cambridge Phil. Trans., III., 1883, p. 231, and following.

${ }^{2}$ Sir Charles Wheatstone: "Scientific Papers" collected and published by the Physical Society of London in 1879.

${ }^{3}$ H. Grassmann: "Leitfaden der Akustik," Progr. Stettin., 1854.

4 "Zur Klangfarbe der Vocale," Annalen der Physik u. Chemie, 1864, CXXIII, 528.

5 "Sensations of Tone," translated by A. J. Ellis. 
view is sometimes called the accommodation theory, sometimes the fixed-resonance theory. Willis believed no relation to exist between the mouth tone and the voice tone. Helmholtz differed with him in maintaining that the mouth tone is one of the partials of the tone from the vocal cords. Pipping ${ }^{1}$ in 1890 agreed with Helmholtz in the main; but with regard to the range of reinforcement he was very emphatic in voicing a contrary opinion. By 1895, however, Pipping had come to the conclusion that the range of accommodation even exceeded the limits set by 'Helmholtz. Hermann ${ }^{2}$ (1889), on the contrary, finds an essential factor in determining the quality of vowels to be the intermittent or oscillatory blowing of the mouth tone by the voice. It makes no difference, he said, whether the resonance tone is the same as any fraction of the voice tone period or not, though he was confident that each vowel has one or two fixed tones whose pitch varies within narrow limits, if at all. These he called formants. The formants, he objected to the overtone theory, lie too high above the larynx tone to be considered as one of its partials. Miller, however, has found the twentieth and even higher partials to be of common occurrence, which vitiates Hermann's opinion in no small degree. Hermann departs from the fixed-pitch theory as formulated by Willis in that he adds the intermittence of the voice tone as one of the possible characteristics of vowel sounds. The most recent authoritative supporter of the fixed-pitch theory is E. W. Scripture, whose investigations led him as early as 1899 to say:-

1 "Zur Klangfarbe der gesungenen Vocale" (1890).

"Zur Lehre von den Vokalklängen" (1895).

2 "Photographische Untersuchungen," Archiv. f. d. ges. Physiol. (Pflüger), 1890, LXXIV., 380, 381; Ibid., 1894, LVIII., 274; "Weitere Untersuchungen ü. d. Wesen der Vocale," Ibid., 1895, CXI, 192. 
"The mouth cavity with the pharynx and the vocal cords may be considered as a pipe with membranous reeds. The theory of its action will be similar to that of an ordinary reed organ-pipe.

"Each vibration of the reed sends a wave of condensation and rarefaction along the pipe. When the pipe is of such a length that the wave is reflected back in such a way as to reinforce the vibration of the reed, the resonance tone is a loud one. Thus, when a properly adjusted resonator is placed behind a vibrating fork, the tone of the fork is strongly reinforced. The reinforcement is also strong when the resonator coincides with an overtone of the reed." 1

Thus far he agrees with Helmholtz and the others; but at this point his divergence of opinion begins:

But "Such a coincidence," says he, "between the periods of the pipe tone and the reed tone is not necessary. Each impulse from the reed may be considered as striking the pipe with somewhat the nature of a blow, whereby the proper tone of the pipe itself may be aroused for an instant. The pipe may thus have its own pitch and be heard, no matter what relation there may be between it and the pitch of the reed. When the blow is rapidly repeated, both the reed tone and the pipe tone will be heard." 2

In opposition to the fixed-pitch theory, the relative-pitch theory has been advanced. The quality of every musical sound, whether of instrument or of voice, is determined by a particular series of partials accompanying a given fundamental. The pitches of the partials vary with that of the fundamental in such a way that the ratios remain constant. Lloyd ${ }^{3}$ (1890) considers that a vowel is characterized by the relative pitches of two or more partials.

1 "Researches in Experimental Phonetics," p. 79 (Washington, 1906).

${ }^{2}$ E. W. Scripture: "Researches in Experimental Phonetics," p. 80.

3 "Speech Sounds: Their Nature and Causation."

Note in Proc. Brit. Assoc. Adv. Sci., 1891, 796. 
Auerbach ${ }^{1}$ (1876) concluded that strongly reinforced partials are present in every vowel sound, but that they alone are insufficient to characterize it. In addition, a tone of fixed pitch is always necessary.

Louis Bevier," writing in the Physical Review from 1900 to 1905 , after a most thorough analysis of vowels, substantiates the fixed-resonance theory as advanced by Helmholtz. A still more recent writer, Dayton Clarence Miller ${ }^{3}$ (1916), also is in entire agreement with Helmholtz.

In proportion as instruments for the analysis of tone have been perfected, very naturally better and more reliable results have been obtained. The photographing of sound waves as conducted by Miller is the most refined method as yet devised. Until a still more accurate means of analysis shall supersede this, I think we may be justified in assuming Miller's explanation of vowel quality to be substantially correct.

Preliminary to a statement of Miller's opinions, I wish to quote several passages from Scripture, in the saneness of which I believe not only Miller but every one of the later writers on vowel sounds would agree:

A diphthong is not the sum of two vowels, as Sweet, Storm, and others ${ }^{4}$ have supposed, but "an organic union into a new sound. ... Thus, there is no necessary pause or sudden change of intensity or change in pitch or even change in character. The later sound shows its influence in the earlier one, and the earlier one keeps its influence far into the later one. That is what would be expected on physiological grounds. The speaker does not think of two sounds separately but of only one; the execution of this

1 See Lord Rayleigh: "Theory of Sound," Vol. II., pp. 469-477.

2 Physical Review, X., 193 (1900); XIV., 171, 214 (1902); XV., 44, 271 (1902); XXI., 80 (1905).

3 "The Science of Musical Sounds" (Macmillan, New York, 1916).

4 Sweet: "Primer of Phonetics," p. 76, Par. 204.

Storm: "Englische Philologie," 2 Aufl., 358, 405, 424. 
one idea by two distinct processes would be unusual. The various degrees of perfection of the synthesis of the two elements would correspond to the various expressive characters of the resulting sound." 1

Josselyn has shown that a double consonant is likewise simply a single consonant strengthened and lengthened.

"The degree of synthesis of the two elements would be lessened by any great or sudden change in intensity, pitch, or character of the cord tone or the resonance tone."

"Particular emphasis must be laid on the fact that the tones in a vowel are not constant factors and that the changes they undergo from instant to instant are presumably highly important in producing its peculiar character." 2

"A vowel is not a fixed thing but a changing phenomenon. There is no such thing as a vowel $a$ with a definite character under all circumstances. Even for the same speaker there are continual changes and variations in this vowel. For different speakers, for different dialects, and for different languages the changes become so great that the $a$ finally has little resemblance to the one chosen as the standard. We may say that a large number of our speech sounds may be classed together by a more or less close resemblance and may be designated by the term $a$. A similar statement would hold good for any speech sound." ${ }^{3}$

\section{Lloyd is of much the same opinion:}

"In no language or dialect are the sounds which pass current for one and the same vowel absolutely identical. They vary perceptibly in individual use: and hence ... a vowel is not one single definite sound, but a group of more or less closely resembling sounds which in a given community pass current for one vowel. There seems to be no practical limit to the range of this wandering

1 E. W. Scripture: “Elements of Experimental Phonetics," p. 53.
2 Ibid., p. 54.
3 Ibid., p. 79. 
so long as the sounds employed do not actually overlap those of any other vowel which happens to be used in the same language." I

We are now prepared for a summary of Miller's opinions as they are contained in a few important paragraphs:

"It must be remembered that any change in the pronunciation produces a different vowel, though we may understand the word to be the same, and that the quantitative results would vary for the slightest change in intonation or inflection. Since individual pronunciations vary greatly, even within the range of one language, there seems to be no better method of defining a vowel than by specifying several words, in each of which the author gives the vowel the same sound." 2

"Vowels are speech sounds which can be continuously intoned, separated from the combinations and noises by which they are made into words." 3

"There is not a fixed partial which characterizes the vowel, neither is there a single, fixed pitch. The greater part of the energy of the voice is in those partials which fall within certain limits, no matter at what pitch the vowel is uttered, nor by what quality of voice; that is, the vowel is characterized by a fixed region, or regions, of resonance or reinforcement." 4

"The mouth with its adjacent vocal cavities is an adjustable resonator; but varying the positions of the jaws, cheeks, tongue, lips, and other parts, this cavity can be tuned to a large range of pitches. When the mouth is wide open and the tongue is low, the cavity responds to a single pitch of high frequency, and is set for the vowel father; ... . when the opening between the lips is small, $\overline{\text { oo, }}$, the pitch is lowered as for gloom. The mouth cavities may be adjusted to reinforce two different pitches at one time, as has been explained by Helmholtz; when set for the vowel meet,

1 "Speech Sounds: Their Nature and Causation," Phonet. Stud., 1890, III., 254.

2 D. C. Miller: "The Science of Musical Sounds," p. 217.

3 Ibid., p. 217.

4 Ibid., p. 224. 
... the cavity responds to two simple tones, one corresponding to the back of the oral cavity, and the other to the channel between the tongue and the roof of the mouth." 1

"It is necessary that the sound generated by the vocal cords should be a composite of at least those partials which are characteristic of the vowel to be spoken. The sounds of the voice are normally very rich in partials; in one analysis of the vowel mat was found every partial from one to twenty inclusive; in another analysis of the same vowel, there are eighteen partials, the highest. being number twenty-four; in the vowel met, an analysis shows sixteen partials, the highest being number twenty-three." 2

"The process of singing the rowel is probably as follows. The jaws, tongue, and lips, trained by lifelong practice in speaking and singing, are set in the definite position for the vowel, and the mouth is then tuned unconsciously to the tone characteristic of that vowel. At the same time the vocal cords of the larynx are brought to the tension giving it the desired pitch, automatically if one is trained to sing in tune, but usually as the result of trial. When the air from the lungs passes through the larynx, a composite tone is generated, consisting of the fundamental of the given pitch accompanied by a long series, perhaps twenty in number, of partials, usually of low intensity. The particular partials in this series which are most nearly in unison with the vibrations proper to the air in the mouth cavity, are generally strengthened by resonance, and the resultant effect is the sound which the ear identifies as the specified vowel sung at the designated pitch.

"If, while the mouth cavity is maintained unchanged in position, the vocal cords are set successively to different pitches and the voice is produced, then one definite vowel, the same throughout, is recognized as being sung at different pitches. In this case the region of resonance is constant, though the pitch of the fundamental may vary, as may also the pitch and order of the partials which fall within the region of resonance.

"It follows that a vowel cannot be enunciated at a pitch above that of its characteristic, a condition which is easily shown to be

1 D. C. Miller: “The Science of Musical Sounds," p. 239.

2 Ibid., p. 241. 
true for those vowels having a low-pitched characteristic, such as gloom. Words which are sung are often difficult to understand; this may be due in part to the fact that the tones of the singing voice are purer than those of speaking, that is, that they have fewer partials; also, the words must be intoned upon pitches assigned by the composer, and the overtones may not correspond in pitch with the characteristics of the vowel; furthermore, singing tones are often too high to give the characteristic, even approximately." 1

Therefore, in order to secure a pure tone, singers often sacrifice the sound of the vowel. Sometimes they change the word itself. Oftener, however, they give the vowel a neutral tint, so that, except for the combination of the vowel with the other vowels and consonants of the word and for the position of the word in the sentence, the vowel would be unrecognizable.

The following table ${ }^{2}$ gives the pitches of maximum intensity for several of the vowels. "The highest-pitch,

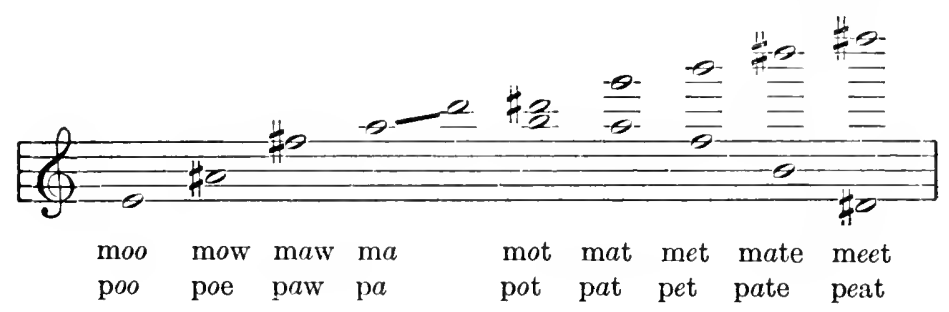

articulate sound of the human voice is ah as in father," says Miller. In fact, it is the only vowel that can be clearly characterized by all voices at all pitches. Moo and meet, for instance, are difficult of vocalization in the upper ranges of a soprano voice; but any vowel can be intoned freely upon "any lower note of which the characteristic note is a

1 Ibid., pp. 241-243.

2 Ibid., p. 260. 
harmonic, such as notes an octave, a twelfth, or a fifteenth lower (in musical intervals) than the characteristic." Of course, it can be produced at other pitches than these, but less clearly. Observe, too, that the letters of the alphabet are merely symbols. $A$, for instance, is the symbol for more than half a dozen distinct vowel sounds, the regions of maximum intensity for, which vary greatly, and which are in no wise related one to the other ( $f a t$, fate, far, fall ask, fare, errant). Although dictionaries use as diacritical marks longs $(\bar{a}, \bar{e}, \bar{\imath})$ and shorts $(\breve{a}, \breve{e}, \breve{\imath})$ and various dots $(\dot{a}, \ddot{a}, a)$ and curves $(\tilde{e}, \hat{u})$ over or under the letters and speak of the sounds as the long or the short, this method of nomenclature is purely for convenience and has nothing whatsoever to do with either the actual nature of the sound or with the time consumed in its pronunciation, as I shall show later.

If we regard as vowels all sounds produced by vibrations of the vocal cords, in some words, when sung, $m, n, l$, and $n g$ are just as much vowels as $a$ or $o$ or any one of the sounds to which the term vowel has been restricted in the past; but in the same words when spoken the $l$ or $m$ or $n$ or $n g$ may be so greatly reduced as to become merely a consonant, - that is, a noise accompanying some vowel. In other instances, however, as in heaven, they may in some pronunciations perform the function of a vowel (heav'n). So, then, in vowel and consonant sounds, as in all phenomena examined thus far, it is noteworthy that there is no clearly defined point of division. About a large majority of the sounds there can be no doubt; but a few of them certainly lie on intermediate ground and must be regarded sometimes as vowels, sometimes as consonants, according to the function which they are performing.

To summarize the situation: The difference between the tone quality of an instrument and that of the voice is 
due, in the first place, to a greater number and a greater prominence of the partials of the voice tone; in the second, to the fact that for instruments it is the relation of the intensity of the various partials, and not the pitch of the partials, that is constant, while for the voice the intensity of the several partials will vary according to their approximation in pitch to the pitch of maximum intensity afforded by the cavities of the mouth and of the nose when acting as a resonator.

The tone effect produced by the different vowel successions of any artistic composition is exactly analogous to effects secured by playing a melody on a given instrument in such a manner that each tone is made to have a different color. However, in music, great care is taken not to vary the color too rapidly. Except in orchestral music, a unit impression of quality is what is commonly sought. In both speech and song the general voice quality is constant, but the specific vowel quality infinitely varying. As A. J. Ellis, says "In singing they [the vowels] have to be sustained at a steady pitch and with a steady quality, and the ear consequently rapidly fails to recognize any particular vowel." 1 In poetry the vowels are pronounced with the greatest care. They are deliberately prolonged beyond the time lengths usually assigned them in conversational speech in order to make their tone-color prominent, even when assonance, alliteration, or consonance are not in question, and to furnish a temporal basis for the development of rhythm, though with regard to each other some vowels may be relatively shortened. ${ }^{2}$

In view of the fact that onomatopœia is a question of considerable importance to prosodists, before leaving tonecolor, I must direct attention to a series of experiments

1 "Speech in Song," p. 30.

2 Paul Verrier: "Essai sur les principes de la métrique anglaise," Vol. I., p. 23, Par. 37. 


\section{THE FOUNDATIONS AND NATURE OF VERSE}

conducted by Dr. Robert Chenault Gilver of the University of Washington. ${ }^{1}$ His purpose was twofold, - (1) To throw light upon the so-called tonal theory of poetry, by measuring the emotional value of the sounds in poetic language without reference to alliterative or grammatical devices, and (2) to discover what auditory, kinæsthetic and organic sensations are aroused by the play of vocal functions in meaningful as well as meaningless collocations of the elements of language." After eight years of work, during which time he examined 540,000 sounds and measured nearly 300,000 bits of data involving more than a million computations, he could offer nothing more definite than this:- (1) Though strictly speaking the terms long and short are equivocal, the so-called short vowels and the explosive consonants are provocative of more motor arousal than the long vowels and the liquids; (2) In answer to the question, if this or that number of sounds will produce this or that effect, the reply can be made in the affirmative only after taking into consideration the number and the arrangement of the sounds. "Only in the longer passages does there seem to be a trend toward a tonal calculus. And here, the surprising thing is that a very small number of explosive sounds in one passage over those in another produced a motor difference greater than that deducible from the single effects of the elements involved;" (3) "The tonal pattern of poetry is quite more definite than hitherto suspected, and a poet may be known by his overtones as well as by his subject-matter and stanza form. ... It is not an impossible assumption that poetry as well as other forms of art may possess in each of their leading features, form and content, a sufficiency of emotional wealth

1 "The Psycho-physiological Effect of the Elements of Speech in Relation to Poetry," Psychological Monographs, Vol. XIX., No. 2, April, 1915, Psychological Review Company, Lancaster, Pa. 
to be considered each alone as able to arouse the æsthetic consciousness to the full. The union of the two may add nothing but unity." 1

To this let me add an account of a few experiments of my own, which, though rough in the extreme, nevertheless, appear to me to yield something of significance. I read before a group of college students unacquainted with German a number of poems in that language. Each poem was read several times. Regardless of the sense, one reading I would make very quiet and pastoral; and the subjects were told to write down their impression of its content. The next reading would be light and merry; the third, tragic and somber. I found that they took their cue entirely from the interpretation which I gave the words, and that at no time did there seem to them to be anything incongruous between the words themselves and the manner of my reading them, although I had been particularly careful to select only poems generally cited as highly onomatopoetic. Such an example in English is offered by Poe's "The Bells." This poem was undoubtedly composed with special reference to fitting the sound to the sense; yet I have my doubts about the power of the sounds themselves to arouse any definite conception when disassociated from the sense. Gold and ghoul are certainly not widely different in sound, though in the poem how different their effect! Then, too, the word bells must certainly be taken as a factor common to every stanza. Sargent ${ }^{2}$ thinks that its repetition is almost fatal; and Tolman ${ }^{3}$ deliberately omits it in making up his percentages of the vowel sounds

1 Gilver: "The Psycho-physiological Effect of the Elements of Speech in Poetry," pp. 124-130.

2 In "Cyclopedia British and American Poetry."

3 "Laws of Tone-Color in the English Language," Andover Review, Vol. VII., March., 1887, p. 331. 
in that poem. Yet I have heard it so read that bells clanged or boomed or tinkled or shuddered in most perfect keeping with the several stanzas. It seems to me that the word has no tonal value whatsoever aside from that imposed upon it by the reader. Of itself it suggests nothing. It can be made to suggest anything.

Of course, some words are agreeable, some disagreeable; some easy to pronounce, some exceedingly difficult. ${ }^{1}$ What vowel and consonant combinations offer is the opportunity to build from them more or less pleasing successions or patterns. The pleasant combinations are regarded as suggesting quiet, love, beauty, and all high emotions; the disagreeable, as suggesting strife, hate, tumult, baseness. $^{2}$ Yet, even in artistic verse, these various sounds are so intermixed that only in rare instances does any one element predominate. A number of words are undoubtedly imitations of sounds in nature; ${ }^{3}$ but to me it seems that their importance in language has been overestimated. Tolman, however, is quite near the truth in claiming that: "Particular ideas and feelings have analogues in sound which best express them, and that this is felt to be true in the present time by the resthetic sense, the language consciousness, of the cultivated users of English. In this way I believe in sound-metaphor." 4 Of course, it must never be forgotten that this language consciousness is acquired through the association of ideas with words. For

1 Louise Roblee and M. F. Washburn: "Affarent Values in Articulate Sounds," American Journal of Psychology, 1912.

Gilver: "The Psycho-physiological Effect," etc., pp. 28-29, 35-36.

2 Gilver: Ibid., p. 35.

${ }^{3}$ Heyse: "System der Sprachwissenschaft."

"Tolman: "The Laws of Tone-Color in the English Language," p. 326 .

- See also Verrier: "Essai sur les principes de la métrique anglaise," Vol. I.. p. 11S, Par. 150, and following. 
instance, the noun rush, meaning a kind of reed, does not awaken at all the same emotional response as the verb to rush, though their tone-color is identical.

The correct statement of the case seems to me to be this:Certain sounds set to certain rhythms will produce given effects provided (and here the provision is of the utmost importance) other elements are introduced to suggest to the imagination something far more concrete than that suggested by the sounds themselves. Speed of utterance combined with pitch and intensity of voice are most important factors; but they, too, are subjectively determined. Behind them must be some idea with which they, as well as the syllables, must be infused. Musicians are very careful to state at the beginning of their compositions at what tempo and with what intensity the notes are to be rendered; and there is never the slightest doubt as to the tone-color to be employed. Yet what could be more general or more indefinite than the emotions aroused in hearing a given composition? "Music," says Harry Porter Weld after a most thorough investigation, "is powerless to portray a definite picture in any uniform or universal sense, or to convey the same group of imagery into the minds of each of its auditors." I It is this to you and that to me unless we are given a hint as to what channels the imagination is to follow. Here both prose and verse have a decided advantage over pure music. Words are associated with ideas. They impose their moods upon the sounds of which they are built up; but the ideas to be expressed determine the choice

1 "An Experimental Study of Musical Enjoyment," American: Journal of Psychology, XXIII., April, 1912, p. 300.

For an interesting dissenting opinion see "Music and Emotion" by Dr. Albert Balz (Journal of Philosophy, Psychology and Scientific Methods, XI., No. 9, April 23, 1914). I believe that, if Dr. Balz had. extended his inquiry to the music of all lands through many ages, he might have reached a far different conclusion. 
of words, the rhythm, the tempo, the intensity, and the pitch. Inversely, given the word (that is, the tone-color) uttered in the same rhythm at the same speed and with the same intensity and pitch, a similar emotional state can be reinduced. The definiteness of the emotional state, however, will depend largely upon the amount of prompting received from the words. Almost every poet displays a marked preference for certain sounds. Poe reveled in $o o$, Byron in $o$, Shelley in $e$ and $i$; yet all were able to produce somewhat similar effects, though rarely by the same means. In like manner poets are prone to use characteristic rhythms and stanzaic forms; but how far any one word, any one rhythm, or any one form is preëminently fitted to express a particular idea or emotion is certainly worth pondering. I rather suspect that ghost, Gheist, and spectre are equally eery, no matter in what language they appear. To my mind, such fitness of material is largely a matter of association, on the one hand, and of skill on the part of the user, on the other. Where A, B, C, and D may fail with certain materials to produce a satisfactory work of art, $\mathrm{E}$ may erect for himself therefrom an arch of triumph. This same truth holds good in music. The possibilities of orchestration had been thought to be exhausted long before Wagner came; yet Tschaikowsky and an entirely new school of Russians have arisen since. I had always regarded the flute as an instrument of rather limited capacity until I heard a great artist play it. Now I know that it possesses both fire and passion as well as mellowness and airy grace. About such matters, then, I feel it wiser not to dogmatize. It seems is the most that can be affirmed; for no sooner is a law laid down than whisk! and some wizard has accomplished the impossible. Thereafter it is thought that only by this means can the desired end be reached, - that is, until some new genius arrives to show us otherwise. 
As was found to be the case with melody and harmony, in combinations of vowels and consonants we accept as agreeable that to which we are accustomed, that which we can in a measure anticipate. Therein lies the charm of rhyme, alliteration, and assonance. A pattern in tonecolor is set up. Expectation is awakened. With its fulfillment muscular tension is released; and a feeling of satisfaction ensues. In general, our judgment of tonecolor is not of this type, but vague, indefinite, illusive. Therefore, when into this moving spectrum of sound some sound that can be anticipated appears, a more intense and concrete pleasure is at once experienced. The Law of the Return has been fulfilled. It is not necessary, however, from an artistic point of view that the emotions or the mental images of the creator should coincide with those of his auditors, since in the cultivation and exercise of both music and verse one's intention "is not so much to make himself intelligible as to inspire his fellow-men." 1 Toward this end vowel color is a factor common to prose, verse, and music, though in music, and particularly in verse, there is a deliberate attempt to make of it a definite source of inspiration. It is brought under control by the rhythmic impulse; and, when it appears in its most studied form (as alliteration, as assonance, or as rhyme), it has the double function not only of providing an agreeable succession of sounds but also of supplying an auxiliary to rhythm. Therefore, further consideration of vowel color must be deferred until it can be taken up again in its proper place under the latter heading.

To this point the important facts with reference to vowels are these:- (1) Although some vowels impress the ear as being high, others as low, and still others as medium, ${ }^{2}$ in

1 Richard Wallaschek: "Primitive Music," p. 258.

2 Gilver: "The Psycho-physiological Effect, etc.," p. 20. 
reality there is no such thing as a high or low or medium vowel. All tone quality results from the presence of partials. The tone quality of vowels has this peculiarity, - that for each vowel there is a certain range of pitch within the limits of which its characteristic upper partials must fall in order that the vowel may be produced. Regardless of actual pitch, a thin sound often impresses the ear as being high, a rich sound as being low. An abundance of brilliant partials makes for richness; their absence, for an opposite effect. (2) It can not be maintained that vowels and consonants in and of themselves can induce either separately or in combination any certain emotional state, though, when aided by pitch, intensity, rhythm, and tempo, and especially when infused with the suggestive power of language, they may become most potent in arousing a general emotional impression. (3) Vowel quality is common to prose, verse, and vocal music; but it finds its most definite artistic value as a phenomenon of verse. 


\section{CHAPTER VI}

\section{INTENSITY}

Intensity in physies and mechanics is defined by the "Century Dictionary and Cyclopedia" as the amount or degree of energy with which a force operates or a cause acts; effectiveness, as estimated by the result; the magnitude of a force, measured in appropriate units. Within the range of pitch used by speech and the more common sounds of music, intensity and degree of energy may be regarded as practically synonymous terms. Therefore, the intensity, or loudness, of a sound may be thought of as the degree of energy with which the sound operates. We have seen that the pitch of a sound is the result of speed of molecular vibration; and color, of the form of molecular vibration. The amplitude of the vibration determines its loudness. Let me illustrate. If a violin string be plucked with the fingers, it can be seen to swing back and forth like a pendulum. If the string swings through a small arc, the sound is soft; if through a large arc, the sound is loud. Amplitude, then, "is the range on one side or the other from the middle point of the motion, therefore it is half the extreme range of vibration." 1 The energy of a sound "varies as the square of the amplitude, the frequency remaining constant; when both amplitude and frequency vary, the intensity varies as the square of the product of amplitude and frequency." 1 Although intensity of tone can be thus reduced to a formula, there is still no appropriate unit of measurement. For pitch of

1 D. C. Miller: "The Science of Musical Sounds," p. 7. 
tone a definite standard of tone can be agreed upon, and the other tones can be measured with reference to it. But not so with intensity. The nearest approach to a standard is at best only a very general thing. Musicians write across their scores soft, loud, moderately loud, etc.; but these directions furnish no clue to how soft or how loud. Were speech not governed by habit of utterance, chaos would reign supreme. Intellectual and emotional considerations, however, determine the amount of energy that shall be put into any sentence, clause, phrase, word, or syllable, so that for a given art product the degree of energy expended is determined by the content of the words themselves. It is no longer a difficult matter for physicists to plot the intensity of tones or to determine the relative intensity of a given tone at a particular instant of time. ${ }^{1}$ Still, this is very different from establishing a standard of tone intensity or from saying that the ear makes other than vague, general judgments as to the intensity of any sound or group of sounds presented to it. The ear of every hearer is individual in its degree of sensitivity. Furthermore, certain people are peculiarly sensitive to sounds of different pitches and various tone-colors. There can be no unit of intensity, because we are entirely dependent upon subjective factors for the determination of the degree of this particular class of sensations, ${ }^{2}$ and these sensations are too fluctuating to be coördinated.

Nevertheless, intensity remains one of the most important structural factors in tonal art. For prose, verse, and music,

1 P. Bourdon: "L'application de la méthode gràphique à l'étude de l'intensité de la voix," L'Anée Psychologique, 1907.

D. C. Miller: "Science of Musical Sounds," pp. 92-141.

2 Winkelmann: "Akustik," pp. 228-254.

A. G. Webster: Physical Review, 1903, 16, 248.

D. C. Miller: "The Science of Musical Sounds," p. 53. 
though each may employ it within the conventions peculiar to the particular form, intensity is essential. General effects of diminuendo and crescendo, of sustained loud and soft, of marked and abrupt changes from loud to soft, and vice versa are common to all three; yet, because of their variableness and of their incapacity for standardization, they call for no further comment. Though having important ancillary functions, they are not essentials. They give variety; they help to show degree of emotion as well as to induce it; but they are matters of individual interpretation and nothing more. The manner in which they are used may inclicate whether the interpreter is an artist or a tyro. Yet for all that, they simply do not enter into the scheme of the prose writer or of the poet. Even the composer might fail to indicate them on his score without material damage either to his reputation or to our understanding of his work. In these matters almost every performer, every singer, every conductor allows himself the utmost latitude. Here he feels that he has a right to express his own conception of the composer's intention, sometimes even in defiance of the latter's explicit instructions. In no other particular (excepting, of course, all considerations of tempo) would the interpreter feel that he had an equally free hand. Certainly he would never dare to change the time or the tonal structure in any way, no more than a reader could with impunity alter the position of a word or the tone-color of a rhyme.

The second function of intensity, - its use as accent, - can not be thus summarily dismissed, however. While I am not prepared to say that tonal art can not exist without it, certainly one school of English prosodists has taken the position that it is the sine qua non of English verse. Respect for the opinion of Edwin Guest and his followers as well as the inherent importance of the subject itself 


\section{THE FOUNDATIONS AND NATURE OF VERSE}

demands that I enter at some length into its discussion. First, however, it is necessary to direct attention to general considerations of time and time relationships, and with this preparation to pass immediately to the discussion of accent as one of the determining factors of rhythm. In the meanwhile, what should be kept in mind is this: Our judgments of intensity are relative. A sound, which, when associated with some other sound or group of sounds, may become relatively prominent, may in fact possess very little intensity. It is judged to be loud because it is louder than another sound of group of sounds, though perhaps in reality it may be no louder than the others, but merely appear to be so because of some peculiar conditions of pitch or of tone-color to which the hearer is susceptible. The length of duration also influences our judgments of intensity. So much in passing. Each of these phases of the subject will be proportionately developed in due season. 


\section{CHAPTER VII}

\section{GENETIC ASPECTS OF RHYTHM}

To surplus of animal vigor is probably traceable the origin of the temporal arts. ${ }^{1}$ Among certain of the anthropoid apes and even among birds, ${ }^{2}$ this surplus of vigor finds vent in muscular movements resembling those of the communal dances of primitive peoples. Of course; these movements are entirely lacking in coördination, even when they are practised by gregarious animals and birds; but so, too, are the dances of the lowest types of savages. In some instances these animal dances are even accompanied by rhythmical noises not unlike the beating of instruments of percussion. Bird song, however (and to this I have not been referring), is as lacking in definiteness of rhythm as it is deficient in systematization of pitch; and herein lies the distinction between music and mere vocal utterance.

"True music," says Wallaschek, ${ }^{3}$ "requires a degree of observation, an intention and a participation of the intellect, and not only a momentary reflex of feeling; it requires the form of timeordered perception which is lacking in the animal and so strongly pronounced in the choral dance-music of primitive men. An

1 Herbert Spencer: "On the Origin and Function of Music."

2 Charles Darwin: "Descent of Man," 2d ed., pp. 68-74.

Guessfeldt, Falkenstein, Pechuël-Loesche: "Die Loango Expedition," p. 152.

C. Lloyd Morgan: "Animal Sketches," p. 171.

Richard Wallaschek: "Primitive Music." In a note on page 241 both $\mathrm{Du}$ Chaillu and Koppenfels are said to confirm this in reference to the gorilla.

${ }^{3}$ Mind, New Series, Vol. IV., No. 13, p. 35. 
individual vocal reflex arises and vanishes with the stimulus of the moment, while singing in concert requires a definite purpose, a definite arrangement of utterances, which are to be intentionally worked out, practised and preserved in memory. In this unsettled condition song would become monotonous, ineffective, and therefore calls for variety. Variety in the face of tradition means progress, development, and thus choral music alone affords the starting point for our art; in its intrinsic character lies the germ of music. . . . Men dance in a unison and with a symmetry which are wanting in animals' dances, and this deficiency is due to a mental cause which betrays - if I am not mistaken - the most serious difference between men's and animals' intelligence on record."

It seems, therefore, that the desire to expend surplus energy in rhythmical movements of the body is common to man as well as to many animals related to the human family in only the remotest degree. The habit of dancing is universal among both civilized and uncivilized peoples. Wherever the communal instinct prevails and there is leisure in which to give expression to the desire for play, there dancing is the most frequent of pastimes. ${ }^{1}$ The degree of coördination of movement among the dancers is variable. Sometimes it is almost negligible. Sometimes it is very highly developed. Invariably, however, the dance is accompanied by some sound to mark the rhythm, whether the sound be produced by the beating of drums, the clapping of hands, or the human voice. ${ }^{2}$ Not infrequently the

1 Except, of course, where Christianity has discouraged dancing.

2 Richard Lander: "Records of Captain Clapperton's Last Expedition to Africa," I., p. 293, p. 151.

Joseph Corry: "Observations upon the Windward Coast of Africa," p. 153 .

Henry Foster: "Narrative of a Voyage to the South Atlantic Ocean," pp. 275-276.

Wood, Livingston, Grant, Mauch, Baker, Ratzel, Violloteau, Barker 
dancers stamp, play some instrument, and either sing or recite, - all at one and the same time.

To my mind Wallaschek presents the most plausible theory by which to account for the origin of both music and verse in finding their common source in the accompaniment to the dance. ${ }^{1}$ Very early they may become dissociated from it; but they are never completely and irrevocably separated. Even when they exist independent of each other, however, they are still of common occurrence together.

As I have already stated, wherever there arises the necessity for the expression of communal feeling, whether in war, work, mourning, joy, religious rite, or as a mere pastime, some unifying principle must be found. Otherwise there could be only the chaos of individual emotion. For the dance, music, verse, and, to a limited extent, for prose, this principle is furnished by rhythm. The muscles, surcharged with energy, find relief from their tension by means of rhythmical movements.

"The first stimulus is the muscular sense, and the sense of hearing only comes into action later as an additional help in getting a greater number and superior quality of sensational impressions which through their qualitative difference and greater substantial richness might facilitate the course of the cortical process. . . . A long time is needed before the sense of hearing can take a part

and Berthelot, B. Smith, Eyre, Beechey, Oldfield, Cook, A. B. Meyer, and as many others are cited by Wallaschek in his chapter on Dance and Music in "Primitive Music" (p. 187) in corroboration of this statement.

${ }^{1}$ Both Andrian and Verrier deny this origin to verse:-

F. von Andrian: "Some Results of Modern Ethnology," Correspondenzblatt der deutschen Gesellschaft für Anthropologie, Ethnologie, und Urgeschichte, 1894, No. 8, p. 71.

Paul Verrier: "Essai sur les principes de la métrique anglaise," III., p. 71 (Paris, 1909-1910). 
of equal importance with the common action based on the muscular sense, and yet a long time before it becomes the more and ultimately only important sense. The whole structure of primitive music shows this: an unsettled melody, an uncertain and constantly varying intonation, a perpetual fluctuation of pitch, and contrasting this with the strict and ever-prevailing rhythm, with the precision and marvelously exact movements of numberless performers - we see where the chief point lies." I

In a state of civilization where violence of movement is not looked upon with favor, a gradual suppression takes place, until, finally, in music, in verse, and in rhythmical prose, muscular contortions become entirely negligible, even though muscular tension has by no means ceased to exist. The dance, too, is greatly modified and refined. For all four there is the process of development from poorly marked rhythm in communal expression to a greater and greater degree of exactness. This exactness becomes so strongly rooted in the feelings of certain individuals that they are able to develop and to maintain rhythms when acting quite independently of the group.

Just here it is interesting to note that the rhythmical expenditure of surplus energy is not instinctive, but acquired. Like our scales and our melodies, it, too, comes to us as a part of our social inheritance. P. F. Swindle is quite right in saying:-

"All experimental evidence seems to point to the conclusion that rhythm is acquired by each individual, and that it is not inherited. Biological conditions, - for example, the anatomical fact that we are two-handed and two-footed and generally twosided, not three-cornered nor star-fish-like beings, - are favorable for the development of those rhythms which can usually be considered to be instinctive, while the other rhythms can be acquired only under special, somewhat artificial conditions. The best means for developing rhythm is that which approaches our

1 R. Wallaschek: Mind, New Series, Vol. IV., No. 13, p. 35. 
ordinary life activities. In the development of a rhythm, the motor activity of the skeletal museles plays the most important rôle. For this reason, the larger movements of a purposive activity are much more conducive to the production of rhythm than the smaller movements which accompany the purposeless activity of the counting method." 1

Exactness of rhythmical movement having been communally acquired by the individual, the process can now be reversed; and the individual is able through the employment of rhythm to address himself immediately to the group and to infuse it with his personal emotions to such an extent that individual and community again merge into one. The dance, music, and verse, it would seem, therefore, are related arts in that all are dependent upon the human appreciation of rhythm. For those who do not possess the faculty of coördinating either movements or sounds, the temporal arts do not exist.'

"It can not be too strongly insisted on," says Robert Macdougall ${ }^{3}$, "that the perception of rhythm is an impression, an immediate affection of consciousness depending on a particular kind of sensory experience; it is never a construction, a reflective perception that certain relations of intensity, duration, or what not, do obtain. If the perception of rhythm in a series of impressions were dependent on intellectual analysis and discrimination, the existence of such temporal limits as are actually found would be inconceivable and absurd. So long as the perception of the uniformity or proportion of the time-relations were possible, together with the discrimination of the regular recurrence in the series of points of accentuation, the perception of rhythm should persist, however great or small might be the absolute intervals

1 P. F. Swindle: "On the Inheritance of Rhythm," American Journal of Psychology, XXIV., 1913, p. 203.

2 Sir John Stainer: "Music in its Relation to the Intellect and the Emotions," p. 28.

3 "The Structure of Simple Rhythm Forms," Psychological Review, Monograph Supplements, Vol. IV., Whole No. 17, Jan., 1903, p. 325. 
which separated the successive members of the absolute series. If it were the conception of a certain form of relation, instead of the reception of a particular impression, which was involved, we should realize a rhythm which extended over hours or days, or which was comprehended in the fraction of a second, as readily as those which actually affect us."

Between rhythm performed and rhythm perceived certain differences must be noted. Between rhythm in nature and rhythm as employed by art still further distinctions must be drawn. Because of the multifold aspects of the subject of rhythm and because of the complexity of the problems which have to be confronted, no matter from what point of view the approach is made, researches have been most productive of exact information when they have been confined to some particular phase of the problem. Yet the necessity for thus limiting the horizon has militated against anything like a comprehensive view. I have very grave doubts as to the possibility of attaining such a conception at the present time. The best that can be done is to direct the mind along certain suggestive channels of thought, leaving to the future the determination of cross currents and edclies as well as the making of more careful soundings in the channels themselves.

Throughout nature, whether animate or inanimate, something resembling rhythm seems to prevail, - that is, there seems to be more or less strict periodicity rather than haphazard recurrence. ${ }^{1}$ It is found in the planetary motions, in the union of chemical elements, in the processes of plant life, and in the functioning of the various organs of the higher as well as of the lower animals. So persistently does it come before us in the beating of the heart, the pulsing of the blood in the veins and the arteries, and in the rising and the falling of the chest in breathing, that not

1 Fiske: "Outlines of Cosmic Philosophy," Vol. II. 
infrequent attempts have been made to establish the existence of a vital connection between the rhythms of art and these life processes. ${ }^{1}$ I shall not undertake to say that in particular instances they do or they do not maintain. I do wish to call attention, however, to the rather patent fact that all human activity is subject to the limitations placed upon it by these various functionings of the parts of our organism. The rate at which any process is repeated, though uniform in the main, is, nevertheless, a variable quantity. The rhythms of art are far more varied, far more complex; and it yet remains to be satisfactorily demonstrated that there is any great degree of dependence of the rhythms of art upon these periodic functionings. Of course, within certain limits art must accommodate itself to nature. Otherwise art would be an impossibility. Some of the rhythms of art are the more easily sustained because they follow in a general way the periodic rise and fall of the chest in breathing or the systole and diastole movements of the heart. It is just as true, however, that other rhythms do not follow these, but are maintained in spite of them. I might even go so far as to say that they are the more effective for requiring a greater concentration of attention and a greater degree of effort on the part of both the producer and the perceiver. ${ }^{2}$ Everything depends upon the artistic effect to be realized.

Art may turn to its own account the recurrent phenomena of nature; but by far the greater number of these pass unperceived altogether, or they are grasped only after severe exercise of the powers of the intellect. Usually

1 L. Drozynski: "Atmungs- und Pulssymt. rhythmischer Gefühle," Psych. Studien, VII., 1912.

2 Harry Porter Weldt: "An Experimental Study of Musical Enjoyment," p. 298, American Journal of Psychology, XXIII., April, 1912.

V. Benussi: "Psychologie d. Zeitauffasung," p. 505, (Heidelberg, 1913). 
they occur in an extent of time either too large or too small to be immediately apprehended, when, to be available for artistic purposes, it is essential that phenomena be restricted to very limited extensions of time or space. Rhythm does not exist for any individual until it becomes an affection of his sensibility. The rhythm of a succession of psychoses is the only rhythm which can become an object of direct experience. The span of rhythmic sensibility is not great. Although it has been investigated quite frequently, ${ }^{1}$ about all that can be said concerning it for verse

1 Bolton: "Rhythm," Amer. Jour. Psych., VI., pp. 145-238.

Dietz: "Untersuchungen über den Umfang des Bewusstseins bei regelmässig aufeinanderfolgenden Schalleindrücken," Phil. Stud., 1885, II., 383 .

Gurney: "The Power of Sound," p. 127.

Lange: "Beiträge zur Theorie der sinnlichen Aufmerksamkeit und der activen Apperception," Phil. Stud., 1888, IV., p. 404.

Johnson: "Researches in Practice and Habit," Studies in the Yale Psychological Laboratory, 1898, VI., p. 91.

Marbe: "Die Schwankungen der Gesichtsempfindungen," Phil. Stud., 1893, VIII, p. 615.

Meumann: "Untersuchungen zur Psychologie und Aesthetik des Rhythmus," Phil. Stud., 1894, X., p. 302.

Pace: "Zur Frage der Schwankungen der Aufmerksamkeit nach Versuchen mit Masson'schen Schreiben," Phil. Stud., 1893, VIII., p. 615 .

Martius: Phil. Stud., 1891, VI., p. 196.

Schmirlt: "Introduction to the Rhythmic and Metric of the Classical Languages," $79 \mathrm{ff}$.

Sievers: "Grundzüge der Phonetik," 2 Aufl., p. 218.

Scripture: "The New Psychology," p. 125.

Smith: Phil. Stud., 1900, XVI., p. 282.

Stevens: "On the Time Sense," Mind, 1886, X., p. 394.

Tichener: "A Primer of Psychology," p. 89.

"An Outline of Psychology," p. 89.

"Experimental Psychology," I., ii. p. 340.

Wallin: "Researches on the Rhythm of Speech," Studies from the Yale Psychological Laboratory, IX., 1901, p. 72. 
intervals is that it falls within the limits set by five seconds as a maxinum and 0.89 of a second as a minimum, or perhaps it may even exceed these slightly. ${ }^{1}$ Wallin ${ }^{2}$ summarizes the entire situation as follows:-

(A) "While the differences of the results of experiments can be partly explained by differences and inconsistency in the amount of the stimuli and in the physical and mental conditions of the observers (due to fatigue, inattention, irrelevant movements, sensations and memory images, passive or active attitude, etc.), the natural period of attention will differ for the different senses and for different individuals. The period for the more purely sensory (receptive) waves may also differ from the more purely motor (voluntary) waves; and those of the involuntary subjective grouping from those of the voluntary grouping.

(B) "The span of the rhythmic sense is definitely limited for each individual, thuugh we do not yet know its precise upper or lower limits, or how it differs in voluntary and involuntary subjective rhythmization, in its sensory and motor aspects, nor its dependence on the psycho-physical conditions and age of the individual.

(C) "The regularity of intervals will be greater for those that fall within the span than for those that do not."

Merely in order to furnish a convenient point of attack and without the slightest intention of accepting his statement of the case as final (as, indeed, he himself does not), I wish to posit as a working definition a transcription of the words of Paul Verrier: -3

Rhythm is constituted by the return of a fixed phenomenon at sensibly equal intervals of time or space, or, still more exactly expressed, by the return of the sign which renders the division of time or of space perceptible to the hearing, to the sight, to the touch, or to the muscular sense.

1 Wallin: "Researches on the Rhythm of Speech," p. 72.

2 Ibid., p. 69.

3 "Essai sur les principes de la métrique anglaise," II., p. 3. 
Although it is often very convenient to illustrate auditory rhythms in terms of rhythms of sight and the structure of verse in terms of architecture, after all there is but a superficial resemblance between the two; and to hold them over against each other for purposes of comparison is likely to result, as it certainly has resulted in one particular case, ${ }^{1}$ in a maladjustment of focus in mental vision.

It is better, therefore, to omit all consideration of symmetry and to center the attention exclusively upon the question of movement in time. Certainly in three of the temporal arts the sense of sight contributes nothing whatsoever. ${ }^{2}$ In the fourth, dancing, sight is involved to a considerable degree; but even here it is not essential. Prose, verse, and music appeal with equal intensity to the blind as to those who see; nor are the blind altogether shut off from the enjoyment of dancing.

The temporal arts express themselves by means of vibrations which we receive in one of two ways or in both, - (1) through the hearing, (2) through the muscular sense. Perhaps for the sake of completeness, I should add (3) through the touch and (4) through the sight. Though deaf, dumb, and blind, Misses Laura Bridgman and Helen Keller were fond of music and dancing. ${ }^{3}$ However, every one would admit, I believe, that the appeal of the temporal arts is to normal human beings in whom the sense of touch would not be involved at all. Sight need be considered

1 George L. Raymond: "Rhythm and Harmony in Poetry and Music" (G. P. Putnam, New York, 1909).

2 This statement must not be accepted too literally. Both opera and drama make a very definite appeal to sight, though here again sight is not essential. This eategorical nothing whatsoever I shall take occasion to qualify in more than one particular from time to time.

${ }^{3}$ Bélugnon, L.: "Une nouvelle Laura Bridgman," in Revue Philosophique, 1889 , tom. 28 , p. 175 . Miss Keller has now learned to talk, I understand. 
only as representing a transference of function, as in the case of the deaf or of those who read without uttering the sounds. Of course, every one not suffering from paralysis of the sensory nerves recognizes as rhythmical certain methods of rubbing, touching, or otherwise stimulating the skin; and all who see can be made to apprehend the rhythm imposed upon flashes of light; but I know of no art form in which these experiences are contributory in even a negligible degree to the arousing of æsthetic emotions.

Our tentative definition of rhythm in general may now be restricted so as to include only such rhythms as are met with in the temporal arts. Rhythm is constituted by the return at sensibly equal time intervals of the phenomenon which renders the division of time perceptible to the hearing, to the sight, or to the muscular sense. ${ }^{1}$

Here three factors are involved, - (1) time, actual and relative; (2) some phenomenon to aid in the measurement of time; (3) the self, as the originator or perceiver of the rhythm. Each of these has called for specialized investigation. One group of psychologists has been concerned with analyzing rhythm as an immediate, subjective experience, involving factors of perception, reaction, memory, feeling, and the like. ${ }^{2}$ Another has dealt with the specific objective conditions under which this experience arises, and the effect of changes in these factors. ${ }^{3} \mathrm{~A}$ third has sought to coördinate the rhythm experience with general laws of physiological activity and repose. ${ }^{4}$ A fourth has

1 I retain to the sight until I can dispose of the art of dancing.

2 Angell and Pierce, Ettlinger, Hauptmann, Mentz, Meumann, Stumpf, Wundt.

3 Binet and Courtier, Bolton, Ebhardt, Hurst and McKay, Meumann, Sievers, Macdougall, Shaw and Wrinch.

4 Bolton, Brücke, Dogiel, Haushegger, Holmes, Mach, Ribot, Sherrington, Scripture, Smith, Münsterberg, Hughlings-Jackson, J. Minor, and others. 
undertaken to describe the historical process by which the various rhythm types have developed, and to formulate the laws of their construction. ${ }^{1}$ Obviously, even a cursory review of so large an amount of material is beyond the scope of a book such as this; nor is a résumé of any kind pertinent to the argument which is to follow. Yet a careful selection of such facts as appear to me to bear immediately upon the specific problems that arise in the course of this investigation ought to enable me to avoid imposing an undue burden upon the attention of my readers without at the same time prejudicing them against the validity of my conclusions. The view which I shall take of rhythm must be subjectively objective throughout.

Rhythm as applied to the dance involves considerations of both time and space. ${ }^{2}$ In so far as it is a question of movement it lies within the domain of space, into contact with the limits of which the dancer is brought by the contraction and the relaxation of his muscles. These contractions and relaxations he so coördinates that they oceur at relatively fixed intervals of time. Sight is not involved. For communal dancing some phenomenon of time furnishes the unifying factor. For the nonparticipant, the enjoyment of the dance is due to stimulation of the optic nerve. He sees the movements take place; and these movements he perceives as bearing sensibly fixed temporal relations to one another. His perception of their coördination is the more intense if at the same time he hears some phenomenon or phenomena with which to relate them. The hearing, however, is not at all essential. For both dancer and onlooker it is primarily a question of the perception of movement as related to time intervals. Now, it so hap-

1 Bücher, Moritz, Scherer, and others.

2 Beneke's "Von Takt in Tanz, Gesang und Dichtung" is an extreme case of genetic explanation of rhythm. 
pens that out of the desire to make this relationship the more immediately felt has developed tonal art. Here it is not a question of relationships of time and space, but of time and sound. In both instances perfectly plastic phenomena have been brought under the control of the time-sense of the rsthetic self. Since the moment of their inception, the lines of their development have perforce been different; yet each has contributed to the advancement of the other wherever the time-relations of movement in space could be made to overlap the time-relations of sound. Rhythm they have in common. However, in order to gain concentration of attention upon the rhythm of sound, I am compelled to exclude from consideration the rhythm of the dance. The time relationships are the same. Only the medium of expression is different. Because of this difference of medium, greater clarity can be gained by concentrating the attention upon a single medium. A far more specific terminology is thus made possible, and the necessity for eternally shifting from one to the other is eliminated. Therefore, I shall deliberately confine my discussion of rhythm to the phenomena of sound. In consequence, it is necessary to alter once more the definition with which I began. Rhythm is constituted by the return at sensibly equal time intervals of the phenomenon which renders the divison of time perceptible to the hearing or to the muscular sense.

In architecture, painting, and sculpture, the element of time does not enter. The impression is instantaneous. It is the now abstracted from the was and the to be. It is without relation to either past or future. It is eternally static. The temporal arts, on the contrary, can exist only as the past and the future can be drawn into relation with the present. The preceding moment must not have faded from consciousness before the present is realized and a 
feeling of expectation is aroused with regard to the future. Since they are limited to time, they must involve succession. Yet it is a succession in which there is no break. In fact, so intimate is the association that to speak of the process other than as a flowing, a continuum, is to make mentally a division which in reality does not exist. In consciousness events take place only in reference to other events. The temporal arts, therefore, are compelled to limit themselves to the use of such phenomena as can be retained in consciousness for such a length of time as is necessary for the perception of these phenomena as constituting a unity.

The acoustical phenomena available for artistic purposes I have already examined from the standpoints of pitch, tone-color, and intensity. The problem of duration must now be attacked. When that has been disposed of, I shall then be in a position to show how all four factors may in the hands of the artist contribute toward the establishment of rhythm and the building up of an æsthetic whole.

So intimate is the association of each of these with the others that it is well-nigh impossible to abstract from a sound any one of its characteristics. In the examination of tone-color, for instance, the sound had to be given some time-value; it had to be produced at a definite pitch; and it had to be invested with a certain degree of intensity. The best that could be done was to keep the other factors as nearly constant as possible so that the mind would not be diverted by them from the one point receiving attention. In order, therefore, to investigate the problem of duration psychologists have made use of various instruments. From certain of these the sounds to be reacted upon by the subjects are nothing more than clicks of uniform intensity. The results thus obtained if applied directly to the solution of the problems of art lead to a most egregious blunder. Still, it is just here that there is mani- 
fested among metrists a tendency to go astray. In the next chapter I shall summarize briefly the attitudes and the findings of several schools of pyschologists as to the meaning of time and the interpretation of time reactions, in hope of avoiding thereby the gins and the snares into which others have fallen through their failure to keep these facts before them. Later I can return to the application of general principles to the specific questions raised in considering the rhythms of prose, of verse, and of music. 


\section{CHAPTER VIII}

TIME

Modern experimental psychology approaches the problem of time from one of three points of view. In the first, as developed by Dr. Ernst Mach of the University of Vienna, ${ }^{1}$ time is regarded as a special state of consciousness. In the second, as championed by Dr. Hugo Münsterberg of Harvard University, ${ }^{2}$ the conception of time is given an exclusively sensational interpretation, and is looked upon as being attached to certain special states of consciousness. The third, or Kantian, view, as greatly enlarged by Dr. Wilhelm Wundt of the University of Leipzig, ${ }^{3}$ is the basis for the modern conception of time as an immediate experience of consciousness in general. All three theories have certain ideas in common. Of some of these I shall make use in attempting to develop a conception of rhythm as intimately associated with the experience of duration and as related to other more or less abstract problems involving considerations of time.

Within our conscious life change is constantly taking place. "Presentations wax and wane in distinctness and intensity, and give place to each other; attention is shifting; conation is constantly undergoing vicissitudes of relative success and failure with their effective accomplishments. Now the bare fact of the existence of such change

1 "Beiträge zur Analyse der Empfindungen."

2 "Beiträge zur experimentellen Psychologie."

3 "Physiologische Psychologie" and "Outlines of Psychology." 
is in itself irrelevant to the problem of time-perception. The essential point is that the transition involves a peculiar immediate experience which we may call the experience of transience." " This immediate experience of transience is momentary in character, - that is, it is confined to the moment in which it is being felt, a very "knife-edge" of experience, as Professor James terms it. In its immediacy it is distinct from all that has preceded and from all that is to follow. This is for us the present; yet, what we usually refer to as the present is not this kind of a present but one extending both into the past and toward the future. "It has a certain breadth of its own, ... from which we look in two directions into time. The unit of composition of our perception of time is a duration with a bow and a stern, as it were a rearward- and a forward-looking end." 2 Psychologists speak of this popular conception of the present as the specious present, a present with real duration, "in which each form flows out of previous forms, while adding to them something new, . . . explained by them as much as it explains them." 3 Because we are able to recall experiences which have preceded the present and to anticipate those which are to come, we are brought to a realization of both the past and the future. The just now is brought into relation to the now, and the about to be with the $i s$. The immediate past moves into the present, and the present on toward the immediate future. Extend the range of this ability to recall and to anticipate, and the present becomes a moment in a moving continuum of experience from which by an act of attention certain moments

1 G. F. Stout: "A Manual of Psychology" (Hinds, Noble, and Eldridge, New York, third edition, 1915), p. 520.

2 James: "Principles of Psychology," Vol. I., p. 609.

3 Henri Bergson: "Creative Evolution" (Henry Holt, New York, 1911), p. 362 . 
already experienced may be abstracted and again made a part of the present experience, and likewise moments from the not-yct expericnced may become an ideal representation of the to be in the now. Time has but one dimension. It is a continuous flow which must always be judged from the standpoint of the present moment; yet no moment of time is like any other moment, and no moment can ever return.

No experience of the self is without duration. Only certain phases of this experience have been investigated, however. Wundt ${ }^{1}$ has shown that an interval of one-fifth of a second is most favorable for the accurate union of auditory impressions. Longer intervals are a strain upon the expectation; shorter soon become fatiguing, so that in both instances errors of judgment are quick to arise. Others agree with him in saying that there is a standard unit of time by which we measure its passage, though this standard is by no means absolute. It differs with individuals, and even with the same individual at different times; yet the closer the approximation to it, the greater the accuracy of judgment. ${ }^{2}$ Intervals shorter than this unit of time tend to approach it. ${ }^{3}$ They can not be meas-

1 Wilhelm Wundt: "Outlines of Psychology," p. 149.

2 Külpe: "Outlines of Psychology."

Ernst Meumann: "Untersuchungen zur Psychologie und Aesthetik des Rhythmus" (Leipzig, 1894), reprinted from Vol. X. of Wundt's Philosophische Studien.

F. Schumann: Zeitschrift für Psychologie, Bd. XVIII., p. 1.

Shaw and Wrinch: "Contribution to the Psychology of Time," University of Toronto Studies, Psychological Series, No. 2, 1899. On page 30 one-half second is given as the unit of time.

3 Külpe: Ibid.

Ernst Meumann: Ibid.

Shaw and Wrinch: Ibid., Tables III., IV., V.

Hurst and McKay: "Experiments on the Time Relations of Poetical Measures," University of Toronto Studies, Psychological Studies, No. 3, 1899, p. 66 . 
ured individually, but must be grouped into a series which divides itself into approximations of the unit or of multiples thereof. ${ }^{1}$ Intervals longer than the unit of time are measured in terms of the unit or in multiples thereof, here represented by some organic function. ${ }^{2}$ The unit of time is a psychic compound containing both objective and subjective factors, in which, however, the objective seem to have the stronger influence. "It may be some organic function, or multiple of such, which has accustomed us to the duration which is our unit more than any other, or the unit of some objective impression or interval to which we have always been accustomed may have played the fundamental part in its formation." 3 Of course, neither in organic functions nor in phenomena of any kind is there time; but, because some of the functions are both continuous and regular, the mind may seize upon them as a standard by which to measure not only their own rate of functioning but also the rate at which phenomena present themselves to consciousness.

Münsterberg's experiments undoubtedly prove that there is no special time-sense in our consciousness; but they do not disprove that in measuring moderately short intervals we compare the actual time-lengths themselves. Neither do they prove that the sensations arising from muscular relaxations and tensions are the only means whereby we may experience immediately the passage of time, though undoubtedly these sensations do bring about changes in the content of consciousness. Smith ${ }^{4}$ speaks of rhythm

1 E. Meumann: Ibid. Külpe: Ibid., sec. 65. Shaw and Wrinch: Ibid., p. 10; and the unpublished experiments made at the University of Toronto as quoted by Shaw and Wrinch. Max Müller is also quoted as responsible for these data.

2 Shaw and Wrinch: Ibid., p. 20.

3 Ibid., p. 21.

- Philosophische Studien, 1900, XVI., p. 291. 
as a progressive emotion with coördinated motor discharges. Nichols ${ }^{1}$ has showed that sustained attention to a rhythm may alter our perception of preceding and succeeding time intervals; and Meumann ${ }^{2}$ has added the facts that the intensity of the limiting sensations rather than the content of time intervals, except in long intervals, as well as æsthetic considerations of pleasure and of pain, must be taken into account. Lipps ${ }^{3}$ stresses even more strongly than Meumann the associative character of the aesthetic feelings. A more exact statement of the case than that given it by Münsterberg is probably this:-

"From the fact that intervals whose limiting sensations fall in similar phases of respiration are much more accurately measured than others which are independent of any organic function of the body, it can only be inferred that the organic functions of the body provide data which enable the mind more accurately to estimate the intervals in which they occur. . . Time is nothing without the facts of consciousness, but it is a property of all facts, all processes." 4

Unity of experience is the keynote of time perception. "There is no cleft between psychical and physical proceedings, nothing purely internal or external, no sensation to which a thing as such different and independent from sensation would correspond." 5 Time does not exist apart from the facts of consciousness. As a property of all facts and all consciousness, by a voluntary act it may be placed

I "Psychology of 'Time," p. 94.

2 Philosophische Studien, X., p. 264.

3 "Aesthetische Einfühlung," Zeit.f. Psychol. u. Physiol., CXXII., p. 441 .

4 Shaw and Wrinch: Ibid., p. 12.

5 Mach: "Beiträge zur Analyse der Empfindungen," p. 141.

James in his "Psychology" and Ernst Grosse in his pamphlet on "Spencer's Lehre von dem Unerkennbaren" also favor this view of within and without. 
in the center of attention; and, thus abstracted, its relation to other properties may be investigated. Each fact of experience is brought by the mind into connection with other facts. In this process of unifying experience time is implied; or, as Shaw and Wrinch very lucidly express it:

"Time is a constant factor, not only of the self, the unity of the immediate experience, but of every conscious process which goes to make up the self. By the union of sensations and feelings or effective elements, which are obtained by abstraction and analysis of the facts of experience, a psychic compound is formel, whose nature depends not so much on its component elements as upon their union. When these compounds again are united, the result is more than the sum of the compounds." 1

Psychic compounds are processes embracing all the components of psychic experience. Time-presentations, being of the nature of psychic compounds, are continuously changing, continuously uniting with other compounds in the formation of more intimate connections. Time compounds are composed of both sensational and affective elements, though the sensational usually predominate. The so-called inner-touch sensations furnish us with a series of affective elements made up of feelings of strained expectation followed by feelings of fulfilment. These, when combined with the still more important sensations of hearing, are the basis for our judgments of time. Time, I repeat, is a constant factor of conscious life, inseparable from the continuum of consciousness.

An examination of auditory sensations yields a number of facts of unusual value to the student of rhythm. (1) The sensations which go to make up our idea of time are confined to the end of single intervals. (2) During the interval there is an absence of almost all objective sensation.

1 Shaw and Wrinch: Ibid., p. 14. 
There is, however, a very noticeable affective content of strained expectation followed by a feeling of fulfilment. Then, too, tension of the tympanic membrane and of other parts of the ear enters as a further sensational element. But by far the most important consideration in determining auditory judgments of time is the subjective self. Through it ideas not only of expectation and fufilment and of unity but also of pleasure and of pain and of a certain degree of emotion are brought into play. Investigation, therefore, must follow two general lines:- (1) It must seek to determine what are the phenomena marking the end of single time-intervals and how these phenomena affect our perception of time; (2) It must examine the phenomena that make up the content of time-intervals and must seek to show in what manner these phenomena influence our perception of time. This is the method of procedure which I shall follow.

A most noteworthy distinction, applicable alike to the dance, to music, and to both prose and verse, is brought out by Dr. Richard Wallaschek in his excellent discussion of the difference between time and rhythm. It is this:-

Suppose beats from an electric hammer are made to follow each other in equal and regular succession. They will "always present the same monotonous rhythmical movement, but the observer's mind may assume different attitudes of observation, may change the time division by altering the length of the periods (bars), or uniting another number of beats into one group. The rhythm is in the object, while the time-division is only the form in which our mind perceives the rhythm, arranges, systematizes, unites the sensations of several beats into one whole period, into timeunity. It must be noted that this time-sense of the observer, his ability to arrange regular sensations into periods, to perceive them not as single beats, is an immediate (intuitive) perception, i.e., the observer does not arrive at this form of group perception through counting the number of beats which make up the group (bar or 
period), but he immediately perceives the group as such without the medium of counting. . . .

"One and the same rhythm may be perceived in different time, one and the same time may contain different rhythms. If we ourselves, not the electric hammer, are the performers of the movement, we should very soon alter the accentuation in accordance with the alteration of the time-division, but this would be only a probable and not a necessary coincidence; for in spite of an accentuation which is likely to suggest say triple-time, the observer may still follow double time in his thought, to such an extent can rhythm and time be kept distinct from each other. In one word: rhythm is the form of objective movement, time-sense (mesure, Takt) the form of the perceiving subjective mind. . . The time-sense is not a sensation proper as hearing, seeing, etc., but a mental work of grouping the sensations, and this takes place not in the senses themselves but in the cortex. . . .

"The intrinsic character of time . . . is not in its being beaten, but its being known, it is not the movement of the conductor's arm, but the form of his intellectual perception of music in which his muscular sense alone helps him nothing. I admit that in the music of primitive times, owing to its connection with bodily movements, it was the muscular impression as much as the auditory, that gave rise to the time-ordered perception. But I can never admit that the perception and the movement (time and rhythm) are identical." I

In the light of what I have already said, I shall not pause now to point out that there need not necessarily be movement or vasomotor discharges, but only motor impulses, or, it may be, only mental beats. Nor need I comment upon the degree of importance that should be assigned to the muscular sense, to the auditory impression, to the intellectual perception, or to anything else. Kinæsthesis of some sort is essential to the establishment of a rhythmic perception, but this perception once established, however,

1 Richard Wallaschek: "On the Difference of Time and Rhythm in Music," Mind, New Series, Vol. IV., No. 13, pp. 28-35. 
rhythm may be "consciously carried, in the absence of kinæsthesis of any sort, by auditory or visual processes." I For me the crux of the matter is found in Wallaschek's recognition of the fact that rhythm is the form of objective movement, time-sense (mesure, Talit) the form of the perceiving subjective mind. By way of illustration, suppose we think of time as a blank tape moving past us at a uniform rate of speed. In order to measure this tape we must apply to it the yard-stick furnished us by our unit of time. The line

may then be divided thus:

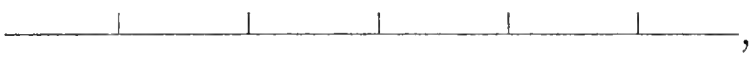

thus:

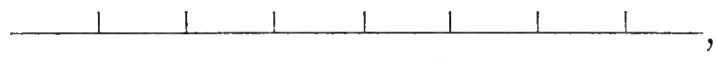

or in an innumerable number of ways. Suppose now that there begins to pass before us on the tape a succession of intervals such as this:-

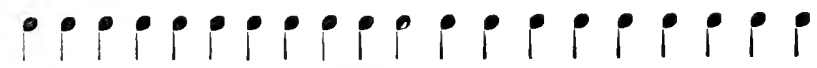

We may perceive at once that the intervals are both equal and periodic. Almost immediately, however, we tire of the succession; and it is only by grouping the intervals that we are able to follow them at all. ${ }^{2}$ Our unit of time may cause us to group them so:

(B)

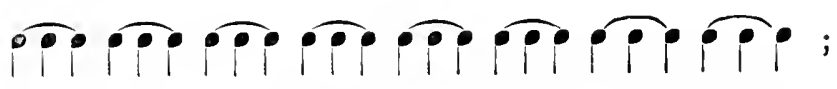

1 C. A. Ruckmich: "The Rôle of Kinæsthesis in the Perception of Rhythm, with a Bibliography of Rhythm," American Journal of Psychology, 1913, XXIV., p. 359.

${ }^{2}$ J. P. Hylan: "The Fluctuation of Attention," Psychological Monographs, Vol. II., No. 6, Review Publishing Company, Lancaster, Pa. 
or so:

(C)

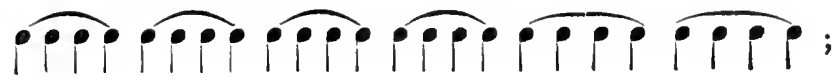

or in any other manner; but group them we must. (A) represents the periodically recurring phenomenon which the subjective self arranges as in (B) or (C). Art, however, never presents its material in any such form as (A). There is always given in the material itself something which forces us to measure it in a certain way. The material comes before consciousness grouped, unified; and, in perceiving the material, consciousness simultaneously perceives the grouping; or, to put it slightly differently, the material is perceived in groups. Thus it frequently happens that a given rhythm may be perceived against a background of $3 / 4$ or of $4 / 4$ time, or that different rhythms may be perceived against a common background. For instance, I may take the rhythmic pattern 2 ; and, conceiving it against a background of $3 / 4$ time, I may write it: $\frac{3}{4}$ ? ground of $4 / 4$ time, I may write it:

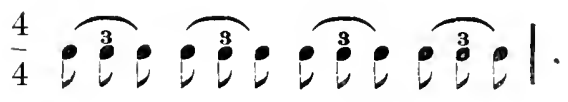

Richard Wagner is very partial to such a method of procedure as this. A notable example is to be found in the "Overture to Tannhauser," the first part of which is written in $3 / 4$ time, the second in $4 / 4$. In both parts the same rhythmic theme appears in such a way as to produce an identical effect. Different rhythmic patterns against the same time background ought to be too well known to 
need illustration; but the citing of an extreme case may make my point a little clearer. The following fragment ${ }^{1}$

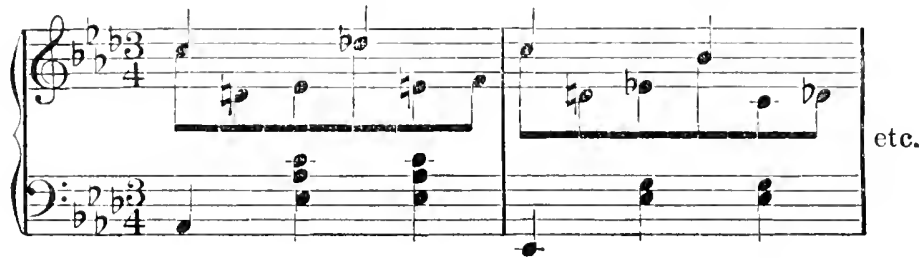

1 I have here in abstract seven temporal recurrences, - that is, seven periodicities. Three are of duration; three are of intensity; one is of pitch.

A. Those of duration are:

(1)
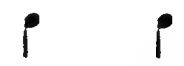

P

etc.

(2)

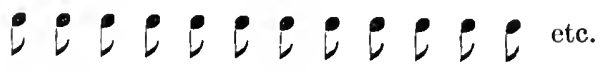

(3)

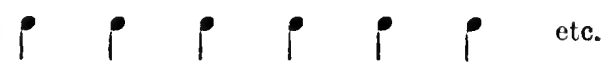

The tempo ${ }^{\mathrm{a}}$ of (1) is slower than that of (2) and (3), which are equal. One note of (1) has the same absolute time value as three notes of (2).

B. The periodicities of intensity are imposed upon those of duration. Theoretically the former have no length. They are simply periodic

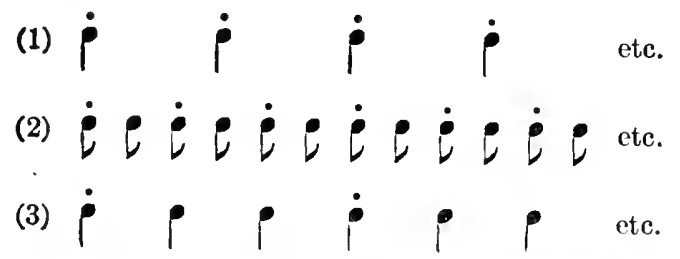

increases in the intensity of sounds which have length. Graphically they might be represented after this manner:-

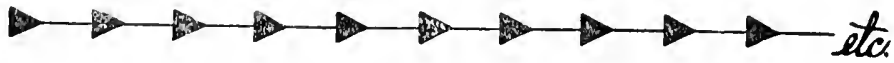


from F. Chopin's "Valse" (Opus 42) is written in 3/4 time. It is to be observed that the left hand keeps to a rhythm

The sound is struck with unusual intensity. It begins to die out almost immediately; but before its vibration ceases another sound has superseded it. A dot is written above each note that is to be stressed.

(a) Tempo means the actual time value of a note as expressed in fractions of a minute.

C. The lowest bass notes, as they occur at regular intervals, furnish a periodicity of pitch.

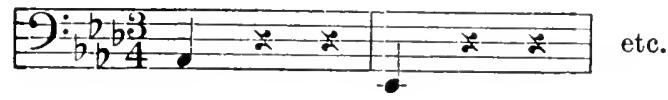

It can now be seen that three of these always coincide in the first beat of each measure. Their coincidence furnishes the ear with a composite sound of particular prominence that can be seized upon as the measure of the unit of time. The hearer is made the more keenly aware of time in being thus aided in his measurement of it. Any one of these periodicities, if occurring alone, would not be sufficient to force the ear to follow any particular method of grouping. Since it is impossible to sustain attention without grouping, the ear would have been forced to adopt a subjective grouping of its own, which might not have been at all the grouping which the hearer has in this instance been forced to adopt. This prominent, composite sound itself establishes a periodicity, the relative value of the units within which determines what the time shall be felt to be. If it is felt to be divided into three parts, it is for the hearer $3 / 4$ time, as given in the signature. If he listens only to the melody, he must feel it to be $2 / 4$. As in this particular case the accompaniment is the more prominent rhythmically, the time is felt in units subdivided into three parts; therefore, it is heard, as written, in $3 / 4$ time.

Perhaps it has already been objected that time in this sense of the word is not the same thing as time in the sense in which it was originally introduced, or that, at the least, the latter is a highly technical use of the term as applied only to music. But let us see.

Out of the vast continuum of time we are accustomed to settle upon some particular occurrence in nature and with this as a starting point to reckon events in relation to it. We might make the spring equinox the point of reckoning; or we might make it the first appearance of the new moon. But suppose for convenience we make it the moment when 
which makes this $3 / 4$ time very marked. The right hand, on the contrary, maintains a rhythm in $2 / 4$ time. This fusion of the two is made possible because both are really working against a background of $6 / 8$ time in which the

the sun reaches the meridian. Within the span of time from noon to noon we may then make any further artificial division which we care to. We can think of it as divided into day and night, - roughly speaking into halves; for we can think of it as divided into twenty-fourths, that is, into hours. Now let us reckon time from the first of January, in which case our unit of measurement is the year. We can divide the year into months and into weeks - both perfectly arbitrary divisions. (1) In speaking of months we are thinking of the year as divided into twelfths. We can group these months in units of three, in which ease we think of the seasons as fractions of time. We are dividing our larger time unit into twelf ths and then grouping these twelfths by threes. Each season is represented by the fraction $3 /$ months, or $3 / 12$. Any event taking place in one of the seasons is occupying some part of this $3 / 12$ division of time. (2) When speaking of weeks, we are thinking of the year as divided into fifty-sixths. We can group these weeks in units of two, four, seven, or eight, as we please. If we group them by sevens, we think of the divisions of the year in terms of the fraction $7 /$ weeks, or $7 / 56$; if by eighths, in terms of the fraction $8 /$ weeks, or $8 / 56$.

Now earry this same method of thought into the realm of art. Out of the continuum of time we select as the unit the time-length required to produce a given emposition. Then we decide to make the crotchet $(\boldsymbol{P})$, or quarter note as it is now called, the unit for subdivision. We further select to group these erotchets in threes. To indicate to the person who is to interpret the composition the grouping which we wish him to follow, we write at the beginning of our composition $3 /$ crotchets, or, what is the same thing, $3 / 4$. Into each division, therefore, he will put three crotchets or the equivalent thereof. The time unit will be three crotchets, which, relative to the whole composition, represents a definite period of time. Within this unit, as it is repeated in passing, an almost indefinite number of rhythms (related time events) may be presented to consciousness. The one requirement is that each rhythm be capable of being fitted into this matrix of time without thereby having its own peculiar pattern destroyed, or without interrupting the flow of the other rhythmic patterns. 
melody is accenting the first and the third beats, while the accompaniment is accenting the first, the third, and the fifth. This sort of thing is entirely too complicated ever to find use in verse. There only one voice is sounding, and that, too, without accompaniment, so that unless the rhythm is very plainly marked it cannot be followed. Yet, for prose nor verse nor music would any degree of art be possible if numerous rhythmic patterns could not be presented against a uniform background of time. All that is required is for these rhythmic patterns to be capable of being brought into relationship with one another through the common medium of a uniform time-division. When these rhythmic patterns are presented to consciousness, they appear inseparably woven together in a continuous flow of measured time. In fact, in them lie the data furnishing the content of time. To separate them from each other or from consciousness is to be guilty of an abstraction, excusable only because it is impossible to grasp their interrelation without first bringing each factor of the continuum individually before the attention. So long as this essential indivisibility is kept in view, it does not matter whether we think of rhythm as embedded in measured time or as imposing itself as a measure upon time. Rhythm is made perceptible through the instrumentality of measured time; time is made perceptible through the content furnished by rhythm.

Let me repeat once more the definition of rhythm with which I began my discussion of the rhythms of tone. Rhythm is constituted by the return at sensibly equal time-intervals of the phenomenon which renders the division of time perceptible to the hearing or to the muscular sense. Clearly this is not a very good description of the beast we have just left in the wood. Yet what need is there to point out the particulars in which this verbal photograph is not what might 
be called a striking likeness? It was brought forward for inspection principally in order that, by keeping it before us as our own ideas of rhythm expanded, we might gradually outgrow its conception and be able to lay it, and many more like it, aside as inadequate accounts without having to examine them in detail either to refute or to amend them. Letting what I have already said furnish a basis for further argument, I shall now begin to build up definitions which I hope will not prove altogether unsatisfactory statements of the nature of the phenomena which make possible the arts of prose, verse, and music. 


\section{CHAPTER IX}

\section{RHYTHM DEFINED}

IN Chapter VII I spoke of something resembling rhythm as being of common occurrence throughout nature; and I gave planetary motions, chemical reactions, and biological functioning as typical examples. In doing this I was perfectly aware of employing with exceeding looseness as a means of expressing general considerations terms the application of which I now wish to limit very materially in attempting to present my thought in more detail and with greater accuracy. I must retrace my steps, therefore, and, as I again go over the same ground, confine myself to the exact and the particular.

Such a succession of dots as the following

may be looked upon as the recurrence of the same phenomenon (.) at unequal intervals of space. They do not form a series, nor are they related in any way. Now bring these dots together so that each dot is exactly the same distance from the two adjacent dots; thus, -

Again there is recurrence of the same phenomenon; but this time each dot bears the same spacial relation to the dot preceding and the dot following. The dots are ar- 
ranged at equal intervals of space. Therefore, they are periodic in occurrence. Suppose this second line of dots, instead of representing measurements of space, be made to represent such regular occurrences in time as the crossing of the equator by the sun or as the crossing of the meridian by a fixed star. The former phenomenon would have a period of six months, the latter of twenty-four hours; yet the moment of transit for each would be just like every other moment of transit. There would be unbroken periodicity caused by the recurrence of the same phenomenon. To grasp such a series immediately would be a physical impossibility, first of all because of the length of the timeintervals involved; second, because the succession itself presents to the mind no tangible means of grouping.

Consideration of the matter of breathing or of the beating of the heart leads to much the same result, though in each of these instances two phenomena, instead of one, are concerned. Representing the expansion by - and the contraction by - , the succession is as follows:-

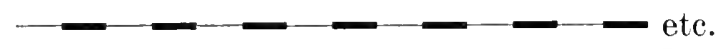

Here again there is periodicity. This time the intervals are quite within the limits of immediate experience; but, because there is given in them no phenomenon that would cause them to be grouped, they pass unnoticed by consciousness. Ordinarily they present, just as the ticking of the clock presents, periodicity and nothing more. If the attention is directed to them, they can be counted; but the process is fatiguing. In consequence, consciousness thrusts them from the center of attention. When forced to regard them, it does its best to relieve the monotony by introducing into every other beat an increase of intensity which the beat itself does not possess. In fact, this subjective differentiation is something more than a mere desire 
to escape monotony. Perhaps its explanation is to be found in the periodic character of attention itself. ${ }^{1}$

If I take any two sounds of fixed intensity and tonecolor and of the lengths $n(-)$ and $m(-)$ such that they shall fall within the span of attention, I can arrange them in any number of successions; for instance,

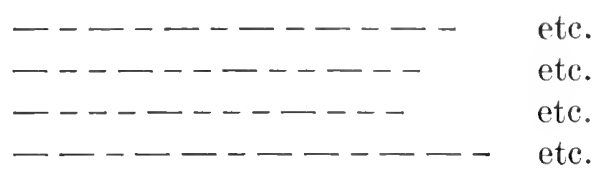

As long as there is in these sounds themselves nothing to catch the attention and thus force it to group them, they are merely periodic occurrences. As soon, however, as one sound presents itself in such a manner as to force a grouping, so that it is a case of longer sounds marked off by shorter, or of shorter marked off by a longer, a fixed pattern is set up and rhythm is established. If there be in the series itself nothing upon which the attention can fix as a means of grouping, subjectively it will supply a beat which it uses to this end. This subjective grouping will be determined by the rate at which the components of the series appear, each liearer fixing upon a group length corresponding as nearly as possible to his individual unit of time or to some multiple thereof.

Notice that in the diagram just given two phenomena are concerned, the length $n$ and the length $m$. Exactly the same would be true if either $n$ or $m$ were silences. For, of course, in this sense silence is just as much a phenomenon as is sound, since it, too, represents an occurrence. Every time

1 Ladd: "Psychology: Descriptive and Explanatory," $71 \mathrm{ff}$.

J. P. Hylan: "The Fluctuation of Attention," Psychological Reviewo publication, Psychological Monographs, Vol. 2, No. 5 (Lancaster, Pa.). 
two phenomena form a series, they do not necessarily establish a rhythm; but, in order that there may be rhythm at all, there must be at least two phenomena. The number of phenomena that may enter into a composite rhythm is quite indefinite. At this moment I can think of at least half a dozen; but as many more might readily be added, I imagine. What is necessary is that the material be presented to consciousness in such a way as to be recognizable as forming a pattern. Of course, the perception of the pattern depends upon the active or the passive attitude of the subject and upon important variations peculiar to individual subjects. For instance, when the succession falls below a certain rate, the elements appear to be isolated, and no impression of rhythm arises; when the succession is above a certain rate, the impression of rhythm is either destroyed altogether or transformed from the original pattern by the substitution of either a different grouping or of a composite grouping. ${ }^{1}$ Suppose I make three strokes with a hammer in equal succession and at such a fixed rate as to be favorable for grouping, - thus, ... Regarding the hammer stroke as a phenomenon and silence as another phenomenon, I have here a rhythmic pattern, because the three strokes are recognizable as grouped. Now, just as long as I impose them upon silence in such a way that they continue to appear as grouped, I have rhythm. As these three strokes stand in isolation, their rhythm is only rudimentary; but it is rhythm, nevertheless; and from exactly such rhythmic groups as this the great works of tonal art are built up. Not a page of Beethoven can be turned without one's finding there as many illustrations as heart could desire, though the opening theme of the "Eroica" is in its simplicity the most striking example.

1 Macdougall: "The Structure of Simple Rhythm Forms," p. 321 and following. Psychological Review, Series of Monograph Supplements, Vol. IV. (Whole No. 17), Jan., 1903. 
Of course, a single rhythmic pattern can be repeated indefinitely, as any one familiar with the music of the less advanced savage tribes can testify; but for more advanced art numerous rhythmic patterns are readily discoverable in every composition. Usually a pattern is repeated; but repetition is not invariably necessary - Macdougall and others to the contrary ${ }^{1}$ - in order for a succession to establish itself in consciousness as a rhythm, though nearly always it is only upon repetition that it is recognized as forming a distinct pattern and that the impression of movement is set up. Notice, too, that I have said nothing about the relation to each other of the several units of length within the rhythmic group. Theoretically the time lengths of the sounds and the silences in music maintain a simple ratio to one another; but it is quite possible to have a rhythm in such a succession as the following, in which the first and the last units are each five times longer than the middle unit:

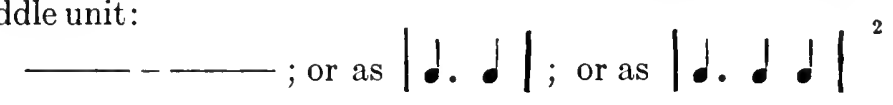

As soon as I begin to repeat any one of these patterns, even where the intermediate pauses are not equal, it is still recognized as a pattern and as a rhythm, although, if I make my pause too short, the pattern is likely to be broken down. ${ }^{3}$ If not the pause, then something else must occur to make the grouping evident. It should be clear, therefore, that it is perfectly possible to have rhythm without having among the time-lengths of the group any such ratio as is conventionally assumed in musical notation, where the time-lengths of the

1 Macdougall: "Structure of Simple Rhythm Forms," p. 318.

2 Ibid., p. 367 and following.

Wallin: "Researches on the Rhythm of Speech," p. 33.

${ }^{3}$ Macdougall: Ibid., p. 321, c. 
notes are to each other as in the series $2: 4: 8: 16: 32: 64{ }^{1}$ To illustrate again, I can arrange a pattern in which the first unit has a length of three, the second of two, and the last of seven. This pattern I can repeat indefinitely.

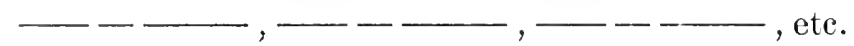

However, before I can build out of any such rhythmic pattern or patterns an artistic whole, it is essential that they be capable of being fitted into some general scheme which is felt to maintain throughout the composition. It is here that the time element becomes a prime factor in establishing the feeling of artistic unity or completeness. There must always be some phenomenon, no matter what, to recur with sufficient frequency and regularity to set up a measured interval of time into which the given rhythm or rhythms can be fitted, and by means of which they can be felt as related to one another. This phenomenon, or what is accepted as this phenomenon, does not itself establish a rhythm, but appears only as a periodic recurrence, the point of division marking the boundaries of the time-unit adopted as the standard of measurement from a given composition. It is here that Guest, Verrier, and many others have allowed themselves to be misled. They have mistaken stress, accent, or whatever it may be called, for rhythm, when accent is only one of several phenomena which may mark the recurrence of the time-intervals, though it is, indeed, the most usual method of marking them. The sign of division, whatever it may be, is essential to both verse and music; but the time-division itself is of equal importance, as, too, are the rhythmic units. The content of these rhythmic units is, I believe, the most prominent feature of prose, verse, and music. It is this which is immediately perceived,

1 Wallin: "Researches on the Rhythm of Speech," Studies from the Yale Psychological Laboratory, Vol. IX., 1901, p. 33. 
and through which both the length of the time-unit and the phenomenon which marks that length are made apparent. Theoretically neither the time-unit nor the recurrence of the sign which marks its boundaries ought to vary; but, as a general thing, the content of the time-interval - that is, the rhythm - is changing constantly, and upon its skillful variation rests much of the beauty of prose, verse, and music. Rhythm, then, I define as constituted by the consecutive occurrence of phenomena which are perceived as forming a succession of distinct, related patterns in time. From the point of view of the psychologist the phenomena are sound (in which each of its four characteristics is regarded as separate phenomenon) and silence; from that of the psychologist they are peculiarly felt motor reactions. Rhythm may or may not be periodic in character; periodicity of recurrence may under certain conditions present a rhythm; and even the same series may be heard as different rhythms; ${ }^{1}$ but, to be of value in music or in verse, rhythm must be felt in relation to some comparatively fixed unit of time, which unit the rhythm itself assists in determining.

"Perhaps the only undisputed characteristic of rhythm is the impression of regularity which it occasions. Some hold that this impression arises from the regular recurrence, in time, of certain features of the rhythmic series; others claim that the regularity resides in the structure of the elements composing the series; but in either case some regularity is admitted. A rhythm lacking regularity in its structure and failing in the regular repetition of its elements would be no rhythm." 2

Let us now examine the several types of phenomena which enter into the formation of temporal rhythm, with a view to

1 R. S. Woodworth: Journal of Philosophy, Psychology and Scientific Methods, IV., 17 (1907).

2 Warner Brown: Psychological Review, Vol. XVIII., No. 5, Sept., 1911, p. 336. 
102 THE FOUNDATIONS AND NATURE OF VERSE

determining therefrom, first, to what extent any one feature of the rhythmic series may be looked upon as of regular recurrence, and, second, to what extent the structure of the elements composing the series may be lacking in regularity and still be considered as constituting a rhythm. 


\section{CHAPTER X}

\section{DURATION}

Have you ever gone into a room in which nothing could be heard except the unvarying hum of machinery? Have you ever been out on the ice at night miles and miles away from anything which could cause the slightest sound, when even the wind was asleep? If you have, then, perhaps, you are prepared to imagine what an eternity of either sound or silence would be like. Sound implies such a stimulation of the nerves of the ear as can produce a reaction in the mind of the hearer; silence, the absence of such stimulation. Stimulation that is perfectly continuous and uniform soon ceases to attract attention to itself. It passes unnoticed. Sound compels attention only when some one of its characteristics, or perhaps even more of them, are varying, or when there is alternation of sound and silence. If the tone-color, the pitch, and the intensity of a sound are kept constant, it can be measured only by breaking, no matter how briefly, the continuum of sound. The duration of the sound becomes limited by silence; the duration of silence is limited by sound. Each breaks the other. ${ }^{1}$ It is incomparably more convenient, however, to measure with reference to sound than to silence. Psychologists, therefore, always adopt some convenient time-length as the standard of measurement when they are presenting mechanically produced sounds for the introspection of those upon whom they are experimenting.

1 Squire (American Journal of Psychology, 549, XII., 501, 1901) and Macdougall (Psychological Review, IX., 461, 1902) appear to agree with. me as to the possibility of rhythm when only length of sound is involved. 


\section{THE FOUNDATIONS AND NATURE OF VERSE}

Of course, this sound-length may be changed as frequently as is convenient during an experiment; but each judgment as to the length of a sound or of a silence must be in reference to some standard of sound-length. Even in the laboratory, under the favorable conditions for judgment made possible by the control of both objective and subjective factors and when attention is centered upon just one property of sounds already simplified to the last degree, it is quite astonishing what an amount of inaccuracy still persists in our judgments of comparative time-lengths. We both overestimate and underestimate. $^{1}$ Likewise we accept as equal time intervals which are unequal (sometimes by almost as much as fifty per cent), particularly where it is a case of comparing length of sound with length of silence. ${ }^{2}$ Even when the number of sounds to be compared is limited to successions of two or three in a group, not only their relative lengths, the order of their arrangement, the silences which separate them, and the frequency with which the silences occur, but also the rate of speed at which they are presented to the observer make a very marked difference in the perception of them, while to intensify one of the sounds produces in the hearer a still greater illusion as to both the duration of the sound itself and the duration of the sounds and silences adjacent to it. ${ }^{3}$

1 Hall and Jastrow: "Studies in Rhythm," Mind, XI., No. 41, Jan., 1886, pp. 61-62.

V. Benussi: "Psyehologie d. Zeitauffassung," p. 419 (Heidelberg, 1913).

2 Ibid., p. 486.

Hall and Jastrow: Ibid.

Wallin: "Researehes on the Rhythm of Speech," p. 133.

3 Bolton: American Journal of Psychology, VI., 222 (1891).

Ettlinger: Zeitschrift für P'sychologie, XXII., 132-133 (1900).

Kafka: "Über das Ansteigen der Tonerregung," Psycho. Studien, II., 256-292 (1907).

Meumann: Philosophische Studien, IX., and X.

Miner: Monograph Supplements to Psychological Review, Vol. V., 
If this takes place when duration, and duration alone, is involved and when attention is doing its best to make accurate judgments, the amount of aberration attendant upon judgment when not only variety of pitch, of tone-color, and of intensity, but also intellectual content are present to complicate matters must be seen at once to be extreme.

Now, reversing the situation, let the former subject become the producer of sounds the duration of which he feels to be either equal to each other or to the duration of certain silences, or which he feels to bear fixed ratios to each other or to the duration of certain silences. Even when he calls to his aid marching, beating time, or any other mode of measurement not external to himself, he is still no more able to produce them accurately than he was to perceive them accurately when they were objectively produced. ${ }^{1}$

No. 4 (1903). Lights were used instead of sounds. For us, therefore, the results are more suggestive than conclusive.

Macdougall: "The Structure of Simple Rhythm Forms."

Schumann: Zeitschrift für Psychologie, XVIII., 30-36 (1898).

Wallin: "Experimental Studies of Rhythm and Time," Psychological Review, March, 1911, XVIII., No. 2, and May, 1911, Vol. XVIII., No. 3.

Woodrow: "A Quantitative Study of Rhythm," pp. 30-52, Columbia University Contributions to Philosophy and Psychology, XVIII., No. 1, June, 1909 (Science Press, New York).

1 Warner Brown: "Time in English Verse Rhythm," p. 7 (c).

Johnson: "Researches in Practice and Habit."

Martius: Philoso. Studien, 1891, VI., 196.

Meumann: Philoso. Studien, 1894, X., 302.

T. V. Moore: "A Study in Reaction Time and Movement," Psychological Review publication, Psychological Monographs, Vol. VI., No. 24 (Lancaster, Pa.).

Scripture: "The New Psychology," p. 125.

Smith: Philoso. Studien, 1900, XVI., 282.

Wallin: "Researches on the Rhythm of Speech," p. 27.

R. S. Woodworth: "The Accuracy of Voluntary Movement," Psychological Review publication, Psychological Monographs, Vol. III., No. III. (Lancaster, Pa.). 
When he adds variety of pitch and tone-color, as well as thought content, to his sounds, the possibility of his securing even an approximation to mathematical precision as regards time-length is not very great. However badly he may be decciving himself in respect to his performance, the fact remains that he is satisfied with it, that he believes himself to have judged accurately, and that others, hearing the sounds, believe him to be producing them accurately - all of which goes to show what a decidedly faulty piece of mechanism the human chronometer really is. Even when it is properly oiled, when it is on the level, and when conditions of temperature and humidity are just what they ought to be, it can not be got to run on time, it will not tick with the metronome. Indeed, it abhors absolute regularity, and will judge of the passage of time only in reference to the intensity of its own experiences. Nevertheless, it is equally opposed to running without some show of accuracy, and is constantly priding itself upon being just to the second. It wills to be exact. It demands exactness of itself. Yet it is so put together that it can not be exact, and that it is quite complacent about its own performance so long as appearances are maintained.

Every sound must possess some length. Imaginary points and imaginary lines with no dimension except length may be conceivable; but sound without length is not even conceivable. Various sounds are capable of continuation for varying lengths of time. That a sound should be available for artistic purposes, the length of time during which it may be made to continue must be under control. In music, for instance, the sounds produced by any instrument are of perfectly indefinite duration except as they are incited and checked by the performer. The mobility of sound makes possible its employment as a source of æsthetic enjoyment. The sounds from some instruments are more easily controlled than the sounds from others; and the artistic value of any 
instrument is in a large measure determined by the degree of flexibility with which it yields itself to the will of the performer. A skillful artist, however, as the result of practice or otherwise, can get from his instrument an amount of response simply impossible to the man unfamiliar with its mechanism. Every one is so habituated to the use of the voice that speech sounds are under his control to a marvelous degree. Normally by the time a child has reached the age of eight or ten, one sound is as easy of production for him as another; and he produces with equal fluency all the sounds of his language. Indeed, he does not have to give the slightest thought to their production.

As the sound-lengths involved in music are so closely analogous in every particular to the sound-lengths of the vowels, and as these have been investigated, whereas the sound lengths of the other tones have not received very careful consideration, before passing to the discussion of the former, I shall present what is known about the latter. ${ }^{1}$

Although it would seem that Sweet $^{2}$ is right in asserting the only division actually made in language to be that into breath groups governed by the pause and the expiration interval, the experiments performed by J. E. Wallace Wallin ${ }^{3}$ must occasion us a readjustment of opinion. The testimony of the ear is not to be relied upon where the findings of science are to the contrary. Wallin's records were made with a

1 I regret that I have been unable to see Meyer's records in "Skrifter Kongl. Humanistiska Vetenskaps-Samfundet Upsala," VIII., 1903. He has measured the English vowel sounds and some of the consonants, his records including vowels, stressed and unstressed, in initial, medial, and terminal positions for words of different lengths. Dr. Warner Brown says ("Time in English Verse Rhythm," p. 24) that the records are clear and apparently accurate to at least one-hundredth of a second.

2 Sweet: "Primer of Phonetics," p. 42.

8 "Researches on the Rhythm of Speech," pp. 23-32. Studies from Yale Psychological Laboratory, Vol. IX., 1901. 


\section{THE FOUNDATIONS AND NATURE OF VERSE}

Lioret phonograph and were later reproduced upon an Edison. His measurements, taken from the readings of men of professed literary tastes, were made with painstaking exactness.

"The speed of the phonograph was reduced until a group of rapidly recurrent sounds, which had previously appeared as a homogeneity, was split up into discrete elements of sound separated by gaps. .. The degree of reduction was determined, not by the threshold of audibility, but by the threshold of articulability, which is higher than the former. . . Physically, the sounds represent vibrations of given lengths, amplitudes and periods. The gaps or silences probably correspond in some cases to very weak vibrations (glides). Not infrequently, however, they are physically interpretable as absence of vibrations. . . Physiologically, the sounds and silences are interpretable as changes in the condition of the vocal organs."

The following is a typical example, selected because of the frequent repetition of the same vowel. The dots over the words represent stresses in which loudness is slightly more important than duration and pitch. "The silences are indicated by dashes (-). The numeral below the dash indicates the duration of the silence in units of contacts; numerals above the syllables indicate the duration of the syllable to which they pertain." The recording speed was one hundred revolutions per minute; and the unit of measurement, one contact every $\frac{1}{40}$ of a second.

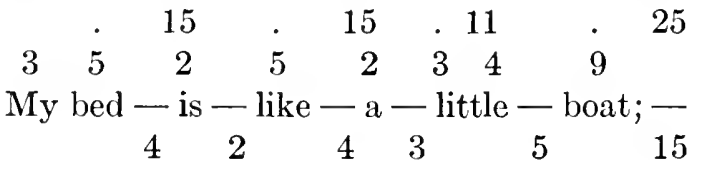

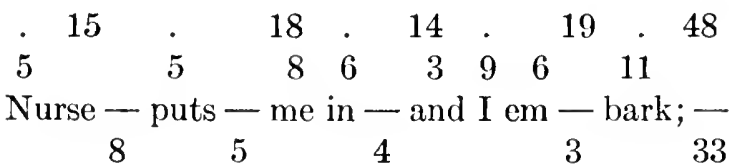




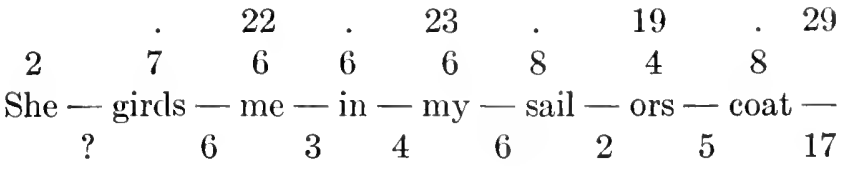

$$
\text { And - starts - me - in }- \text { the - dark. }
$$

(Robert L. Stevenson.)

Let me present in tabulated form the time-lengths of a number of syllables containing the same vowels.

\begin{tabular}{|c|c|c|c|c|c|c|c|}
\hline 3 & 6 & 5 & 9 & & & 8 & 9 \\
\hline $\mathrm{m} y$ & $\mathrm{~m} y$ & like & $I$ & & $o$ & coat & boat \\
\hline 2 & 3 & 6 & 6 & & & 2 & 8 \\
\hline$i \mathrm{~s}$ & $\mathrm{lit}$ & in & in & & $a$ & $a$ & sail \\
\hline 8 & 6 & 21 & 14 & 2 & & 5 & 7 \\
\hline $\mathrm{m} e$ & $\mathrm{~m} e$ & $\mathrm{me}$ & the & she & $u$ & nurse & girds \\
\hline 5 & 6 & & & & & & \\
\hline
\end{tabular}

From experiments such as this Wallin concludes:

(1) "The absolute duration of any syllable is variable.

(2) "The average emphatic syllable is invariably longer than the average unemphatic," the average long syllable being one and three-fourths times as long as the average short syllable.

(3) "The ratio sustained between the average unemphatic and emphatic syllable varies with the different subjects;" and for English all the emphatic syllables are at least half as long again as the average unemphatic.

(4) "The ratios exsisting between individual emphatic or unemphatic syllables of the same or of different records, are neither invariable, nor are they the rates of simple proportion. . . . Not 


\section{THE FOUNDATIONS AND NATURE OF VERSE}

infrequently the rate is reversed, so that the sporadic unemphatic syllables may be longer than the average of the emphatic syllables. ... These facts incontestably refute the theory of 'simple proportion.'

(5) "The long and short syllables are about equal in regularity," the average long syllable being one and six-tenths more irregular than the short.

(6) "The ratio between the number of emphatic and unemphatic syllables" is as $1.2: 1$, which is smaller than the total duration of the same.

\section{Wallin continues: ${ }^{1}$}

"The most general deduction to be made from this series of measurements is the disparity in the time-span of so-called long syllables. It has been shown that the temporal distinction is true to fact.

"All speech is quantitative; and the distinction, popularly and confidently posited, between quantitative and non-quantitative verse is grounded upon fallacious assumptions. The question of the quantitative character of poetry or prose, is closed. The only crux of contention that remains affects the character of the laws governing the temporal relation of the components of language. The question contains several phases.

"The first determination has settled the fact that speech as a phenomenal occurrence is conditioned on the time-intuition of sensibility.

"The second question has already been settled, namely, that the strong syllable is temporally longer than the weak.

"The third question is partly closed. It has been shown that for English, Swedish, and Persian the ratio between the individual long and weak syllables is never constant. The general character of the ratio was for artistically free declamation of English poetry, in the proportion of 1:1.7; . . 1:1.5 for English prose."

To this Warner Brown replies: "Of course, no one in his senses ever doubted that speech is quantitative, but there 1 "Researches on the Rhythm of Speech," pp. 32-33. 
has been grave doubt whether quantity in speech gives rise to the rhythm of verse." 1

Unfortunately, not a few men of undeniable sanity not only have doubted that English speech is quantitative, but do doubt so at present, and will continue in this state of mind even in spite of Dr. Brown's own most valuable contribution to our knowledge of the subject.

"So far as Wallin's results show anything at all on this point," Dr. Brown goes on to say, "they indicate that quantity is not responsible for the phenomena of rhythm."

Brown followed the method developed by Marey, ${ }^{2}$ Rousselot, ${ }^{3}$ and Meyer. ${ }^{4}$ Movements of the lips, tongue, palate, and larynx were recorded by direct levers writing on a revolving drum or by electric keys connected with levers. $\mathrm{He}$ measured from the beginning of words and syllables, counting as a prolongation of the previous sound any gap which occurred between the two sounds. He made no attempt to separate the last syllable and the pause proper; and the final syllable does not enter into his calculations. For nonsense verse there appears to be a fair degree of equality of duration in the length of the feet; but even in the most simple and regular cases of actual verse the irregularity in the length of the syllables is beyond question (Brown, Tables V-XII), though there is a decided tendency toward approximate sameness in the duration of the feet.

The following (Brown, Table XII) is of unusual irregularity. It represents averages of ten readings by the same subject. The time-length of each syllable is written below it, and below that the mean variation per cent. The accents are my own and are not a part of the original table.

1 "Time in English Verse Rhythm," p. 35.

2 Marey: "La méthode graphique," p. 309.

3 Rousselot: La Parole, N. S., I., 1, 401, 769 (1899).

- Meyer: Die neueren Sprachen, VI., 123 (1899). 
112 THE FOUNDATIONS AND NATURE OF VERSE

\begin{tabular}{|c|c|c|c|c|c|c|c|c|}
\hline & • & & & & & & 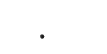 & Verse \\
\hline $\mathrm{Al}$ & most & $\mathrm{u}$ & pon & the & wes & tern & wave & \\
\hline 2 & 34 & 11 & 26 & 11 & 28 & 15 & 48 & 195 \\
\hline 9 & 8.8 & 13 & 18 & 19 & 20 & 7 & 9.6 & \\
\hline
\end{tabular}

Res ted the broad bright sun

$\begin{array}{llllll}28 & 20 & 13 & 37 & 20 & 89\end{array}$

$\begin{array}{lllllll}22 & 19 & 15 & 9.5 & 19 & 6.5 & 207\end{array}$

When that strange shape drove sud den ly

$\begin{array}{lllllllll}21 & 16 & 45 & 46 & 28 & 28 & 11 & 36 & 194\end{array}$

$\begin{array}{llllllll}9 & 17 & 12 & 12 & 8.6 & 8 & 13 & 21\end{array}$

\begin{tabular}{cccccccc} 
& & & & & \multicolumn{5}{c}{ Pause } \\
17 & 28 & 27 & 27 & 12 & 40 & 99 & 250 \\
8.4 & 8.4 & 9.6 & 14 & 16 & 6.7 &
\end{tabular}

I add for convenience in comparison the time-lengths of a number of the syllables in which the same vowel occurs.

$\begin{array}{rrrlll} & 11 & 89 & 28 & 27 & 40 \\ u & u & \mathrm{~s} u n & \mathrm{~s} u \mathrm{~d} & u \mathrm{~s} & \mathrm{~s} u \mathrm{n}\end{array}$

$\begin{array}{llc} & 34 & 28 \\ \text { o } & \text { mo } & \text { drove }\end{array}$

26

o pon

$\begin{array}{llll}11 & 12 & 13 & 17 \\ e & \text { the } & \text { the } & \text { the be }\end{array}$

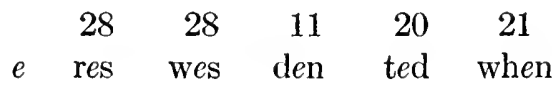


DURATION

\begin{tabular}{|c|c|c|}
\hline & 48 & 45 \\
\hline$a$ & wave & strange \\
\hline$a$ & $\begin{array}{l}22 \\
a \mathrm{l}\end{array}$ & $\begin{array}{c}37 \\
\text { broad }\end{array}$ \\
\hline$a$ & $\begin{array}{l}16 \\
\text { that }\end{array}$ & $\begin{array}{l}27 \\
a \text { nd }\end{array}$ \\
\hline
\end{tabular}

Still more conclusive evidence is presented by this record of "The Bells," in obtaining the figures for which, says Brown, ten readings by the same person were averaged. Because I wish to show from this the variability to which the same syllable is subject, I produce here only those lines containing the words time and bells. (See Table XXXIV, p. 68.)

$\begin{array}{lll}78 & 79 & 110\end{array}$

Keeping time, time, time

98

To the pæan of the bells -

125

Of the bells:

$\begin{array}{lll}78 & 78 & 109\end{array}$

Keeping time, time, time,

103

To the throbbing of the bells

$\begin{array}{llll}77 & 79 & 75 & 113\end{array}$

Of the bells, bells, bells, bells.

$\begin{array}{lll}79 & 74 & 112\end{array}$

Bells, bells, bells. 


\section{THE FOUNDATIONS AND NATURE OF VERSE}

R. H. Stetson ${ }^{1}$ gives the following measurements from the one original graphophone record which he produces in criticism of Lanier's musical interpretation of verse.

$$
\begin{aligned}
& \text { I saw a ship a sail ing } \\
& \begin{array}{lllllllll}
50 & 16 & 20 & 13 & 9 & 16 & 32 & 23 & 132
\end{array} \\
& \begin{array}{cccccccc}
\text { A } & & \text { sailing } & \text { on } & \text { the } & & \text { sea } & \\
10 & 16 & 45 & 22 & 8 & 15 & 49 & 68
\end{array}
\end{aligned}
$$

And it was full of pretty things

$\begin{array}{llllllllllllll}8 & 6 & 20 & 6 & 6 & 27 & 37 & 12 & 8 & 7 & 20 & 12 & 41 & 34\end{array}$

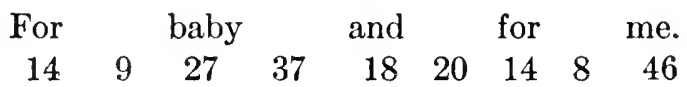

Totals of the feet:

$$
\begin{aligned}
& -/ 66 / 60 / 187 \\
& 26 / 45 / 45 / 187 \\
& 14 / 59 / 49 / 47 / 75 \\
& 23 / 64 / 60 / 46 \text { - } \\
& \begin{array}{ccccc} 
& 9 & 10 & 32 & 27 \\
a & a & a & \text { sail } & \text { baby }
\end{array} \\
& \begin{array}{lll}
8 & 49 & 46
\end{array} \\
& e \text { the sea me } \\
& \begin{array}{cccc} 
& 20 & 20 & 41 \\
i & \text { ship } & \text { it } & \text { things }
\end{array} \\
& \begin{array}{ll}
8 & 18
\end{array} \\
& a \text { and and } \\
& \begin{array}{rr}
14 & 14 \\
0 \quad \text { for } & \text { for }
\end{array}
\end{aligned}
$$

1 "Rhythm and Rhyme," p. 463, Psych. Review, Harvard Psy. Studies, 1903. 
Although I entertain very serious doubts as to the validity of the results obtained through experiments in which the measuring of time-intervals is by beats of the finger accompanying the reading of verse, I can offer with due reserve the findings of Brücke ${ }^{1}$ and of Hurst and McKay. ${ }^{2}$ Miyake $^{3}$ has proved that in experiments of this type there are decided discrepancies between the moment of occurrence of the beat of the finger and the accent given by the voice. The accuracy of the results obtained by Hurst and McKay are further prejudiced because the subjects were taught to read and to beat as regularly as possible without neglect of the rhythm. Even after that all large variations were deliberately discarded. But one example is given in illustration of their experiments, though the authors report that a large number were made. The figures represent relative percentages expressed in hundredths of a second.

come from deep glen and from mountain so rock $y$ $\begin{array}{lllllllllll}34 & 18 & 17 & 33.5 & 17 & 16 & 32 & 18 & 17.5 & 27.5 & 28.5\end{array}$

Brücke's work was done at a much earlier date (1871) when apparatus with which accurate results could be obtained was impossible of construction; yet both agree in declaring that there is no fixed proportion between the time-lengths of the syllables, although the emphatic syllables are longer than the unemphatic. The longer sound naturally appears the louder, Dr. Herbert Woodrow states, after numerous experiments upon thirteen subjects. ${ }^{4}$

1 Brücke: "Physiologische Grundlagen der neuhochdeutschen Verskunst," Wien, 1871.

2 Hurst and McKay: "Experiments on the Time Relations of Poetical Meters," Univ. of Toronto Studies, 1899.

"Miyake: "Studies from the Yale Psychological Laboratory," X., 1902 .

4 Herbert Woodrow: "A Quantitative Study of Rhythm," p. 41, Columbia Univ. Contributions, 1909. 


\section{THE FOUNDATIONS AND NATURE OF VERSE}

If the investigations of Král and Mares ${ }^{1}$ had not been confined to the Bohemian language, they would be of the greatest assistance just here; still I do not feel justified in citing their conclusions, although I believe them to hold good for the English language.

Judging, then, from Brücke and from Hurst and McKay, but especially from the measurements of both Wallin and Brown, - the latter using different methods of investigation and certainly to some extent opposing each other, - to my mind several facts are definitely established:- (1) No vowel sound or any syllable possesses a definite, fixed length. The so-called short vowels require just as much time for their pronunciation as is required by the so-called long vowels. (2) The consonants accompanying a vowel do not have any appreciable effect upon the actual duration of the vowel, though they may sometimes affect the duration of the syllable. $^{2}$ The strong syllable is temporally longer than the weak. To this statement may be added the testimony of Verrier $^{3}$ and of Herbert Woodrow, the latter to the effect that all his subjects frequently remarked upon the greater apparent duration of the louder sounds over the weaker 4 (although in this instance the time-lengths of all sounds were kept equal), so that it seems correct to say not only that the strong syllable usually is longer than the weak, but also that, even when it is equal to the weak, the strong still makes the

"Král and Mares: "Traváni hlásek a slabik dle objectivné miry," Listy Filologiké, 1893, XX., 257.

2 The addition of consonants may shorten or lengthen a syllable, according to Král and Mares, but never proportionately or regularly (Listy Filologické, 1893, IV., 17). I have been unable to see their account of these experiments. Paul Verrier's tabulation of sound lengths (Vol. I., par. 3, p. 65) seems to add weight to their conclusion.

3 Paul Verrier: "Essai sur les prineipes de la métrique anglaise," tom 3 , p. 68, especially (1).

4 Herbert Woodrow: "A Quantitative Study of Rhythm," p. 33. 
impression of being the longer.

(3) The ratio of the strong syllables to the weak is never constant or in simple proportion, although for any one particular reading the ratio remains fairly well fixed. (4) Faster or slower rates of reading do not seem to have any uniform influence on the ratio of the syllables. ${ }^{1}$

Therefore, any theory of English poetry which assumes for the syllables either equality of time-length or the existence among them of any degree of simple proportion is without foundation in fact. Both Professor George Saintsbury as the most notable exponent of the classical point of view (in which the syllables are regarded as having time-lengths as one to two) and the followers of the musical theory of verse (of whom Sidney Lanier is the most celebrated) must seek elsewhere for justification of the faith that is in them. That the syllables bear to each other so simple a relation as the ratio of one to two is out of all question. There is this to be said in favor of the second view: Although musical notation would lead one to believe that the sounds of music are in simple proportion, in actual performance they never are. As I am unable to find any elaborate investigation of this point, the best that I can do is to offer the results obtained by Paul Verrier $^{2}$ in his attempt to discover the time-lengths of the intervals between accents in both verse and music. Incidentally he found out that the value of such a group of notes as this $\mathcal{f} \hat{f}$ when sung might assume the ratios $1: \frac{2}{3}: \frac{1}{3}$, or that frequently there might exist among them no simple proportion at all. When the general averages of a long series of notes are taken, however, a fair degree of regularity does persist, though the actual length of the note as written is only

1 The rates of reading were varied eonstantly in the experiments of Wallin and of Brown.

2 "Essai sur les principes de la métrique anglaise," tom 3, pp. 112184; and "L'isochronisme dans le vers français" (Paris, 1912), p. 48. 


\section{THE FOUNDATIONS AND NATURE OF VERSE}

more or less carefully observed by the singer. Sometimes in artistic singing the greatest amount of freedom is allowed. ${ }^{1}$ Time-lengths of syllables are still more variable in verse than in song, "especially as there are nowhere bars to indicate the accents or the division into feet, and the reader has no guide in these two respects except his own instinct for poetic rhythm." 2

To my mind this instinct is, after all, the paramount factor in determining the time-lengths of both syllables and pauses. Having no time-length peculiar to themselves, they can be used by the interpreter in any manner dictated by his own sense of rhythm. If his feeling for time-lengths is exact, he will assign to the syllables and the pauses timelengths of far simpler proportions than if his feeling is fluctuating and inaccurate. Syllables produced without the least pretense to regularity when spoken as prose can be sung with all the exactness of time proportions possible to music.

To this I beg to add the testimony of my own experience, gained through eight years of very careful study of music from the point of view of both the performer and the composer. During this time I was thrown with music students of all grades of proficiency and with many of the great artists. Although I may be mistaken, I do not believe that there would be among the advanced students of music many to dissent from what I shall say.

In the playing of any instrument, it is impossible to produce tones of accurate length. The most perfect legato still shows either a tiny interval between any two sounds or a slight overlapping of the two. These even a Pachmann or an Ysaye can not overcome completely, although, as

1 Paul Verrier: "Les variations temporelles du rhythm," Journal de Psychologie Norm. et Path., 1913, p. 18.

2 Paul Verrier: "Essai sur les principes de la métrique anglaise," p. 181 . 
far as our ears are concerned, the fraction is less than negligible. In vocal music, when but one voice is singing, there is, of course, no overlapping of tones; but the break between them is unavoidable, in spite of the constant effort to minimize it. The time never comes when pure legato and accuracy of attack cease to require attention. They are not sought, however, with a view to reducing music to so strict an observance of time-lengths as is kept by the pianola or any other mechanical player, although neither are these mathematically accurate. If attention is centered upon the measuring of durations, even the Musical Carpenter, as one very eminent pianist was called, is heard to take all sorts of liberties with his tones. Practically every one plays the second beat of waltz time considerably shorter than the first or the third, and the third shorter than the first. And so it goes. But particularly in singing the greatest amount of freedom is allowable. It is only when the discrepancy is so great that the standard of measurement ceases to be felt that the time sense of the listener is offended. To what extent this discrepancy can be pushed for music, I do not know; but it certainly lies much beyond the belief of those unfamiliar with the intricacies of musical pedagogy. Musical notation is almost as faulty in its presentation of sound-lengths as the letters of the alphabet are in their representation of soundquality; yet for practical purposes both answer very well. Musical notation comes almost as near to expressing the timerelations of verse sounds as to expressing the time-relations of musical sounds. In either case it is only a very rough approximation; yet it certainly comes far nearer to expressing these relations than would any set of symbols positing the ratio of one to two as the standard of measurement. In both music and verse the attempt is to attain a ratio of simple proportions among the time-lengths. How far short of attaining that ideal accomplishment falls, I hope I have 
made apparent. In ordinary prose there is no thought of securing a ratio of any proportions whatsoever; but, under excitement requiring a communciation of emotion to the sociological group, the tendency is toward greater regularity. "The general character of the ratio ... for artistically free declamation," as I have already cited from Wallin, is 1:1.5 for English prose; 1:1.7 for English verse.

Since both syllables and silences are concerned in the building up of rhythms, it next behooves me to state what is known about the ratio of syllable lengths to silence lengths. Unfortunately, Brown neglected the silences occurring in the specimens of verse which he examined. I am compelled, therefore, to rely entirely upon Wallin as to this point. By silences he means those gaps, which in listening to a slowly revolving phonograph cylinder, are perceived to exist between the successive syllables of phrase groups. ${ }^{1} \quad$ The gaps between phrase groups, or expiration intervals, he distinguishes from the other type by calling them vacant intervals, or pauses. His conclusions, offered only tentatively because of the limited number of silences upon which his determinations were based, are these: ${ }^{2}$

(1) The silences that occur between the points of maximum intensity in verse rank highest in order of length.

(2) The silences coming before the points of maximum intensity occupy more time than the silences which come after these points.

(3) The average duration of the silences of speech is about 0.107 of a second.

(4) A. The ratio of quantity of silence to quantity of sound is in the proportion of $1: 2.38$. "In the action of the vocal cords, the period of work is nearly two and a half times longer than the period of rest."

$$
\begin{aligned}
& 1 \text { "Researches on the Rhythm of Speech," p. } 35 . \\
& 2 \text { Ibid., p. } 37 .
\end{aligned}
$$


B. Conclusions: (a) "The quantity of sound of expiration intervals of speech is nearly two and a half times greater than the quantity of silences.

(b) "The average emphatic and unemphatic syllables of speech are both uniformly longer than the average silences."

Of course, the vacant intervals can not be neglected for prose or verse or musie. Wallin measured these pauses, too, for prose and verse; but, because he considers each line in verse as a distinct unit, and because the phrase ends with the line in the specimens of verse he examined, he did not compare the pauses with the length of the syllables within the group. I doubt that tabulating them would yield significant results, for this reason, - The ear judges vacant intervals of time to be longer than corresponding intervals of sound; so the length of the pause would be no criterion of the length of time the speaker believed himself to be offering in compensation for incomplete time-intervals occupied by sound, or of the time-interval the hearer believed to be the proper compensation for the incomplete intervals of sound.

It appears, therefore, that in music and in verse the interweaving of sounds of different lengths with silences, when these sounds and silences are considered apart from the other characteristics of music and of verse, there is not sufficient regularity to establish either a basis for time-measurement or a pattern definite enough to be considered a rhythm. Light must be sought elsewhere. Can the differentiating characteristies of prose, verse, and music be attributed. to regularity of time-lengths between accents? 


\section{CHAPTER XI}

\section{ACCENT}

A worD or a syllable may be made conspicuous by using it in one or more of several different ways. It may be given an intensity at variance with the other words by which it is surrounded, in which case a whisper may become quite as effective as a very loud tone. It may attract attention to itself by virtue of its being noticeably prolonged or shortened, by its being pronounced upon a higher or lower pitch than the common level, by its having some tone-color peculiar to itself, or by the occurrence of a protracted pause either before or after it. Usually three or four of these ways are combined in one and the same word or syllable when it is found necessary to give to the word or syllable an unusual degree of prominence. Broadly speaking, any method of making a word or a syllable more conspicuous than the other words or syllables by which it is surrounded accents it, - that is, causes it to stand out to a marked degree.

Taken in its simplest terms, however, accent is usually thought of as meaning a sufficient increase or decrease of intensity to make a sound more noticeable than the other sounds with which it is associated. Normally it is increase rather than decrease of intensity. If of two clicks one is just audible at a distance of eight feet and the other at the distance of sixteen feet, the click audible at the distance of sixteen feet is for our purposes twice as loud as the one audible at the shorter distance. These two sounds represent phenomena which, when properly arranged, may establish a rhythm. Where these sounds are made to occur periodi- 
cally, or at such intervals as are accepted by the ear as periodic, and at such a rate as permits of their being grouped by the perceiver, unquestionably rhythm is established. Even in such a rhythmic pattern as that furnished by an accented beat followed by an unaccented beat, where the time-intervals between all the beats are equal, the impression received is that the accented beat has much more time-value than the unaccented. Meumann found that the effect of the more intense sound varied with its position in the group, and that the interval preceding the accented beat was sometimes overestimated, sometimes underestimated, as, too, is the interval following the accented beat. ${ }^{1}$ Macdougall says that only the interval preceding the accented beat is overestimated and that the interval following the accented beat is underestimated. ${ }^{2}$ For my purposes, it makes no difference which is right. What does concern me is, that the presence of a louder sound interferes with the perception of equality among the time-intervals, even though there is present in the intervals no thought content to distract the attention from the making of accurate judgments. Shaw and Wrinch ${ }^{3}$ affirm that:

"Intervals which are bounded by a fairly loud, sharp sensation are judged to be shorter than intervals bounded by a weak sensation, ${ }^{4}$ while on the other hand they are judged to be shorter likewise than intervals whose end-signals are still stronger. ${ }^{5}$ This difference is accounted for by the subjective strain of attention or expectation in the weak and also in the very strong sensations, which tends to lengthen the intervals."

1 Ernst Meumann: Phil. Stud., II., 264-306 (1894).

2 Robt. Macdougall: "Harvard Psy. Stud." I., Mon. Sup. Psych. Rev., IV., (1903), 309-412.

3 Shaw and Wrinch: "A Contribution to the Psychology of Time," University of Toronto Studies, p. 19.

4 Ibid., Tables IV., V., VI.

5 Wundt: "Outlines of Psychology," p. 151. 


\section{THE FOUNDATIONS AND NATURE OF VERSE}

In not one of the temporal arts, however, is it ever a question of judging accent and accent alone. Accent is always found in combination with pitch, tone-color, and length; and not infrequently it is simply impossible to tell to the presence of which one of these factors the greater intensity of a sound is due. For the moment it may be one or another; or it may be a combination of all. What is called by prosodists accent is in reality a focal point of intensity. ${ }^{1}$ In music I may secure such an effect in numerous ways: (1) I can make one sound louder than the others. (2) I can introduce a deeper sound in such a way as to cause it to stand out from a series of lighter sounds. (3) I can so repeat a particular tone-color as to make it prominent. (4) I can repeat a sound of marked length so frequently that at the moment of its beginning it is felt as prominent. (5) I can combine all these into one sound, as, for instance, would be the case if I introduced into an orchestral composition in six-eight time a half-note played very loudly on a heavy brass instrument at the beginning of every measure. Usually the marking off of the measures is ly mere increase of louchess; but this means of accentuation is not at all obligatory. Provided a feeling of a fairly definite time-length has once been estahlished, the ear will scize upon any phenomenon at hand that will assist in maintaining the periodicity of occurrence. Misled by half truths, some prosodists have clamed that increase of loudness is the sole means of securing this marking; others have said that the recurrence of a sound of a particular length is the thing; still others, that a change of pitch is the controlling factor. Although

1 E. Landry: "La théorie du rhythme et le rhythme du français déclamé" (Paris, 1911). Accent is made to depend upon energy, and, especially, upon duration. The combined effect of number, duration, and energy, this author calls weight.

F. Saran: "Deutsche Verslehre," (München, 1907), p. 21. 
Scripture ${ }^{1}$ had already discovered in the curves which he examined the presence of centroids and had given his interpretation of their meaning, still it is greatly to the credit of that most excellent prosodist, T. S. Omond, that as early as $1903^{2}$ he had seen the truth of the matter, and that by 1907 he could express it thus definitely and clearly:

"I submit that, as a matter of fact, accent with us does not necessarily imply either elevation of piteh, or increase of loudness, or prolongation of time. Normally we like to unite all three on one syllable, and this is probably our commonest type of accent. But it is possible to accent a syllable by lowering the voice instead of raising it, by uttering it more softly instead of more loudly, by shortening instead of prolonging its duration. Any device which thus distinguishes a syllable from its fellows makes it conspicuous, and this conspicuousness is what we really mean by accent. This rendering conspicuous of some syllables more than others is highly characteristic of our speech." 3

Bolton ${ }^{4}$ found that his subjects mistook a strong sound to be longer than a weak sound of the same duration and that a long sound frequently appeared to them to be accented. Miner, too, although investigating with lights, found that an increase in duration often had exactly the same effect upon the subjects as if it had actually been an increase in intensity. ${ }^{5}$

1 E. W. Scripture: "Researches in Experimental Phonetics." Studies from the Yale Psychological Laboratory, Vol. VII., 1899, pp. 100-101.

2 T. S. Omond: "A Study of Metre," edition of 1903, pp. 20-30. (There is a second edition brought out by the De La More Press, London, 1907.)

3 T. S. Omond: "English Metrists (18th and 19th Centuries," pp. 3-5 (Oxford University Press, London, 1907).

4 T. L. Bolton: "Rhythm," American Journal of Psychology, 1894, VI., pp. 145-238 and 310 and 488.

5 J. B. Miner: "Motor, Visual and Applied Rhythms," Psychological Review publication, Psychological Monographs, Vol. V., No. 21 (Lancaster, Pa.). 


\section{THE FOUNDATIONS AND NATURE OF VERSE}

I am convinced that the possibility such as Scripture's limited investigations suggested may be regarded as a thoroughly established fact in consequence of the more exhaustive experiments of Wallin. The latter has undoubtedly come to a correct understanding of the case in thinking of accent as produced by length, pitch, and intensity, singly or in combination, when centered in some syllable made emphatic by their presence. This syllable he calls a centroid syllable; and he defines the centroid as an impression which arouses the sense of hearing to a certain pitch of intensity for a certain length of time. ${ }^{1}$ This definition is equally applicable to prose, verse, and music, but peculiarly so when it is recognized that the psychological differences in the centroid may be accompanied by correlative differences of tone-color, or timbre, of voice. Tone-color "can be considered as a substitute for or an intensification of intensity - whether because of strain sensations common to both, or because of associations which reduced to their ultimate ground are of an intensive character." 2 The failure of Ettlinger ${ }^{3}$ and of Woodrow ${ }^{4}$ to concur in this is due, I believe, to their misunderstanding of the exact nature of the centroid. "Although the essence of the centroid is always a threefold complexity, any one of the elements may become predominant, though not entirely supreme." ${ }_{5}$ "The elements of loudness ranks highest in the degree of intensity attainable through the employment of any one element as a substitutive instrumentality; duration is equal to about one-half the effectiveness of loudness, while pitch independently is inferior to

1 Wallin: "Researches on the Rhythm of Speech," p. 11.

2 Squire: American Journal of Psychology, XII., 1901, p. 558.

3 Ettlinger: Zeitschrift für Psychologie und Physiologie der Sinnesorgane, XX., 1900, pp. 180-181.

4 Woodrow: "Rôle of Pitch in Rhythm," Psychological Review, XVIII., No. 1, Jan., 1911, pp. 61-62.

5 Wallin: Ibid., p. 20. 
duration." 1 In a later article ${ }^{2}$ Wallin takes occasion to emphasize his surprise in discovering that pitch may at times play the dominant rôle in the speech centroid. ${ }^{3}$ Mijake, too, finds a relation between accent and pitch, the accented sound having generally a higher pitch than the unaccented. ${ }^{4}$ This rise of the voice Squire attributes to the desire to secure greater ease of enunciation. ${ }^{5}$ In Wallin's records it is very rare that any one element became even approximately independent, thus tending to heighten the effect, in harmony with general principles of contrast, when the several elements were fitly employed. ${ }^{6}$ Accordingly he was able to classify centroids as loudness centroids, in which loudness is predominant; loudness-pitch-duration centroids, in which loudness is still predominant; loudness-pitch centroids; duration-loudness centroids; pitch-duration; duration-pitch; etc. Here both the principle of substitution and the principle of synthesis must be invoked, with the result that richness, variety, and all the pleasing qualities to be noticed in artistic renderings of prose, verse, and music are secured. ${ }^{7}$ Since in listening to a composition of any kind the ear does not analyze the various intensities which it hears, but accepts them indiscriminately as accent, it is exceedingly inconvenient, perhaps impossible, to differentiate them in scanning. Therefore, I believe it wiser to continue to use one symbol

1 Ibid., pp. 18-19.

2 "Experimental Studies of Rhythm and Time," Psychological Review, March, 1911, XVIII., No. 2, pp. 100-131, and May, 1911, XVIII., No. 3, pp. 202-222.

3 Wallin: "Experimental Studies of Rhythm and Time," p. 209.

"Mijake: "Researches on Rhythmic Action," Studies from Yale Psychological Laboratory, 1902, pp. 1-48.

5 Squire: American Journal of Psychology, XII., 1901, p. 557.

6 Wallin: "Researches on the Rhythm of Speech," pp. 18-19.

7 Dr. Herbert Woodrow does not agree with this. I shall comment later upon his point of view. 


\section{THE FOUNDATIONS AND NATURE OF VERSE}

for all these different shades of intensity, provided, of course, exactly what factors are involved be kept clearly before the mind.

Great difficulty has been experienced in determining at what particular point in a sound or a group of sounds the moment of maximum intensity may be said to lie. Scripture found the centroids in the following lines from the record of the reading which he secured to be located as represented by the dot below the printed lines: ${ }^{1}$

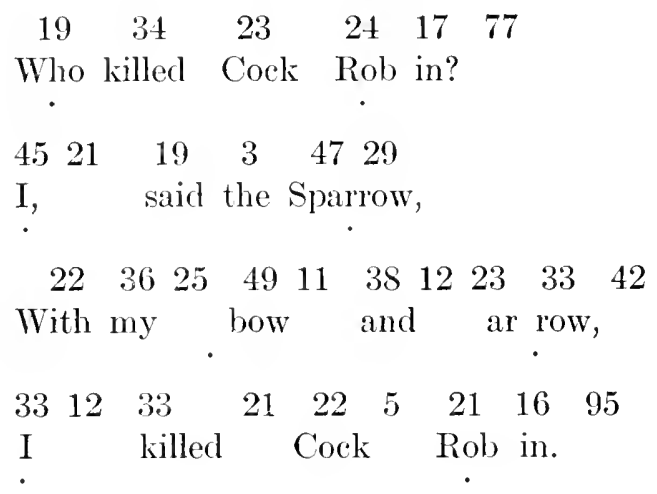

"The point of emphasis," he remarks, "may lie even in some weak sound or in some mute consonant if the distribution of the neighboring sounds produces an effect equivalent to a strong sound occurring at that point. Thus the point of emphasis in the third line lies somewhere in the group mybow, probably between $y$ and $o . " 2$ Brücke gives a number of rules of position for it ${ }^{3}$ Meyer regards it as falling at a

1 The measurements here given are R. H. Stetson's modifications of the original.

2 E. W. Scripture: "Researches in Experimental Phonetics," p. 101.

${ }^{3}$ Brücke: "Die Physiologische Grundlage der neuhochdeutschen Verskunst," p. 24 (Wien, 1871). 
particular point; ${ }^{1}$ Miyake $^{2}$ and Brown $^{3}$ found it marked by a tap before the sound; and so they go in unanimity of disagreement. It really does not make very much difference just where it does lie; ${ }^{4}$ but it is quite probable that each was right in his determination of the point of emphasis for the particular subjects upon whom he experimented. The exact position of the centroid is worth knowing for only one reason, and that is, to settle the question as to whether or not there is equality of time-length between accents in either verse or in music. Unless it is possible to determine with accuracy the points of maximum intensity, it is obviously impossible to obtain accurate measurements of the time lengths between them. Thus far absolute accuracy has not been achieved. The best results have come from considering the moment of attack for the emphatic sounds as the point from which to measure. In music this point normally would be the begimning of the measures; in verse and in prose it is for convenience considered as beginning the emphatic syllables. What really counts to the listener, says Dr. Woodrow," is "neither the actual interval between the sounds nor the time elapsing from the beginning of one sound

1 Meyer: "Beiträge zur deutschen Metrik," Neuere Sprachen, 1898, VI., 122-123.

${ }^{2}$ Miyake: Studies from the Yale Psychological Laboratory, X., 45, (1902).

3 Brown: "Time in English Verse Rhythm," p. 23, Columbia Contributions to Philosophy and Psychology, Vol. XVII., No. 2 (Science Press, New York, May, 1908).

${ }^{4}$ Hofbauer: Archiv. f. d. ges. Physiol. (Pflüger's), 1897, Bd. 68, S. 553.

A. Cleghorn: American Journal of Psychology, 1898, I.

Robt. Müller: Phil. Stud., 1901, Bd. 17, S. 1.

E. W. Scripture: "The New Psychology," p. 182, (London, 1897).

5 Herbert Woodrow: "A Quantitative Study of Rhythm," p. 50. Columbia University Contributions to Philosophy and Psychology, Vol. XVIII., No. 1 (Science Press, New York, June, 1909). 


\section{THE FOUNDATIONS AND NATURE OF VERSE}

to the beginning of the next, but the interval between certain points of greatest subjective stress, the subjective stress being due, perhaps, to the occurrence, at certain points, of greater attention, of motor performances, or to unknown factors; and these theoretically possible points of greatest subjective stress might conceivably occur almost anywhere." As a matter of fact, they do not occur at random, but at periods of a fair degree of regularity.

An examination of two records of the same song made by Verrier ${ }^{1}$ show the first four measures to contain the following relative time-lengths:-

$\begin{array}{rrrrr} & \text { I } & \text { II } & \text { III } & \text { IV } \\ \text { B } & 160 & 116 & 166 & 178(5) \\ \text { G } & 160 & 116 & 166 & 133(6)\end{array}$

This means, of course, that the point of emphasis, if located at the beginning of each measure, can not be regarded as being repeated at regular time-intervals. The attempt to play in time to a metronome will convince almost any one that it is only with the greatest difficulty that the accents in music can be got to fall invariably with the ticks. Absolute regularity is not only impossible but disagreeable. No person who plays with a regularity of accent approaching that of the unvarying tick of the metronome is thought of other than as a mechanical performer; and every one recognizes that mechanical music, whether produced by hand or by pianola, is something to be shunned.

I will give next four sets of measurements made by Wallin, - the first, of a piece of ordinary prose; the second, of oratorical prose; the third and the fourth, of four lines of verse. The specimen of verse is selected because of its unusual regularity. For the first two the unit of measure-

1 "Essai sur les principes de la métrique anglaise," tom 3, p. 138. 
ment is one-forty-eighth of a second; for the others, onefortieth. The dots represent the centroids.
(a)
(b)
(c)

. $12 \cdot 18.62 \quad 62.20$.

I. "The class of ninety-nine - did not hold a very high (d)

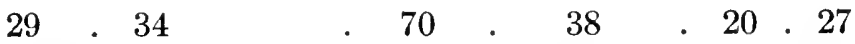
reputation - as scholars, - either for study or for 80

morals. -

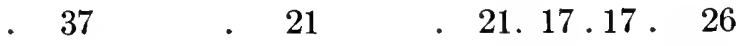

And it was notorious that they paid no attention to the . 21 .

Sunday services," -

(p. 52.)
(a)
(b)
(c)
(d)
(e)

17 . 11. 13. 13.20. 23 . 22

II. "Almighty God, unto whom all hearts are open,(f) $\quad(\mathrm{g}) \quad(\mathrm{h})$ . $32.25 \quad$. $34 \quad$. 28 . 11 . 16 . 34 all desires - known, - and from whom no - secrets are hid."

(p. 53.)
(A, read as prose.)
(a)
(k)
(b)
(c)

. $18.23 \quad 9 \cdot 15 \cdot 23 \cdot 16 \cdot 15$

III. "Oh yet we trust - that somehow good will be the final 
132 THE FOUNDATIONS AND NATURE OF VERSE

(e) (f)

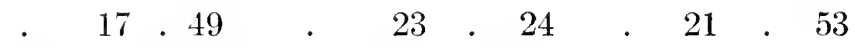
goal of ill, - to pangs of nature, - sins of will, -

. 19

25

21

defects of doubt, - and taints of blood." (p. 59.)

(B, read as poetry.)

. $20.28 .9 . \quad$ ?

IV. "Oh yet we trust - that somehow $-\operatorname{good}-$

23 - 19 . 18. 21.40

Will be the final goal of ill, -

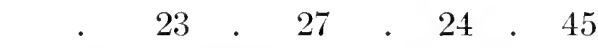

To pangs of nature, - sins of will, -

$$
23.46 \quad \text {. } 22 \text {. }
$$

Defects of doubt, - and taints of blood." - (p. 59.)

In the first specimen it is noteworthy that, if those periods in which pauses occur be excluded, and if (a) and (b) be counted as one length and (e) and (f) as one length, the difference between the shortest time-intervals between centroids (c) and the longest time-interval between centroids (d) is eighteen units, or about a third of a second. Observe, too, that, when the time-intervals containing pauses are divided in half, the time-length of each half is very nearly equal to the time-length of almost any interval near it.

In the second specimen, after grouping (a) and (b), and (c) and (d), and (f) and (g) together as single units, the difference between the shortest time-interval (e) and the longest time-interval (h) is fourteen units, or about onefourth of a second.

In the third specimen, after combining (a) and (b), (c) and $(\mathrm{d}),(\mathrm{c})$ and (f), and (g) and (h), the difference between the 
shortest time-interval $(k)$ and the longest time-interval (onehalf of $\mathrm{g}$ plus $\mathrm{k}$ ) is eighteen units, or almost half a second.

Treating the fourth specimen in like manner, the difference is ten units, or one-fourth of a second.

In all cases the greatest difference is found to occur in those time periods in which there are pauses. The greatest changes in the time-lengths between centroids are observable after the pauses, that is, before the time-sense, or muscular period of contraction, or whatever one chooses to consider it, has had an opportunity to reëstablish itself.

Verrier's prose specimens are entirely too fragmentary to deduce anything from; and even his specimens of verse are hardly more than phrases. Here is an example:

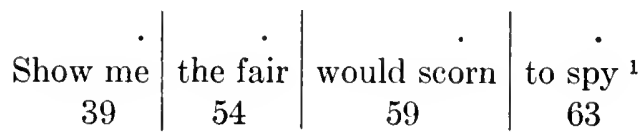

Neither he nor Brown was measuring the distances between centroids, or intensities; but, by taking Brown's measurements of syllable lengths and using the accents as he gives them, I can arrive at a rough estimate of the distance between accents. Even rough estimates, however, are better than none at all.

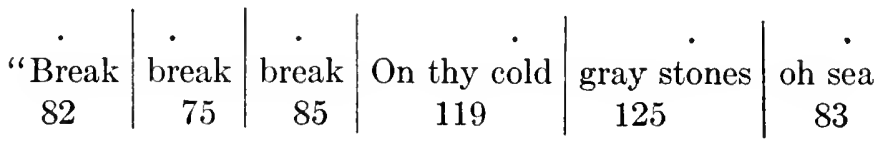
\begin{tabular}{c|c|c|c|c} 
But the ten & der grace & of a day & that is dead & will ne \\
62 & 73 & 68 & 120 & 45
\end{tabular} \begin{tabular}{c|c} 
ver come back & to me." - (p. 48.) \\
86 & 60
\end{tabular}

1 Paul Verrier: "Essai sur les principes," etc., tom 3, p. 233. 


\section{THE FOUNDATIONS AND NATURE OF VERSE}

The following lines were both read and sung. The length of the periods between accents is given in ordinary numerals for the readings, in italics for the singing.

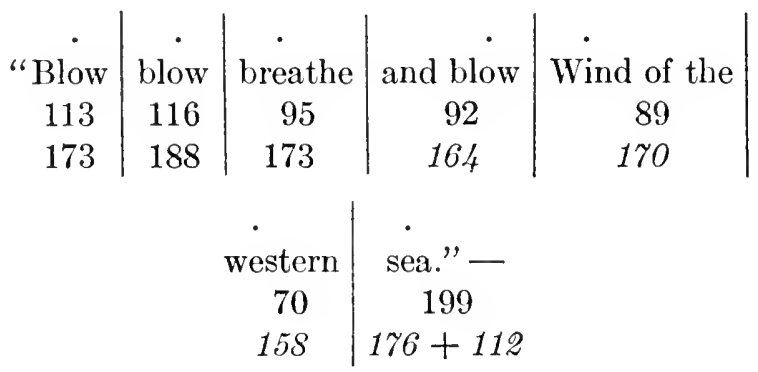

The reading required 774 units, the singing 1314.

I believe I have showed that for prose nor verse nor music is there any accuracy of time-lengths between the accents, though there is a greater approximation to unity for verse than for prose and for music than for verse. Further, there is a tendency to prolong the time-intervals between accents as ordinary prose moves toward oratory, oratory toward verse, and verse toward music.

In view of the fact that Guest and others have said that no two accented syllables can appear in succession without a pause intervening, I wish to exhibit for inspection several instances from the records of Wallin. Of course, it must be remembered that accent is here being considered as a combination of loudness, length, and pitch, in which all are felt as giving the syllable greater intensity than that of any one of the syllables adjacent.

$\begin{array}{lll}2 & .14 . & 17\end{array}$

"Whose fortunes run back and whose spirits mutiny. (p. 62. Prose by Francis Bacon.) 
.20. 28.30 . 14. 24 .

"As is the light of a dark eye in woman." - p. 48. Byron. . 12.11 .11 .22 .

"Thou wert not sent for slumber." - p. 48. Byron.

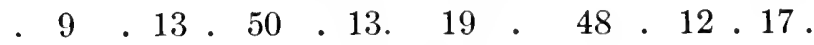

"Shut those eyes, - next life will open, - stop those ears."

- p. 56. Browning.

Of course, in the final analysis, there is a break between each syllable and the following; but in ordinary speech the
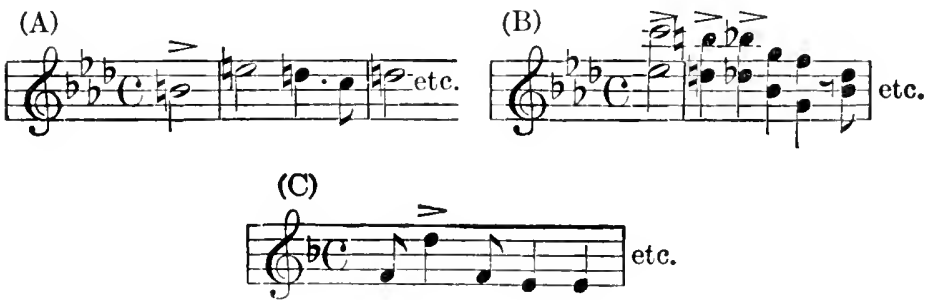

break is entirely too short to be detected. Only when breath is taken does it become apparent.

A succession of accented syllables is in music of too common occurrence to need more than a very few illustrations. A and B are from the "Impromptu" by F. Chopin (Op. 29); $\mathrm{C}$ is from "Good-bye Sweet Day," a song by Kate Vannah. It is understood, of course, that the first beat of each measure is always played with an accent whether the accent be written or not.

As to the real nature of the spondee, Wallin ${ }^{1}$ has this to say:

"In the 1-syllable interval, the centroid extends throughout. its entire length. This interval is customarily called a spondee. The definition of this as a "foot consisting of two equally accented. 1 "Researches on the Rhythm of Speech," p. 112. 


\section{THE FOUNDATIONS AND NATURE OF VERSE}

syllables,' is based upon the misconception that a centroid interval consists of more than one centroid. When the components of a series are equally strong (are real centroids as the theory supposes) each centroid constitutes a so-called foot: there is no reason for including two centroids in the interval, rather than three or four, or all in a spondaic verse. The spondee of prosody is thus based upon a misconception and a certain arbitrariness. The spondee, to mean anything, should signify a 1-syllable centroid interval; and as signifying this, it may be a convenient term. It is arbitrary and unwarranted to include two centroid intervals in one interval.

"The 1-syllable interval is limited to short sequences. In long ones the tendency is to so emphasize certain of the centroids as to make the others subordinate."

Closely allied to this question of two accented syllables in a foot, bar, or measure, or whatever one chooses to call it, is that of two unaccented syllables as filling the bar, foot, or measure, as in the so-called pyrrhic foot. Again I can reply by offering illustrations from Wallin.

$$
\text { . 14. 14. } 13.25 . ? 10 \text {. }
$$

I. "The big rain comes dancing to the earth." - (Byron) (p. 49)

The next three are readings of the same passage by different persons.

$$
\text { . } 22.19 .11
$$

II. "Or cast as rubbish to the void." - (Tennyson) (p. 60)

$$
\text { - } 25.29 \text {. }
$$

III. "Or cast as rubbish - to the void." - (p. 60.)

12

- 23 . 43 .? 17 .

IV. "Or cast as rubbish - to the void." - (p. 61.) 
Here in II. the reader unquestionably accented the to just as if it had been an important syllable. In I. and in IV. Wallin is unable to determine just what took place, though he writes down a centroid. It is more than probable that following the tendency that had been set up to accent every other syllable, the readers here continued to feel the accent, even though they did not in speech give the accent its full force. This seems to me to be undoubtedly the case in I. In IV., however, I am inclined to think, that, pausing after bish, the reader felt the accent to come during the pause, as in III. The explosive $t$, following immediately after the pause, probably received a little more prominence than usual, yet without causing the syllable to be felt as a centroid. In III. the subjective accent falls during the pause, so that to and the may be considered either as unaccented syllables in the foot of which the subjective accent is the first beat, or as the first syllable of the foot in which void receives the accent. I have never been able to find in English verse of this nature a single case in which one of three things does not take place. In the first, one of the unaccented syllables is given a subjective accent to make it conform to the general scheme of periodicity of accent. In the second, a pause is introduced in order that the subjective accent may be felt during the pause. In the third, the unaccented syllables belong with either the preceding or the succeeding accented syllable. Exactly the same condition holds where three or four syllables are concerned instead of only two.

In music unquestionably there is no such thing as having two, or any other number of unaccented beats fill the entire measure. The accent must come, even if it has to be felt as occurring during a period of silence.

Another figment of the prosodic imagination is the socalled compensating foot such as occurs in 
"Shé | that hath that | is clad | in com | plete steel." In com | pléte steel is described as "a pyrrhic foot compensated for by a succeeding spondee," which "may be read with a suspended or deferred stress over in com. Both syllables of the succeeding foot are heavily accented." The fault here is with the grouping, not with the statement that two unaccented syllables are followed by two accented. The theory of substituting one foot for another, in which Saintsbury takes such great delight, is perfectly meaningless, because there is behind it no unifying principle. Is verse a sort of mosaic or picture puzzle into which the various blocks can be fitted? I think not. The way has not yet been prepared for a full explanation of what constitutes verse; yet, for the once, adopting the method of scansion used above and considering theaccented syllable to have twice the time value of the unaccented, something akin to order can be brought out of disorder.

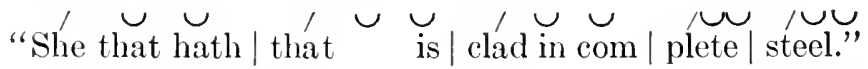

If the pause after that be considered as occupying the time of an unaccented syllable, at once each measure is seen to contain the same number of beats. What is there to be compensated for?

"I suppose," Professor Gayley had already remarked on the preceding page, "that sometimes, however, it is more reasonable that a pyrrhic $(\cup \cup)$ should receive half a stress on each of its syllables or a full stress on the second than that the line should be read with a rhetorical pause. Such may be the case in

'The best $\mid($ and of $\mid$ the prin | ces some | were such)'. |

1 Gayley and Young: "English Poetry: Its Principles and Progress," lxvi (Macmillan, 1908). 
This is especially true when the syllable to be stressed has a secondary accent of its own, as in

"To fúr | ther thís | Achit | ophel | unites.' "'

To my mind it is far more reasonable to believe that the poet introduced the parentheses for the particular reason that he wished the line to be read with the rhetorical pause, and that this pause has its particular value in the rhythmical pattern of the poem. He wrote the line to be read, not to be scanned; and he could not have wished a single word in it to be accented in any way which could interfere with its meaning. I read with a decided pause after best. And of the I pronounce so rapidly that the three words have about the same time value as any one of the other syllables marked as short. In the next line quoted, this does not modify Achitophel; and it is absolutely essential that the two words be separated by a pause if either the sense or the rhythm is to be maintained. So I read:

“To further| this $\cup / \breve{A} \mid$ chitophél u | nites." |

The centroids, or accents, on this, chit, and nites are much heavier than those on fur and phel, just as in 4/4 time in music the accent on the first beat is much heavier than that on the third. I believe that I have read the line properly; and I also believe that I have come as near to showing its rhythmic pattern as it is possible to come with the symbols I am using.

Both hovering accent and deferred accent must be considered in this connection.

Says the same author:

"In the first line of 'Lycidas,'

'Yet once | mòre, Oे | ye Lau | rels, and | once more,' 
a heavy stress hovers over both syllables of the second foot, and of the fifth; the unaccented syllables of the fourth are pronounced slowly, as if they divided with difficulty the little stress that they can win from the and. This is hovering accent. When it stresses alike two heavy syllables, like 'more O,' it may be called spondaic, , like 'rels and,' it may be called deferred. And the reader will find that the foot with the deferred stress is usually followed by a foot of heavy syllables, spondaic, like the final 'once more,' upon which the lighter stress seems to fall, as if atoning for its reluctance."

I, too, read every word in this passage with all the gravity and all the deliberateness I can put into it. Read thus the syllables are of about equal duration; but six of them are centroid syllables in which it is difficult to distinguish whether duration or loudness is the more responsible for the intensity they are felt to possess. In considering the structure of this line great importance must be attributed to the pauses. The scansion given above neglects them entirely. As I read the line, they fall as follows:

"Yet $\mid$ once more, I Ó ye | Laurels, and | once more."

Here again occurs the succession I have already explained. The feet contain two accents, the first slightly stronger than the second. At (a) the stronger accent comes during a pause; at (b), the weaker accent. Once and more are so greatly protracted that they are of about the same duration as an accented plus an unaccented syllable. The so-called hovering accent is nothing more than a centroid in which duration is more prominent than loudness. The so-called deferred accent in the pyrrhic is here easily explained as two unaccented syllables separated by a pause during which a subjective accent is felt to occur.

Quite a number of prosodists are very particular to explain the differences between word accent and logical accent and 
metrical accent. Word accent is the greater amount of emphasis placed upon one or more syllables of a polysyllabic word. Logical accent is the greater amount of emphasis placed upon the important word or words in a group of words. Metrical accent is the accent given a syllable in verse in order to mark the rhythm. As far as the ear is concerned, and as far as any method of recording sound waves can show, there is no difference between them. Emphasis is emphasis, no matter for what purpose it is introduced; and neither the ear, nor the voice, nor records of the voice, show any distinction as to this purpose. So-called metrical accent is nothing more than the result of arranging syllables in such a way that both the word accent and the logical accent, singly or in combination, occur with sufficient regularity to establish a feeling of periodicity. This having taken place, the ear occasionally demands the supplying of an accent at some point where neither the word accent nor the logical accent would naturally fall. The free use of accents in prose is brought under greater restriction in verse. In music, though the word and the logical accents frequently fall with the accent at the beginning of each bar, it is not essential that they should. Both the duration and the accent which the syllable would normally receive give place to such prolongation and such accentuation as is demanded by the melody and by the necessity for marking off the time-intervals. In verse written to be set to music the natural accents are frequently neglected; and even elsewhere, if the feeling of periodicity is sufficiently strong to warrant such a procedure, especially if this feeling would be destroyed by following usual habits of speech, the accent is transferred from one syllable to some other upon which it would not normally fall. An accent thus transferred is called a wrenched accent. Except in the case of rhyming syllables, I find the occasions for wrenching accents very few indeed. Usually a slight pause is all that is 


\section{THE FOUNDATIONS AND NATURE OF VERSE}

necessary to adjust the equilibrium and to bring the periodic accent and the word accent together at the right moment.

Even after accents have been wrenched and everything else possible done to make them fall at exact intervals of time, in prose nor verse nor music is there anything approaching mathematical precision in the duration of the time-lengths between them. Can it be, then, that Samuel Taylor Coleridge ${ }^{1}$ was right in saying that it is not the time-interval between accents, but the number of accents in the line, which characterizes verse? Let us see.

It is quite true that numberless stanzas are to be found in which each line does contain the same number of accents or in which alternate lines contain the same number. The "Cock Robin" stanza as recorded by Scripture, "Break, break, break" as measured by Brown, and "Oh yet we trust" when read as poetry by the subject upon whom Wallin experimented, would assuredly be reckoned as among these. Two other subjects read this same passage for Wallin. For the first record by each it was written as prose and read as prose. Both the prose and the verse records show practically the same accentuation. Two subjects regarded the following prose passage from Bacon's "Essay on Death" as poetry, and gave to the lines the number of accents I here record:

To the poor Christian that sits bound in the galley;

To despairful widows, pensive prisoners, and deposed kings; 66 To them whose fortune runs back and whose spirits mutiny, -57 Unto such death is a redeemer, and the grave a place for rest. 66

Wallin's record of his own reading of those eighteen magnificent lines from "Childe Harold" beginning

"The sky is changed! and such a change! Oh night," show the following number of accents to the line:-

$7,5,6,5,5,7,5,5,6,5,7,5,4,7,7,5,5,7$.

1 Preface to "Christabel," 1816. 
Surely Coleridge could never for a moment have doubted that these lines are poetry! I rather wonder what he would have said of the two records Wallin made of the passage I here quote from Browning. The first line has eight centroids, the second eight, the third ten, the fourth twelve, and the fifth ten. -

"Nothing! Henceforth Man's existence bows to the monition wait! -

Take the joys and bear the sorrows, neither with extreme concern! -

Living here means nescience simply: - 'tis next life that helps to learn.

Shut those eyes, next life will open, stop those ears, next life will teach

Hearing's office, close those lips, next life will give the power of speech."

No one is more willing than I am to admit that some prose is so closely akin to verse and some verse so closely akin to prose that it is very difficult to classify it properly; yet I can not believe for a moment that the number of accents in the line will aid in the determination, nor yet that reducing the number of accents in the lines until there is uniformity could possibly make the lines any more poetic than they are already. So Coleridge, too, was misled by a halftruth, though I hope to show later that there is quite an amount of pith in his argument.

When regarded as the sole determining factor, not one of the phenomena thus far considered can be said to differentiate prose from verse or verse from music. Pause and rhyme remain as the only possible hope of solution, - that is, if the solution is to be found in a single phenomenon. I turn first to the investigation of the pause. 


\section{CHAPTER XII}

\section{THE PHRASE: ITS NATURE AND ITS LENGTH}

Those gaps which can be heard between the individual sounds when the revolving disc of a phonograph is sufficiently slowed down in reproducing a speech record are too small to be distinguished by the ear except when some method such as this is resorted to. Therefore, they can not be looked upon as entering into the rhythmic scheme of any art form, and can be neglected, except where in mass they must be considered as forming an addition to the total amount of time occupied by a number of syllables. The pause of which I shall speak is clearly distinguishable at all times. It is necessitated by the impossibility of pronouncing more than a limited number of syllables during one breath. At the moment of inspiration no sound can be produced. Therefore, in order that breathing may not interfere with speech or speech with breathing, we are forced to arrange our words in such a way that the moments of inspiration come only after groups of related words. At the same time natural breathing has to be altered very materially in order to avoid breaking the thought into unrelated groups. The breath may be exhaled gradually during the pronunciation of the words, it may be forcibly expelled at the end of the word group, or it may be held at the close of the group, in such a way as to give the effect of a pause; but inspiration can come only at the end of the phrase. When it takes place elsewhere, the phrase is broken. If an unusually long pause is introduced between two beats, there is always a feeling of suspense or tension. 
"As long as tensions are maintained, there is rhythmic continuity; the feeling of tension is the strain of opposition between the opposing muscle sets." I Thus certain habits of speech have been formed, giving at the close of each breath period a pause, "which is demonstrably not a function of any of the intervals of the period," but during which the sense of muscular tension dies out, in this way producing a feeling of finality. ${ }^{2}$ The grouping together, in a single exhalation, of words belonging together in thought is called phrasing. If words not belonging together in thought are grouped as if they did belong together, the phrasing is faulty. In the sense in which I am using the word, the phrase may be either a single word or a group of words. The grammatical divisions of sentence, member, clause, phrase, and word have no unit existence for the ear except in so far as they can be made to stand apart from each other in a group. One of the most readily available methods of grouping words is by pausing after each group, - that is, by phrasing the words. From this point of view, the sentence $I$ am here is a phrase; and the complex sentence, When you want me, I am here, consists of two phrases, or two breath groups, of which the subordinate clause, When you want me, is one, and the principal clause, $I$ am here, is the other. Of course, Mary, when you want me, I am here, has four breath groups, or phrases, of which the prepositional phrase of course is the first; the word Mary, the second; the subordinate clause when you want me, the third; and the principal clause $I$ am here, the fourth. The necessity for phrasing is in music as great as it is in prose and verse, although, because of the deeper

1 R. H. Stetson: "Rhythm and Rhyme," p. 445, II. Harvard Psychological Studies, Vol. I., Psychological Review Monograph Supplements, Vol. IV., (Whole No. 17), Jan., 1903 (Lancaster, Pa.).

2 Ibid., p. 445, IV. 


\section{THE FOUNDATIONS AND NATURE OF VERSE}

breathing required for singing, the phrases of music can be of much greater length than those of either prose or verse. The points of inquiry for this discussion should be: (1) Are the phrases in prose, in verse, or in music of sufficient equality of length to establish anything approaching periodicity? (2) Would a periodicity of this type be sufficiently marked to differentiate prose from verse or verse from music?

I do not know of any measurements that have been made especially to test the length of phrases; ${ }^{1}$ but of measurements made for other purposes there is quite a sufficient number that can be of use here to justify the formulation of several very definite conclusions.

The selections which follow are taken from Wallin. The first two are prose. The third is verse read as if it were prose. The unit of measurement is one-fortieth of a second. The centroids are indicated by dots; the pauses, by dashes. The curved lines (-) are my own marking of the phrases as I conceive them to be. It is not always possible to measure the exact length of the phrases; but the irregularity is so great that it is hardly necessary to deal in small numbers.

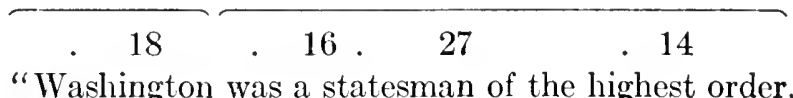

I. "Washington was a statesman of the highest order,

.31 .19 .19 .15 .11 .42

never a wily scheming pol i tician.
42

32

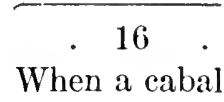

When a cabal

1 “An Experimental Study of Musical Enjoyment," by H. P. Weld (Amer. Journ. Psychol., 1912, XXIII., pp. 245-308), is interesting in many particulars; but unfortunately his subjects were listeners, not producers. From them no constant relation between respiration and the musical phrasing could be established. 
THE PHRASE: ITS NATURE AND ITS LENGTH 147

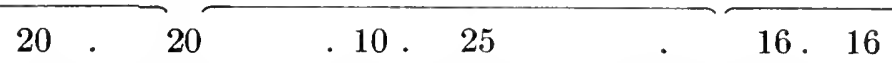

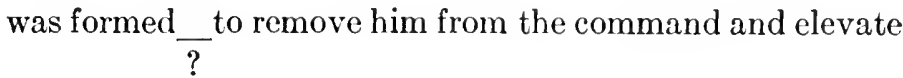

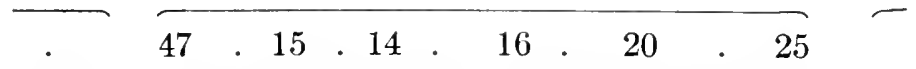
Gates, $\underset{27}{ }$ in perfect equipoise of mind and temper, $\frac{}{6}$ he

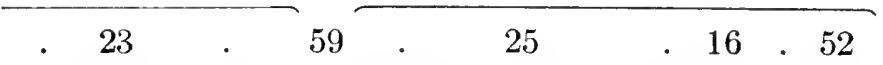
moved not a finger. _either was he a brilliant orator." 47 $-(\mathrm{p} .51$.

Approximate lengths of the phrases:-

$$
16,57,105,40,50,32,84,45,43 .
$$

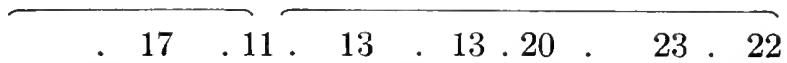

II. "Almighty God, unto whom all hearts are open,

$\overbrace{32.25}^{.32} \cdot \begin{gathered}34 \cdot 28 \cdot 11 \cdot 16.34 \\ \text { all desires } \\ \frac{15}{15} \text { known, }\end{gathered}$
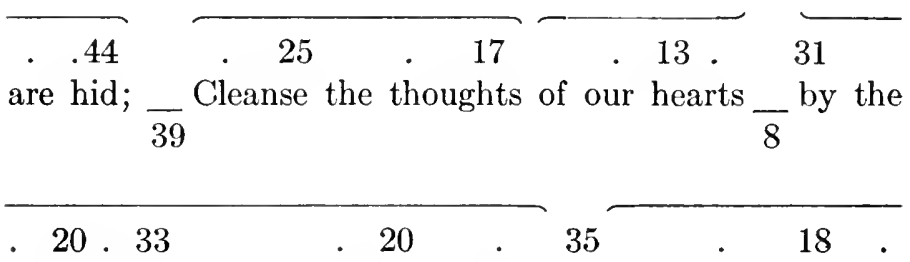
inspiration of thy Holy - Spirit, $\frac{27}{27}$ that we may per- 
148 THE FOUNDATIONS AND NATURE OF VERSE

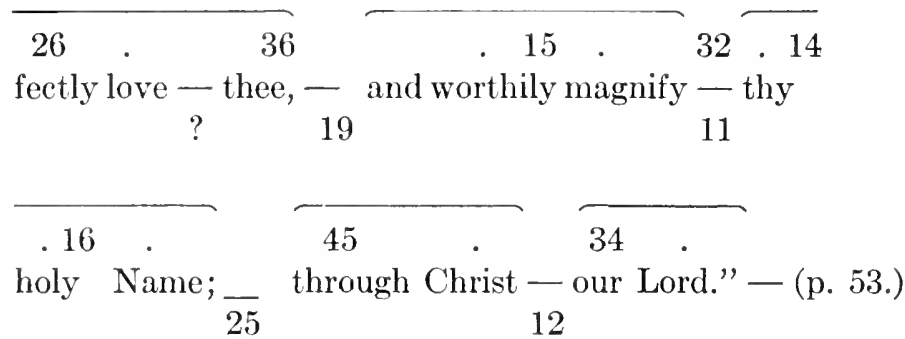

Approximate lengths of the phrases:-

$$
28,84,71,99,35,30,85,59,43,40,25,18 .
$$

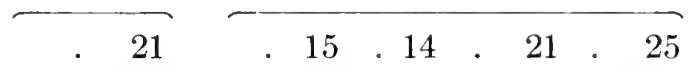

III. "Nothing! $\frac{7}{8}$ Henceforth man's existence $\frac{}{5}$

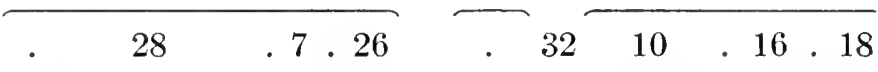
bows to the mo nition $\frac{-}{8}$ wait! $\frac{7}{23}$ Living here means

$\begin{array}{llll}.17 & .35 \quad .11 & . & 23\end{array}$

nesience simply: $\frac{}{25}$ 'tis next life that helps to

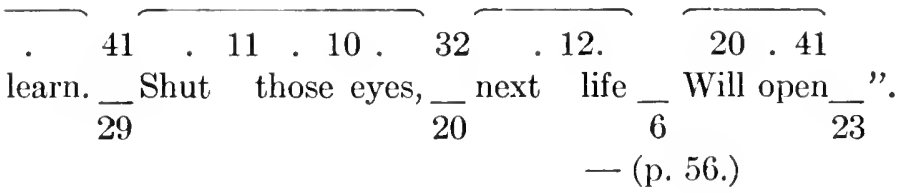

Approximate length of the phrases:-

$$
13,75,32,9,82,81,71,79,33,20,24 .
$$


THE PHRASE: ITS NATURE AND ITS LENGTH 149

I will next give for inspection three selections of poetry treated in the same manner as I have treated the prose.

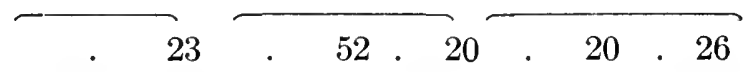

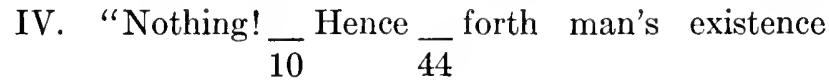

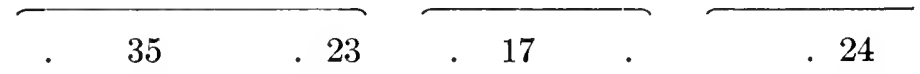

bows to the monition $\frac{}{8}$ Take the joys $\frac{}{29}$ and bear the

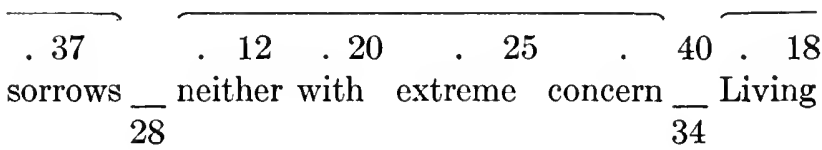

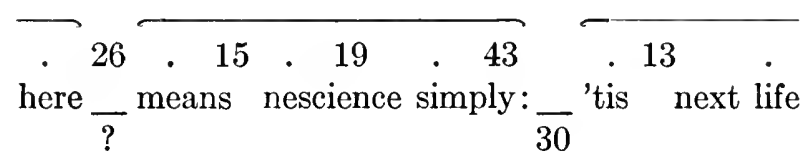

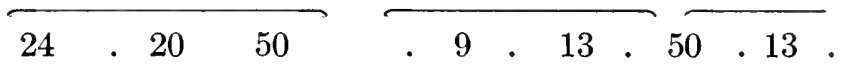

that helps to learn. _ Shut those eyes, $\frac{}{34}$ next life

19. 48

will open $\frac{13}{33} " \cdot-($ p. 56.)

Approximate lengths of the phrases:-

$13,28,46,50,8,27,36,12,51,30,47,27,38,38,47$. 
150 THE FOUNDATIONS AND NATURE OF VERSE

$$
\text { V. "O yet we trust } \overbrace{13}^{20} \overbrace{28 \cdot 9 \cdot}^{\text {that somehow }} \overbrace{9}^{\operatorname{good}} \frac{}{9}
$$

$$
\begin{aligned}
& 23.19 \cdot 18 \cdot 21.40 \\
& \text { Will be the final goal of ill, } \overline{37}
\end{aligned}
$$

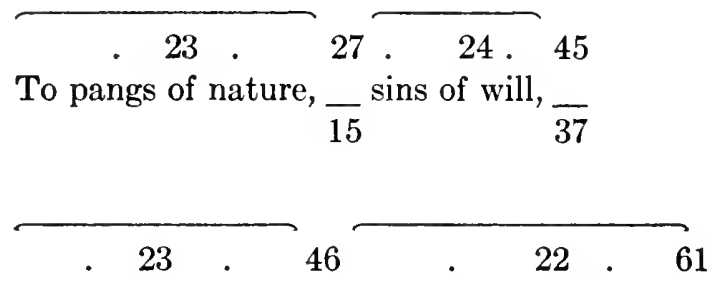

Defects of doubt, $\frac{}{34}$ and taints of blood;

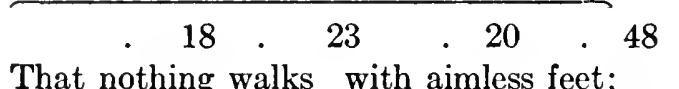

That nothing walks with aimless feet; $\frac{}{43}$

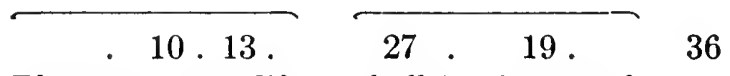

That no one life ${ }_{11}$ shall be destroyed, ${ }_{33}$

$\overbrace{\text { Or cast as rubbish }}^{27.22} \cdot \frac{14}{?}$ to the void, $\overline{34}$ 
THE PHRASE: ITS NATURE AND ITS LENGTH 151

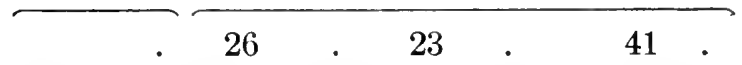

When God hath made the pile ${ }_{16}$ complete." -

Approximate lengths of the phrases:-

?, 25, 25, 10, 63, 37, 29, 34, 34, 69, 35, 27, 39, 24, ?, 80.

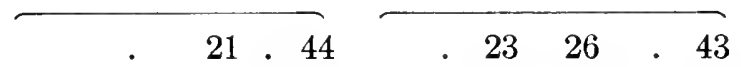

VI. "The sky is changed! $\frac{13}{34}$ and such a change! $\frac{}{35}$

$$
\text { - } 19.43
$$

Oh night,

\section{9}

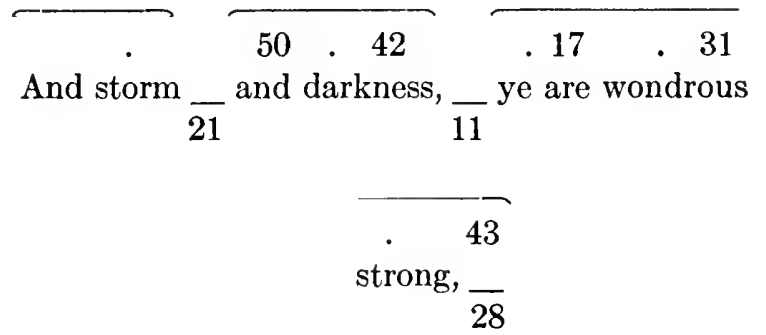

$\begin{array}{ccc}18 \cdot 32 \quad 43 & .20 \cdot 28 \cdot 30 \\ \text { Yet lovely in your strength, } & \text { as is the light } \\ 33\end{array}$

. $1 4 . 2 4 . 4 5 \longdiv { 2 0 . 3 2 }$

Of a dark eye in woman! _ Far along, _ 


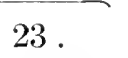

From peak to peak,
35.22 .25 .36 the rattling crags among

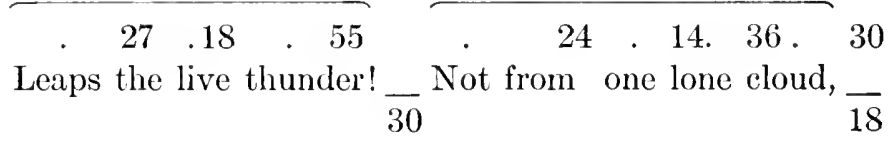
- $16.25 .-21$.

But every mountain now hath found a tongue, $\overline{23}$

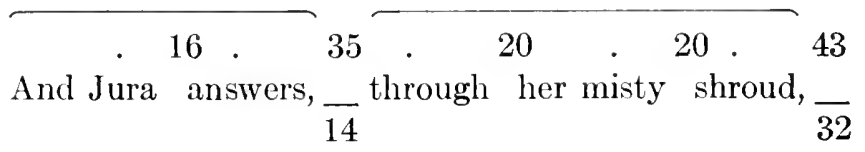

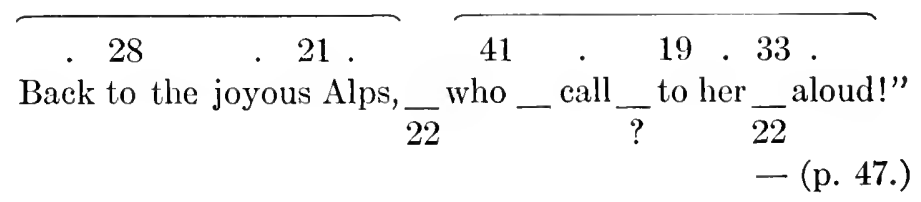

Approximate lengths of the phrases:-

$34,57,35,28,40,58,65,92,21,35,38,64,60,84,43,54$, $52,50,59,72$.

In the following extracts taken from the work of Dr. Warner Brown, it must be remembered that the pauses at the end of the line are calculated as part of the time value of the final word of the line. This, of course, makes 
THE PHRASE: ITS NATURE AND ITS LENGTH 153

the irregularity of phrase length apparently greater than it really is. The phrase length is written at the close of each phrase.

VII. "Double $(73), \overparen{\text { double }}(81), \overparen{\text { toil and trouble }}(198)$,

Fire burn (124) and caldron bubble (281)."-(p.51.)

VIII. "Each purple peak $(178)$, each flinty spire $(177)$, Was bathed in floods (159) of living fire (223)."

IX. "Wha will be a traitor knave?

(206)

Wha can fill a coward's grave? (243)

Wha so base as be a slave? (212)

Let him turn and flee." (49) - (p. 62.)

X. "The splendor falls $(141) \overbrace{\text { on castle walls }}(193)$ And snowy summits (181) old in story." (251)

XI. "I stood on the bridge (123) at midnight $(118)$, As the clocks (68) were striking the hour (217)

And the moon rose o'er the city (229)

Behind the dark church tower" (330) - (p. 62.): 


\section{THE FOUNDATIONS AND NATURE OF VERSE}

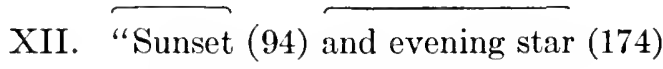

And one clear call (167) for me (115)

And may there be no moaning (170) of the bar (101)

When I (56) put out to sea." $\quad(247)-($ p. 62.)

XIII. "The day is done (150) and the darkness (115)

Falls (from the) wings (of the) night." (178)

XIV. "Know ye the land (118) where the cypress and myrtle (214)

Are emblems of deeds
their clime?" $(314)$ - (p. 63.)

XV. "And he dances (103), and he yells (141);

Keeping time (123), time (79), time (110),

In a sort of Runic rhyme (212),

To the pæan of the bells (195) -

Of the bells (162):

Keeping time (111), time (78), time (109),

In a sort of Runic rhyme (212),

To the throbbing of the bells (242), 
THF PHRASE: ITS NATURE AND ITS LENGTH 155

To the tolling of the bells (210),

$\overparen{\text { Of the bells }}$ (114), bells $(79)$, bells (75), $\overparen{\text { bells }}(113)$,

Bells (79), bells (74), bells (112) -

To the moaning (78) and the groaning of the bells." (223) - (p. 68.)

The following is from E. W. Scripture with the measurements as altered by R. H. Stetson in "Rhythm and Rhyme," page 463.

XVI. "'Who killed Cock Robin?' (194)

'I,' said the sparrow, (164)

'With my bow and arrow, (291)

I killed Cock Robin.'" (258)

The next is from R. H. Stetson:-

XVII. "I saw a ship a sailing (313),

A sailing on the sea (233),

And it was full of pretty things (244),

For baby and for me." (193)

- ("Rhythm and Rhyme," p. 463.)

If the eighth note be regarded as the standard of measurement, the Franz Schubert settings of "Hark, Hark! the Lark!" and of "Who is Sylvia?" show the following phrase lengths: - 
XVIII. "Hark, hark! the lark (6) at Heaven's gate sings, (6)

And Phœbus 'gins to rise, (12)

His steeds to water at those springs, (12)

On chalic'd flower's that lies, (11)

On chalic'd flow'rs that lies!" (9)

XIX. "Who is Sylvia, (12)

What is she, (12)

That all our swains commend her? (16)

Holy, fair (12), and wise is she; (14)

The heav'ns such grace did lend her (16)

That adored (12) she might be, (12)

That adored she might be." (28)

Still using the eighth note as the unit, Bruno Huhn's interpretation of "Invinctus" proves to be equally regular in its phrasal structure.

"Out of the night that covers me, (16)

Black as the pit from pole to pole, (14)

I thank whatever gods may be (16)

For my unconquerable soul." (16) 
The first three phrases of the Adagio sostenuto movement of "Opus 27, No. 2" ("Moonlight Sonata") by Beethoven, show sixteen, four, and sixteen units respectively. The first four phrases of the Allegretto movement give ten, four, four, and ten respectively. The first three of the Presto agitato are fifteen each.

"Opus 32, No. 1" ("Nocturne in B Major") by F. Chopin has seventeen units in its first phrase, seven in its second, eight in its third, and fifteen in its fourth.

Examples of this sort might be produced indefinitely; and it could easily be shown how in music the constant repetition of the same phrase-length is sometimes felt as the controlling time interval in the composition. Although phrase-lengths are very much more uniform in vocal music than in instrumental, because of the limitations set in the former by the breath, still it should never be thought for a moment that they are given anything even approaching the regularity assumed for them by the notation. The important point is that they are of sufficient regularity to be felt as uniform and to be regarded as temporal units.

It must always be borne in mind that we have no accurate means of judging temporal equality. Yet time-relations are of importance in verse, and the phrases of the movement cycle have certain duration relations which can be varied only within limits." "Any unusual irregularity, like a lag, is noted because of the sense of strain and becáuse other events supervene in the interval." 2 Pauses are essential to rhythm. It is only when they are so long that the feeling of continuity is interfered with that they become subversive of rhythm.

1 J. E. Wallace Wallin: "Experimental Studies of Rhythm and Time," Psycho. Rev., May, 1911, Vol. XVIII., pp. 211-212.

R. H. Stetson: "Rhythm and Rhyme," p. 463.

${ }^{2}$ R. H. Stetson: Ibid., p. 461. 
From the measurements I have presented, it would appear, then, (1) that duration of phrase-length is quite as variable as that of the syllable or the pause or as the timelength between accents; (2) that the tendency is from extreme irregularity of time-length for the phrases of ordinary prose toward greater regularity for verse and still greater regularity for certain types of music; and (3) that in and of themselves time-lengths between pauses are not of sufficient regularity to establish a feeling of periodicity or to differentiate prose from verse or verse from music.

Thomas R. Price evidently thought otherwise, when, in speaking of the phrase as a stave, he wrote:-

"The stave is a group of feet, from one to four in number, which can be pronounced together, without pause upon one breath, and be dominated by one accent. As such it is the definite unity of English verse-formation. The English stave can, indeed, if we choose, be analyzed into its separate feet, and broken into trochees and dactyls. But this breaking up of the stave into separate feet is something scholastic and artificial. The stave in its nature is indivisible, living and moving together, the unit of verse construction." 1

That the domination of the phrase by a single, principal accent "about which a number of subordinate accents are grouped is characteristic not only of poetry but of the simplest rhythms," both Meumann and Stetson ${ }^{2}$ agree. "At some point in the period there is a definite climax, a chief accent. This is strikingly seen in nonsense verse spoken with a heavy accent within the verse. The accent does not stand out from a dead level, but the verse culminates at that point." Both Scripture and Wallin noted

1 "The Construction and Types of Shakespeare's Verse as seen in 'Othello,"” p. 14, in "Papers of the New York Shakespeare Society," 1888 (Trübner and Co., London; Brentano and Bro., New York).

2 "Rhythm and Rhyme," p. 456. 
THE PHRASE: ITS NATURE AND ITS LENGTH 159

the dominant character of one or more centroids in each breath group. From this opinion I do not wish to dissent; yet I can not think with Dr. Price that the stave is "the unit of verse construction," although we are in entire accord as to its indivisibility and as to its movement as a whole. The phrase is another of those all-important factors in the building up of verse; still, when unattended by other equally important factors, it of itself is insufficient to characterize verse. 


\section{CHAPTER XIII}

RHYME AND THE LINE: THEIR RELATION TO THE PHRASE

WHAT is rhyme? How nearly periodic in character is it? Can it be regarded as differentiating prose from verse or verse from music?

Rhyme is correspondence of tone-color in any two or more sounds when sufficiently close to each other for the correspondence to be immediately perceived. This correspondence may be of three kinds. The first type, which is constituted by the correspondence of consonants at the beginning of syllables, is known as alliteration. ${ }^{1}$ In Old English, words beginning with vowels were regarded as alliterative, because the initial vowel was invariably preceded by rough breathing just as if the letter had been written in front of the vowel. The second type of rhyme, called assonance, consists in correspondence of tone-color of the accented vowel in two or more words when the sounds preceding and following the accented vowel are not noticeably alike. It is common in Spanish verse; but it has never found favor in English, though several poets have attempted to use it as a substitute for the particular type of rhyme which has been most popular since alliterative verse lost its vogue. This third type of rhyme is commonly spoken of as rhyme, and under this name is regarded as distinguished from both alliteration and assonance. It

1 Fred Newton Scott's article on "Vowel Alliteration in Modern Poetry" (Modern Language Notes, Dec., 1915, Vol. XXX., pp. 233-237) is interesting in more than one particular. 
is in this accepted meaning of the word that I shall use it hereafter. Rhyme, then, is correspondence in tone-color of the final accented vowel and of all the following sounds in one word to the final accented vowel and all the following sounds in one or more other words, when the sound immediately preceding the accented vowel is not the same in any two words. Where the consonant preceding the accented vowel is the same, the rhyme is called identical. Identical rhyme is much sought after in French; but English eschews it, although admitting as a makeshift another form of rhyme which to my ear is even more objectionable than this. The number of rhyming words in English are for some combinations comparatively few. Therefore, words that in print look as if they ought to rhyme are sometimes substituted for pure rhymes. These rhymes are called eye rhymes. In eye rhyme the accented vowel in the rhyming words is not of exactly the same tone-color, - as blood and good.

Although in Anglo-Saxon verse alliteration is a conspicuous element and appears with a regularity which shows it to have been governed by definite rules, its presence or its absence does not differentiate Anglo-Saxon verse from Anglo-Saxon prose; neither is it today a distinguishing element in either our verse or our prose, though it is to be found in both. At no time has it ever occurred with sufficient regularity to establish a feeling of periodicity, though whenever it has appeared it has always aided toward that end. Coming at the beginning of the word, it helps in making the accented syllable more conspicuous; and that is all it does do, if the pleasure derived from the fulfillment of the Law of the Return be for the moment over looked.

Rhyme does not occur in prose except accidentally. Assonance does; yet, having no definite function to 
perform, its presence there is entirely purposeless. In verse, as has been noted already, assonance is sometimes used as a substitute for rhyme. It can, therefore, be considered along with rhyme; and I need make no further mention of it as distinct therefrom.

It is unnecessary to say that rhyme is not an essential of verse. The existence of a large body of unrhymed verse is proof positive of this fact. When rhyme does appear, however, it is invariably found either at the end of the phrase or where the phrase would normally be expected to end. In this position the repetition of tone-color which it furnishes "at once attracts attention and tends to become a structural element because of its vividness in the total effect." By furnishing a well-defined refrain and by binding the phrases together in groups or pairs, it enters into the rhythmic structure. Further, it makes the pause more flexible and aids in producing a feeling of continuous flow. By correlating phrases it builds stanza units and makes possible the control of the larger structural movements. Both accent and expressional changes are forced by it to conform to a stricter type than is otherwise attainable. ${ }^{1}$ In those instances in which rhyme does not occur at the end of the phrase, its presence is more or less obscured. In fact, I can recall poem after poem by Robert Browning which might as well have omitted the rhyme altogether as far as its being heard is concerned. In music rhyme is not of value unless the rhyming syllables are sung upon the same pitch. R. H. Stetson, too, has felt the uselessness of rhyme in words to be set to music, and, after having conducted a series of experiments to aid him in clarifying his judgment, has expressed himself quite pertinently to this effect:- 
"Definite pitch relations in music seem to make rhyme of little significance. We seldom notice the rhymes in a hymn or in a song of any musical worth. In comic operas and popular ditties rhyme does now and then figure. In such cases the pitch of the two or more rhyming syllables is identical; often the whole phrase is repeated for each rhyming verse. A few experiments in singing a rhyme to simple intervals show that when the identical interval is used the two syllables rhyme well, but if the interval be in the opposite direction, or in another chord, the rhyme is very uncertain. It seems that in music we usually have 'feelings of expectation' (i.e., tension of some sort, central or peripheral), which are adequate to unite the phrases into larger unities." 1

Since rhyme, then, to be of value must occur at the end of the phrase in verse, the question as to its periodicity is answered by an examination of the time-length of the phrase.

It should be remembered that phrasing, although necessitated by the impossibility of speaking continuously, has but one object in view, - the grouping together of words that logically belong together. If, therefore, any other phenomenon can perform the same function as the pause, that phenomenon may sometimes either obviate the appearance of the pause or shorten it. Accordingly we find exactly this taking place in those forms of verse in which rhyme is present. Here again the experiments of Stetson are productive of important results, which he summarizes as follows:--

"There are wide, isolated variations as in the case of unrhymed material. As compared with unrhymed verse, the pause is generally decidedly shorter. The verse pauses of the feminine rhymes are generally much like those of the rhymed material. But there are very few cases of the verse pause being as short as the foot pause - only four cases in sixty (6.6 per cent.).

1 “Rhythm and Rhyme," p. 431. 


\section{THE FOUNDATIONS AND NATURE OF VERSE}

"The wide variation of the verse pause and its occasional equivalence of the foot pause in rhymed verses is in accord with the notion that the rhyme in some way brings the verse to a close by a process more rapid than that in unrhymed material." 1

We have already seen the time lengths between the pharsalpauses, which are here identical with the verse-pauses, to be widely variable when judged by any small unit such as a thirtieth or a fortieth of a second. Hence, I believe I am not overstepping the mark in saying that, as in the case of the phrase, the occurrence of rhyme alone is not sufficiently periodic in character to establish a rhythm. Like alliteration, rhyme is certainly a decided aid to accent. It occurs only in accented syllables; and, wherever it falls, the accent is made more conspicuous. ${ }^{2}$ Therefore, because of its appearance as an adjunct to accent, and because it usually either precedes a pause or is itself accepted in lieu of a pause, it furnishes a very salient feature upon which to centre the attention; but, I repeat, it is in no wise essential to verse. In fact, when it becomes too conspicuous, it may even cause so decided a jingle as to make its presence more of a blemish than an ornament.

While I am piling up negative evidence, although its consideration at this point involves somewhat of a reversal of the method of procedure I have been following, I can not leave the discussion of the larger units of verse without

1 R. H. Stetson: "Rhythm and Rhyme," p. 449.

2 Ibid., pp. 449-453.

Consult the following authorities as to the relation of tone quality to rhythm: -

Squire: "Genetic Study of Rhythm," American Journal of Psychology, XII., 1901, p. 558.

Macdougall: Psychological Review Monographs Supplement, IV., 1903, Harvard Psychological Studies, I., p. 317.

Woodrow: "Rôle of Pitch in Rhythm," note at the bottom of page 62 . 
attacking the problem of the line as an essential factor in verse structure. Not a few prosodists, believing the foot to be common to both verse and prose, have claimed that the essential difference between the two forms lies in the employment by verse of feet in such a manner as to form lines. Professor Charles M. Gayley expresses it thus: "Metre, or measure, as the word signifies, marks off the current of rhythm into artificial divisions, each of which is a line or verse. Metre regulates the number of feet in verse; and with the end of one verse or 'turn' the rhythm begins another." 1 Leaving, for the time being, the question of the foot out of consideration, it devolves upon me to show, therefore, that the writing of verse in lines is a perfectly arbitrary matter and that verse is essentially verse whether it be written in lines of a determined length or written continuously just as in the case of prose.

In the first place, the oldest Anglo-Saxon monuments disclose no difference between the forms of writing for prose and the form of writing for verse; yet I do not see how one could fail before reading very far to perceive that there is a difference between the verse and the prose. In order to make this difference more readily apparent to the eye, and thus to aid in the reading of verse as verse in contradistinction to prose, later manuscripts show a breaking up of the continuous flow of the earlier lines into shorter lines at the end of each of which a pause normally occurs. In the middle of each of these lines a pause of less duration than the pause at the end of the line is found. The two hemistiches might just as well have been written, as sometimes they were, on separate lines, except that, on account of their being linked by alliteration, they are read with

1 Gayley and Young: "English Poetry: Its Principles and Progress," p. liv. (Macmillan, 1908). 
greater ease when written on the same line. Writing them thus is merely a convention adopted for greater convenience. Yet, after all, it is nothing more than a convention, not an essential.

Many a time have I written out as prose some of the very finest passages from Shakespeare, and then asked my friends to arrange the verse into lines. Even after I had explained to them that the verse was iambic pentameter, very seldom were they able to put into each line the same words as written there by the standard editions. Of course, I had to be careful to select passages that did not begin with the first foot of the line. In hearing blank verse that is not end-stopped, I do not believe that any one is able to determine by ear alone where the lines begin or where they end. I certainly can not do it; and I think that rightfully I may lay claim to a more tolerable ear than is necessary for the appreciation of the tong and bones.

Poets themselves are at times decidedly doubtful as to what linear arrangement they should give to their poems. Practically every editor of old manuscript sooner or later has to face the problem as to which of two or more forms he should present to the public when the poet has been so careless as to leave several metrical arrangements of the same poem. Poe certainly sanctioned by publication two such writings of "Annabel Lee"; and I defy any one from hearing the two read to determine which is which.

Where the pause falls in the middle of the line and again at the end of the line, the poem may be written just as conveniently in two lines as in one. The fact that either the pause or the rhyme comes so frequently at the end of the line causes the line to be looked upon as the unit. This, it seems to me, is largely responsible for the misconception which has arisen. But the line itself is not the unit. The unit is to be found in the phrase, of which either the pause 
or the rhyme marks the end, and for the more ready perception of which by the reader the division into lines takes place. To the hearer and to the one reciting from memory the lines are nonexistent. It is easy enough for an inartistic reader so to read verse as to give it the sound of prose; and writing it in lines will not alter the matter. Of course, I do not pretend to say that seeing a passage written in lines does not indicate to the person about to interpret it that he has before him a piece of verse and that he should, therefore, read it as verse and not as prose. However, if the capacity for being read as verse did not rest in the words themselves, no possible method of writing them could enable the reader to make verse of them. Where the phrase and the line end together, the line is an aid to the reader; where the phrase ends within the line or overlaps from line to line, the arrangement of the words in lines of a set length is purely arbitrary; and more often than not by confusing the reader it actually destroys for him the very feeling of rhythmical unity which it is supposed to necessitate. Prose, verse, and music are continuous in their flow. All such devices as writing them in lines and supplying them with various marks of punctuation are entirely aside from their structure. These are guide-posts and nothing more; and they are of value only as they assist the reader in his effort to make a logical grouping of his words. In verse the logical group is also the rhythmical group, whether the grouping is indicated by any form of punctuation or not. 


\section{CHAPTER XIV}

THE STRUCTURE OF THE FOOT: ACCENT, DURATION, AND PITCH IN THE GENERAL PROCESS OF TIME SYNTHESIS

There yet remains to be considered a final point of the greatest possible weight in leading to a clarified view of the nature of verse. Until now I have raised no question as to the structure of the foot, or bar, or measure; and I have spoken of iamb and trochee and the other feet quite after the orthodox fashion and without once taking the trouble to define the meaning of these terms. Even now I shall not undertake to present the views of the prosodists. Instead I must turn again to the psychologists and in interpreting the data afforded by their experiments try to construct a theory more in accordance with fact than any hitherto propounded. In this last act of demolition I am at the same time beginning to build anew.

Dr. Herbert Woodrow in presenting to his subjects rhythmical stimuli used an alternation of two sounds of equal intensity but of unequal, though constant length, of which the duration of the longer sound was .09 second, of the shorter .06. "The total number of series of minimal changes used in this investigation," says he," "was about 24,000 . The indifference point in this series is taken as the point at which the interval after the longer sound is .53 second." In the following table after means the dura-

1 "A Quantitative Study of Rhythm," pp. 27-28. 
tion of the interval after the longer sound; before, the duration of the interval before the longer sound. Both are expressed in seconds.

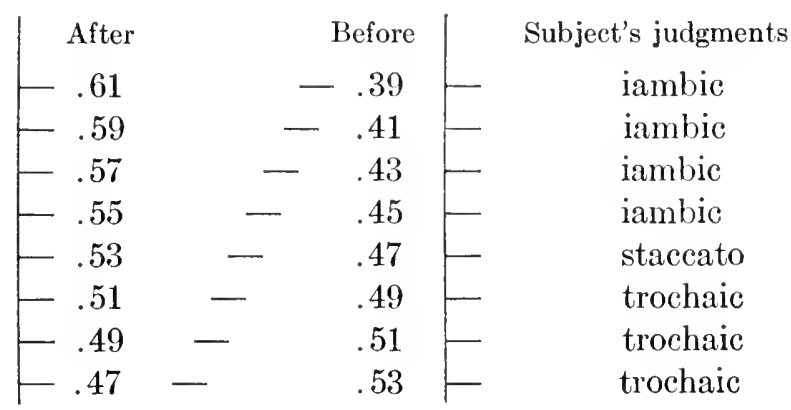

It is to be observed that he began with a rhythm in which the shorter sound was distinctly felt to be grouped with the longer sound which followed it, - that is, it was felt as an iambic rhythm. By gradually changing the time intervals between the longer and the shorter sounds, he reached a point at which no grouping at all seemed to take place. This indifference point once having been passed, however, the order of grouping became reversed and the shorter time length now appeared to be grouped with the longer length preceding it instead of with the one following, - that is, the rhythm became trochaic. At the indifference point a very slight change in one direction or the other reversed the order of the grouping.

The next experiment involved a series of alternate loud and soft sounds, each 0.13 second in duration, and the duration of the time interval from the beginning of one loud sound to the beginning of the following loud sound 1.5 second. The loud sound was audible to the distance of 136 feet, the soft to 24 . This time the objective stimuli were given in irregular order. 
Intervals before and after

the louder sound, in sceonds. Subject's judgments (per cent)

$\begin{array}{ccrcrc}\text { Before } & \text { After } & \text { Trochaic } & \text { Doubtful } & \text { Iambic } & \mathrm{N} \\ .66 & .57 & 100.0 & 0.0 & 0.0 & 26 \\ .62 & .62 & 85.7 & 14.3 & 0.0 & 42 \\ .59 & .64 & 71.4 & 28.6 & 0.0 & 56 \\ .57 & .66 & 31.3 & 59.4 & 9.3 & 64 \\ .55 & .68 & 0.0 & 16.0 & 84.0 & 50 \\ .53 & .70 & 0.0 & 5.5 & 94.5 & 54 \\ .49 & .74 & 0.0 & 0.0 & 100.0 & 36\end{array}$

The rhythm indifference point lies very close to the figures I have written in italies.

"It will be observed," says Woodrow, " ". . that a change by one step from this point is sufficient to make the judgment in over 70 per cent. of the cases either iambic or trochaic depending upon the direction of the change. Moreover, in this case, as in others with the same and other subjects, the results obtained by this method (constant stimuli) agree very closely with those obtained by the method of minimal changes."

In further experiments in which the duration of all the sounds was kept constant and equal, in which the timeinterval from louder sound to louder sound remained unchanged, and in which all the louder sounds were of the same intensity and all the shorter of the same intensity, it was obvious that "the effect of accent is to cause the accented sound to appear to be grouped with the following weaker sound ..., and that the rhythm becomes more and more trochaic as the ratio between the intensities of the louder and weaker sounds increases. It is further obvious that the trochaism of the series increases at first very rapidly and later very slowly relative to the increase in distance 1 “A Quantitative Study of Rhythm," p. 28. 
to which the louder sound is just audible, the weaker remaining constant. . . All subjects frequently remarked on the greater apparent duration of the louder sound. The difference both in loudness and duration seemed greater when the rhythm was pronounced than when near the indifference point." 1

Writing on "The Rôle of Pitch in Rhythm," 2 Dr. Woodrow reiterates this opinion with but slight alteration:-

"I have often found that making every second sound longer and louder may bring about the perception of a very strong trochaic rhythm, one in which the longer and louder sound begins the group. ${ }^{3}$ The result that will be obtained depends upon the direction and magnitude of the effect produced by the particular intensity and duration used, when each is acting alone. This, in turn, depends upon a large number of factors, including both the absolute and relative duration of the sounds composing the rhythmical series." - (p. 55-56.)

"Squire found that when she presented an exceedingly evenspaced series of sounds of equal intensity and duration, in which every second or every third was of a different pitch from the others, that the subjects, though only seven in number, fell into three classes, - those who accented the high tones, those who accented the low, and those to whom highness and lowness were a matter of indifference. ${ }^{4}$ Squire concludes from her experiments that pitch has a great effectiveness as a determinant of rhythm." 5 Yet Woodrow considers that "pitch cannot in the case of a single subject be a reliable or constant determinant of rhythm." 6

In no form of art with which I am acquainted is there the slightest thought of making pitch a determinant of

1 “A Quantitative Study of Rhythm," pp. 32-33.

2 Psychological Review, Jan., 1911, Vol. XVIII., No. 1, 54.

3 See Archives of Psychology, XIV., 1909, Table VI., p. 36.

${ }^{4}$ American Journal of Psychology, XII., 1901, p. 556.

5 Ibid., pp. 549-558.

6 Woodrow: "The Rôle of Pitch in Rhythm," p. 59. 


\section{THE FOUNDATIONS AND NATURE OF VERSE}

rhythm. In music pitch may sometimes be one in many concomitant factors assisting in the establishment of a rhythm; but Shaw and Wrinch ${ }^{1}$ are right in saying that the length of a time-interval is unaffected by pitch; and Sears, ${ }^{2}$ too, quite correctly affirms that the pitch of the tones has "no effect on the relative length given to intervals by the performing musician." Yet I think that Dr. Woodrow is pressing the matter much too far when he declares:

"Pitch, intensity, and duration can no longer be looked upon as stellvertretende factors, any one of which may be substituted for either of the other two. The rôle of each in rhythm is radically different. Intensity has a group-beginning effect: duration, a group-cnding effect: pitch, neither a group-ending nor a groupbeginning effect." 3

In a language in which the centroids are at all times made up of intensity, duration, pitch, and tone-color, and in which first one type of centroid and then another is used without the least regard to the preëminence of any particular type, it seems to me, that, granting the opposite grouping effects attributable to intensity and to duration, and the purely negative effect attributable to pitch, the several types of centroids are still interchangeable, and that once a particular form of grouping has been established, it will persist even though an entirely different type of centroid should appear with a moderate degree of frequency. Upon reflecting, that the centroid is predominantly a matter of intensity; that, where intensity is the determining factor of grouping, the more intense sound tends to begin the group; and, that, although agreeableness is not a conditional test for rhythm, a trochaic type

1 University of Toronto Studies, Psychological Scries, 1899.

2 American Journal of Psychology, 1902, p. 33.

3 Woodrow: "The Rôle of Pitch in Rhythm," p. 77. 
of rhythm "gives greater satisfaction than an iambic," 1 I am more and more firmly convinced of the interchangeableness of the types of centroids, especially as I believe rhythm to be less a matter of judgment than a feeling due to an active functioning of the physiological or neural substrate. The case seems to me to be all the stronger for Gilver's observation that the stress of the accented syllable of the iambus brings into greater prominence the sounds meant to be stressed than does the trochee. ${ }^{2}$ He found exactly the same to hold true for groups of three sounds under conditions of experimentation similar to those employed for groups of two, so that what has been affirmed of the iambic-trochaic movement is equally true of the anapæstic-dactylic.

"The prolongation of the foot pause makes of the dactyl a modified trochee. The amphibrach laid out on this scheme would coincide with the dactyl, as there are but three possible zones for foot elements: the zone of the limiting sensation (always occupied by the accented syllable), the zone of the contraction phase (occupied by the unaccented syllables of the iamb and anapæst), and the zone of the relaxation phase (occupied by the unaccented syllable of the trochee and the middle syllable of the dactyl)." 3

In the next series of experiments "the absolute duration of the measure and of all its parts, intervals and sounds, was varied, while all relative durations were kept constant," as, too, were kept the intensities of the sounds. Where every second sound is the louder, "the subjects perceived the sounds in groups of two except for the measures whose

1 Wallin: "Experimental Studies of Rhythm and Time," pp. 9-15.

2 Gilver: "The Psycho-physiological Effects of the Elements of Speech in Relation to Poetry," Psychological Monographs of Harvard University, Vol. XIX., No. 2, April, 1915, p. 7 (Psychological Review Co., Lancaster, Pa.).

${ }^{3}$ R. H. Stetson: "Rhythm and Rhyme," p. 461. 
total duration is . . . .75 or .5 second. At these last-mentioned rates, the sounds were grouped by four so that as a matter of fact at these two rates the total duration of the groups was twice that indicated ... as the duration of the measure." I The conclusions which may be drawn from these experiments on the rates at which rhythms are presented to consciousness Woodrow summarizes as follows:-

"Within certain limits the degree of temporal segregation presented by the groups remains very nearly constant. With slower rates the rhythm entirely or almost entirely disappears. The limits within which the degree of temporal segregation remains relatively constant vary with individuals and with the nature of the objective series. . . . From a rate of 1.0 second for one measure up to a rate of between 4.0 and 7.0 seconds for one measure, the degree of rhythm remains about constant. . . There is some indication, however, that with rates faster than 1.0 second for one measure there is a marked increase in the amount of temporal segregation presented by the rhythm. . . Inasmuch as subjective rhythm comes in very markedly at rates of about 1 second for two beats or faster, the increase above noted in the rhythmical effect for the faster rates can hardly be regarded as the effect of an increase in rate on the rhythmical effect of intensity or duration. It seems rather that we have in the case of these rates a subjective factor which is more or less independent of any differences which may prevail in the intensity or duration of the sounds composing the series, since at these rates grouping occurs when all the sounds are equal both in intensity and duration." 2

Wallin gives an interesting tabulation of the rates which Viderot, Wundt, Stevens, Johnson, Meumann, and Bolton consider as most favorable for rhythmizing a series. ${ }^{3}$ Need-

1 "A Quantitative Study of Rhythm," p. 34.

2 Woodrow: "A Quantitative Study of Rhythm," pp. 36-37.

Consult also Meumann (Phil. Stud., X., p. 302, 1894) and Shaw and Wrinch (p. 19).

${ }^{3}$ Wallin: "Experimental Studies of Rhythm and Time," Psycho. Review, May, 1911, XVIII., No. 3, pp. 211-212. 
less to say they are all different. "Persons who chiefly enjoy the melody and harmony in music will favor medium or slow tempos," says Wallin, "and those who prefer the rhythm will select fast tempos." I can agree with him still further in saying: "The fact that fast and slow rates are found in all grades indicates that the preference, or the vigor of the response, is not dependent entirely upon the tempo. The catchiness and familiarity of the music, the distinctness or incisiveness of the accent, and the character of the measure are also important factors." 2 Those who have observed the satisfaction with which a good reader lingers over the words of some beautiful passage in comparison with the energetic jingle which children give to "Mother Goose" will appreciate the appositeness in respect to verse of these remarks on the tempos of music.

After other experiments equally as painstaking as those already cited, Dr. Woodrow makes several generalizations which seem to me both accurate and pertinent. Let me quote them:

"The strongest trochaic which it is possible to produce by duration changes alone, therefore, is produced when the longer sound is longer, but only very slightly so, than the shorter sound. It may be that the trochaic rhythm of the smaller ratios was due chiefly to the difference in apparent loudness between the longer and the shorter sounds." 3

"The effect of intensity is to make the longer sound begin the measure, an effect which may be spoken of as trochaic, whereas the effect of duration, as such, is to make the longer sound end the measure, which usually means an iambic effect." 4

1 Ibid., p. 216.

2 Ibid., p. 212.

3 Woodrow: "A Quantitative Study of Rhythm," p. 46.

See also Hurst and McKay (p. 70) and R. H. Stetson (p. 443).

4 Ibid., p. 46. 


\section{THE FOUNDATIONS AND NATURE OF VERSE}

"The longer sound should naturally appear the louder, as we might say, for sensory reasons, apart from more complicated or more central processes. . . When the longer sound appears the louder, there is no necessity for considering this as due to greater attention directed to the longer. On the contrary, the shorter might be reciving the greater amount of attention and yet not appear as loud as the longer, the physiological or sensory effect exerted 'by duration on intensity being able to swamp the slight effect of the central process on intensity, in case the two processes work in opposition." 1

"There is some ground . . . for the conclusion that usually the intervals which are most important in deciding what will be the nature of the rhythmical impression are the intervals between the end of one sound and the beginning of the following. But, in the case of Ws, there is no doubt that the rhythm was more closely allied to the process of comparing the intervals between the beginnings of the sounds than to that of the comparison of the actual silent intervals." 2

Stetson thinks that the function of stimuli during the movement cycle varies with the position of the stimulus in that cycle, and that this offers a possible explanation of the striking peculiarities of the unit groups.

"The iamb $(\cup$,$) and the trochee (\lrcorner \cup)$ should be quite alike for a general synthesizing process; but not only is the experimental character of the two entirely unlike, but the ratio between their intervals is entirely different." 3

1 Woodrow: “A Quantitative Study of Rhythm," p. 41.

For further confirmation of this point consult: -

Meyer: "Beiträge zur deutschen Metrik," Neuere Sprachen, 1898, VI., pp. 136-138.

Bolton: "Rhythm," American Journal of Psychology, 1893, VI., p. 222 .

Meumann: "Untersuchungen zur Psychologie und Aesthetik des Rhythmus," Philosophische Studien, 1894, X., p. 303.

2 "A Quantitative Study of Rhythm," p. 51.

${ }^{3}$ R. H. Stetson: "Rhythm and Rhyme," pp. 460-461. 
To this he adds:

"It is interesting to note that the unaccented element of the trochee comes at the earlier part of the relaxation phase, where it must intensify the relaxation process, and tend to shorten the total length of the cycle. This may be the reason for its peculiar buoyant, vigorous, and non-final character. On the other hand, the unaccented element of the iamb occurs at a point where it may initiate and intensify the contraction, which gives the limiting sensation; it is, therefore, more closely bound to the limiting sensation and has the character of intensifying the beat." 1

Still other investigators, using different methods and not at all concerned about determining the difference between iamb and trochee or anapæst and dactyl, have noted the tendency of the one to pass into the other and the apparent interchangeability of the two. ${ }^{2}$ Says Wallin:

"There is no physical distinction between the several types of the different modes of distribution. There may be a mental, or felt, difference between the iambus and the trochee, and the anapaest and the dactyl; but physical measurements of them always extend from centroid to centroid, independently of type differences. The modes of distribution are, upon the whole, the same in prose and poetry." ${ }^{3}$

Every one in the least familiar with the structure of verse has met with innumerable instances of iambuses occurring in the midst of trochees and vice versa; and any one who knows the least thing about the English dactyl is sadly conscious of its inability to sustain itself, - so much so that some prosodists have denied the existence of the dactyl in English verse. When to this is added the

1 R. H. Stetson: "Rhythm and Rhyme," p. 461.

2 Shaw and Wrinch, p. 53; R. C. Gilver, p. 13; R. H. Stetson, p. 440.

3 J. E. Wallace Wallin: "Researches on the Rhythm of Speech," p. 113 . 


\section{THE FOUNDATIONS AND NATURE OF VERSE}

testimony of the psychologists from whom I have quoted thus freely, I can not believe that there is any essential difference between the various kinds of feet. As I have taken occasion to remark once before, these units are not like chips of mosaic that can be brought together to form a tone picture. Unless they were intimately and vitally related to each other upon some general principle of greater cohesiveness than mere chance juxtaposition, verse would be without form and void; and its parts would fall asunder as speedily as a mosaic when the matrix is broken. Although I am painfully aware, that, in attempting to bring to light the reason why there is in verse this capacity for equivalence, substitution, and juxtaposition which many eminent prosodists believe to exist in what they consider to be the verse unit, I am courting the scorn of no less a person than Professor George Saintsbury, ${ }^{1}$ nevertheless, the thanklessness of my task must not deter me from seeking still further for some principle which will not only untie the hard knot of confusion in the thought of the metrists, but will also present to them a tangible theory by means of which to approach the study of the structure of verse. From the mass of negative information which thus far I have presented, I must now deduce certain positive and fundamental facts before I am again prepared to return to a consideration of the foot. Hoping that I have made manifest what do not constitute the essential, differentiating qualities of verse, I turn to those facts in which I believe the broader and cleeper truths to lie.

It is a matter of common experience that judgments of time are about as uncertain as judgments upon any subject could well be. ${ }^{2}$ If we are highly entertained, the hours

1 George Saintsbury: "History of English Prosody," Vol. III., pp. 522-523 (Macmillan and Co., 1910).

2 V. Benussi: "Psychologie der Zeitauffassung," p. 505. 
pass very rapidly. There are some moments which seem an eternity. A period of time during which nothing happens may appear to be infinitely longer than the same period filled to the brim. Even when the attention is entirely centered upon the measuring of time, except within very narrow limits accuracy is about the last thing to be expected. Says Wallin:

"The perception of time and rhythm are closely related processes, ${ }^{1}$ but they are not identical, even in the elemental perception of time differences. A temporal grouping is obviously involved in rhythmical grouping, but the temporal grouping due to grouping by segregation, - i.e., by increasing the value of the preceding interval - is secondary. The primary and perhaps the only essential conscious datum in the experience of the rhythmizing subject is the fairly regular alternation of intensity differences (centroids)" 2

"Time differences can be appreciated relatively better than rhythm differences in short series. To secure the rhythmical swing requires a longer repetition of beats; and until a felt rhythmical swing is obtained the discrimination of grades of rhythm is not maximally effective." 3

With the second of these quotations Dr. Warner Brown would agree, I believe; but to the first he would most assuredly take exception. It will be wiser to give a few quotations from him before I comment upon either attitude.

"A rhythm is temporal in so far as there is any return of similar features. But at the same time such a rhythm will also be accentual since there must always be points of emphasis whose return can be marked." 4

' See, too, Woodrow: "A Quantitative Study of Rhythm," p. 50.

2 "Experimental Studies of Rhythm and Time," Psychological Review, March, 1911, XVIII., No. 2, p. 117.

3 Wallin: Psychological Review, March, 1911, XVIII., No. 2, p. 118.

4 Brown: Psychological Review, XVIII., No. 5, 344. 
"If the movements or sounds vary in intensity more than in duration or more than the interval separating them, I submit that rhythm is primarily temporal." 1

"It is in the temporal structure and not in the accentual strueture that we find the greater regularity. If the fundamental regularity does reside in the arrangement of the parts within the units rather than in the recurrenee of the units, it is still to be sought in the arrangement of the parts in time. In any event the predominant regularity on either level is a temporal regularity." 2

For my part, I doubt exceedingly that it is possible to determine whether the greater regularity resides in the interval between centroids or in the temporal relationships borne by the centroid syllables to the non-centroid. I believe further that subjects vary greatly in their feeling upon this point. I am quite sure that many do experience verse rhythm as "the alternation of intensity differences," while others feel the greater regularity to be in the syllable lengths. Usually I feel temporal regularity in both the recurring centroids and the syllable lengths; yet it is simply impossible for me to say which is the predominant element, or whether intensity or duration is the more variable. Both are factors in my consciousness of rhythm; but, in hearing verse as in producing it, I am totally unable to make an analysis of these component factors. It seems to me that the attempt to discriminate in such instances partakes of the nature of hairsplitting. It is essential that we recognize what factors are involved; but I can not see that it makes any difference as to the degree of preponderance, especially as sometimes one, sometimes the other is uppermost. To this extent I believe Wallin to be unquestionably light:

1 Brown: Psychological Review XVIII, No. 5, p. 344.

2 Brown: Psychological Review, XVIII., No. 5, p. 345. 
"Absolute periodic or regular occurrences are not essential to the appreciation of rhythm, although absolute regularity improves the quality of the rhythmic impression. To engender a feeling of rhythm always requires a certain amount of periodicity; but the margin of irregularity is quite considerable." 1

In fact, the impression of rhythm is part and parcel of the experience of time. In prose, verse, and music it is always necessary to perceive simultaneously and immediately at least three periodicities, in which the judging of each aids in the judging of the others. Along with time-lengths of sound and of silence, time-lengths between centroids, and time-lengths of phrases go tone qualities and pitches that are in themselves absorbing. All these combined have a meaning, a thought content, which in prose, verse, and vocal music is sometimes so overmastering as to obscure almost every detail of form. Even pure music induces moods and thoughts that divert the attention to such an extent, that, though the rhythmic groups are still immediately perceived, they are crowded out of the forefront of consciousness and the actual relationship of the sounds more or less obliterated.

With this in mind let us turn once more to some of the measurements made by Wallin. ${ }^{2}$ The figures above the syllables give their time-lengths, those below the dashes the values of the silences. In the first and the second illustrations the unit of measurement is $1 / 40$ of a second; in the third and the fourth, $1 / 48$.

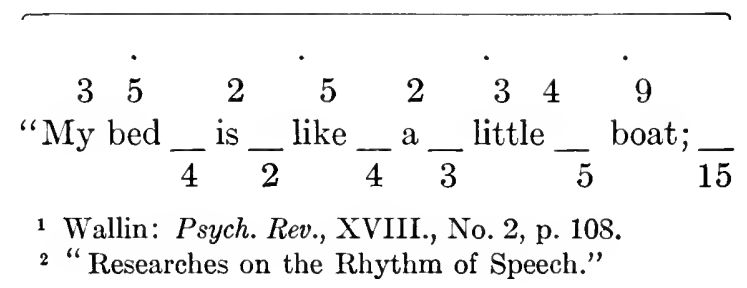


182 THE FOUNDATIONS AND NATURE OF VERSE

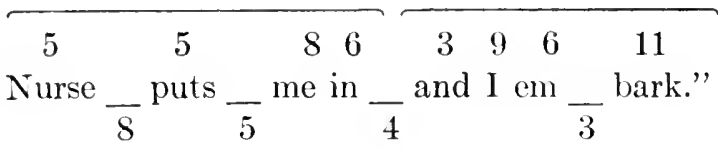

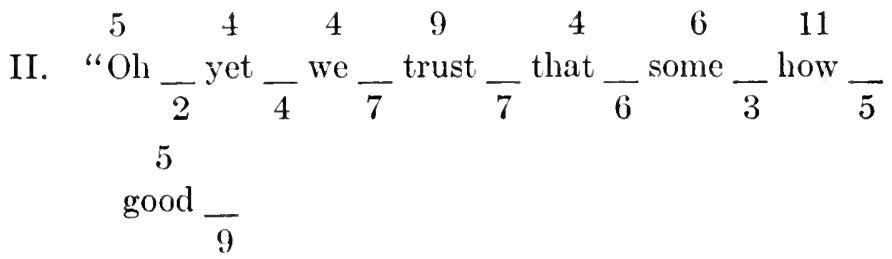

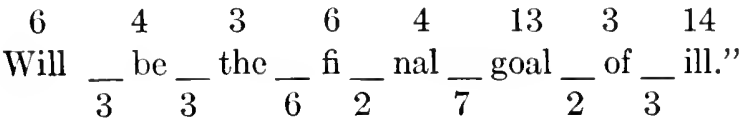

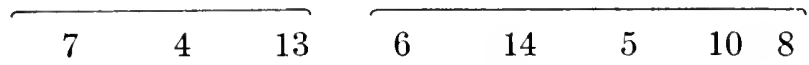

III. "Take $\frac{1}{4}$ the $\frac{3}{3}$ joys $\frac{16}{16}$ and $\frac{\text { bear }}{5}$ the $\frac{\text { borrows. }}{3}$ sow

$\begin{array}{lllllll}3 & 7 & 11 & 6 & 6 & 4 & 7\end{array}$

Shut $\frac{5}{5}$ those $\frac{6}{6}$ eyes, $\frac{\text { next }}{14}$ life $\frac{{ }_{6}}{6}$ will ${ }_{?}$ open."

- (p. 26.)

$\begin{array}{llllllll}7 & 8 & 4 & 10 & 6 & 10 & 5 & 8\end{array}$

IV. "And so $\frac{-}{5}{ }^{\text {no }} \frac{\text { force, } \frac{7}{7}}{\text { how }}{ }^{\text {ev }}{ }_{7}$ er_great, -

$\begin{array}{llllllll}4 & 11 & 4 & 11 & 4 & 8 & 3 & 13\end{array}$

Can strain - a cord, - how ev - er - fine."

$\begin{array}{llll}6 & 7 & 4 & 7\end{array}$ 
I have already called attention to the fact that the silences between the syllables were too brief to be audible when the lines were spoken, and that they could be made audible only by so slowing down the revolutions of the dise to such a degree that the words could hardly be heard as articulate sounds. When spoken, except at the end of phrases, no gaps were heard between the sounds. The syllable and the silence which follows it were heard as a continuous sound. It is to be observed, that, in the first selection, for instance, except for the pause at the end of the phrase, no silence is longer than $8 / 40$ of a second. In the third selection the longest is $7 / 48$ of a second. Now, it is easily seen that not many of the sounds are longer than a fifth of a second, and that most of them fall far below this fraction. When sound and silence are counted together, the lengths of the centroid syllables in the first line of the first selection are only $9 / 40,9 / 40,3 / 40,9 / 40$. The difference of $6 / 40$ of a second could hardly be apparent even if numerous distracting influences were not at work to claim the attention and confuse the judgment. Of course, we do recognize that some syllables are longer than others; but how much longer, we are totally incapable of saying. In music, too, we feel that a quarter note is longer than an eighth note; but, unless our attention is called especially to it, we quite overlook the fact that all the quarter notes in a bar are not receiving the same time-value. Even then some people refuse to admit the truth of the matter. Having gotten the idea that all quarter notes are of equal value, they insist that, if in a particular instance two quarter notes are not given the same length, they ought to be. They forget that such an absolute regularity as they demand would weary the listener and thus make impossible an art of any kind. Only the child mind can take delight in exact repetitions; and we know how quickly the child 


\section{THE FOUNDATIONS AND NATURE OF VERSE}

tires of whatever it is doing, and wanders from one thing to another. Art can aceomplish its ends only in so far as it is able to ereate impressions which ean be sustained suffieiently long to awaken a feeling of unity, wholeness, completeness. Absolute regularity of any kind, in becoming too great a strain upon both the producer and the hearer, negatives that without which art can not exist. Art must ereate an illusion of regularity at the same time that it eschews absolute regularity.

For the building of prose, verse, and voeal music the same material is available, - syllables and silences. What shall he done with this material is entirely dependent upon the different aims which the three forms of temporal art have in view. In prose the intention is not to secure regularity, but to escape from it. If, therefore, the same syllables are given us to be read, as prose we assume toward them a different attitude from that which we would assume if told that they are verse. In reading them as verse we deliberately seek to prolong the syllables and the silenees and to give them a regularity of oceurrence which we should not otherwise eare to attain. In verse and in musie we are desirous of produeing by means of speech sounds an impression of rhythm. Although not so flexible as the sounds of pure musie, still, syllables are relatively flexible, so that we are able to bend them to our uses. A reader with a high degree of interpretative ability will prolong or shorten them in such a way as to eause them to yield an impression of comparative regularity, while some one less brilliantly endowed might be unable to get from them even a semblance of rhythm. For this reason I am inelined to mistrust all readings which I do not myself hear. Nevertheless, because these partieular readings may be taken as representing about the same degree of regularity as would be given the lines when read by the 
ordinary man of artistic tastes, and because both they and others would pronounce their readings to be verse, and not prose, I am compelled to accept them as significant, to say the least. I believe they do establish the facts, (1) that the time-lengths of neither the syllables nor the pauses, when considered separately or in combination, are of sufficient regularity of themselves to arouse either an impression of periodicity or of rhythm, (2) that, in spite of this, when the attention is not occupied specifically with making these measurements the regularity is sufficient, however, to aid in the establishment of a general feeling of rhythm, provided there be furnished concomitantly other phenomena of sufficient periodicity of occurrence to strengthen the general feeling of rhythm toward which the time-length of syllables and of pauses is aiding. Even though the durations of two syllables may differ by as much as 6/40 of a second, or perhaps by even more, where one of the syllables receives a stress or a change of pitch or anything else that could give it prominence, this additional prominence is accepted as an equivalent for length: and the two syllables are considered, if not exactly equal, certainly as being of the same kind and of the same value.

As in the case of syllable-lengths, I have shower that for neither prose nor verse nor music is there, strictly speaking, equality of time-length between accents. It should not be forgotten that in these arts accent is never solely a question of greater amplitude of vibration of the sounding body, but should be thought of as having the nature of the centroid as described by Scripture and Wallin. When accent is regarded in this light, the measurements exhibited from page 128 through page 136 and from 146 through 156 . reveal certain salient facts. The accents of ordinary prose occur without regularity; those of oratorical prose with more regularity; those of verse with still greater regularity; 


\section{THE FOUNDATIONS AND NATURE OF VERSE}

and those of music with the most marked regularity of all. In verse and in music the ear seeks regularity of accent. Accordingly, the poet and the composer do their best to provide the interpreter with material from which a relative degree of periodicity ran be secured. But here again, as in time-length of syllables, many factors are entering to disturb the time-judgments, not the least of which factors in verse and in vocal music is thought-content. Consequently, greater irregularity is found in them than in pure musie, where the intellectual element is almost negligible.

For vocal music the word aceent is made subservient to the musical accent; but in prose and in verse word accent prevails. Racial speech habits are used by the poet to force the interpreter of his verse, in attempting to bring out the meaning of that verse, to place the acents just where they will be needed in establishing a periodicity. The presence of varying numbers of syllables and varying timelengths of these and of silences between the centroids interferes with aceurate judgment to such an extent that the recurrence of the accents is felt to be periodic, although the accents are actually separated from all attendant phenomena, and if the measurements are made in units of from a thirtieth to a forty-eighth of a second, they are seen to be departing from true periodicity by quite a wide range. Of the phenomena of verse, aceent is the most prominent. In both verse and music it furnishes for the ear the most convenient standard of measurement. So strongly does it become established in our feeling for rhythm, that, where it does not occur in the usual syllabie suceession, it is forcibly placed upon some syllable where it does not normally belong, ${ }^{1}$ or it is felt as occurring during a period of silence. Rhythm can exist without accent; but accent

1 R. H. Stetson: "Rhythm and Rhyme," p. 453. 
furnishes so excellent a means of making the rhythm pronounced that I have as yet been unable to find a single specimen of English verse in which the rhythm is not made apparent through the instrumentality of accent. Relative periodicity of accent is not the sole and controlling factor in verse any more than it is the sole factor in music; but it is, nevertheless, of the highest importance in that it is one of the means of marking off the time-intervals for which the sounds and the silences furnish the formal content.

Of equal value with accent as a means of marking timeunits is the pause. Just as the meaning of the words necessitates the giving of greater prominence to the important syllables than to the unimportant, so here, too, in order to make clearer the thought, syllables that logically belong together are grouped in one breath; and that grouping is made apparent by the pause which takes place at the close of each phrase. Phrases increase in regularity of timelength as one passes from prose to verse to music. In actual measurements by units of the values I have already cited, the phrase-lengths of verse cannot be said to be uniform; yet, when the comparatively great length of the phrase is taken into account, and when the distance that one phrase is sometimes separated from the phrase to which it corresponds is reckoned with, there is still less occasion for demanding absolute regularity than there was in the cases either of syllable-length or of time-length between accents. The pauses tend toward periodicity of occurrence; and for verse they are accepted as periodic. Their presence is another of the essentials of verse, although, unless regularity of syllable length and regularity of recurring accent were present to aid in the measurement of the interval between the pauses, regularity either of length or of recurrence in the pauses could not of itself differentiate prose from verse or verse from vocal music. 
Alliteration is a mere convention that may add to the tonal beauty of prose, verse, or music. In Anglo-Saxon verse it was a decided adjunet to accent; but in modern verse it may or may not serve the latter purpose. Rhyme, on the eontrary, though not an essential of verse, when it does oceur establishes a periodicity of tone-color exactly similar to the periodicity established by the pause. Rhyme does not mark the close of the line, as is erroneously supposed, but the close of the phrase; for the line itself becomes a unit only in so far as it is a phrasal unit.

Internal rhyme is not of unusual occurrence, just as the pause within the line is not at all rare; and, to my way of thinking, the line in such instances might with equal eorrectness be broken into two lines instead of being written as one. The real limit to the length of the line, thinks T. S. Omond, is our power of coördination. "Any line which cannot be comfortably grasped as a whole, either when heard or when presented to the eyc, fails to give pleasure, and is shumned by the poet accordingly." 1 The periodicity of recurrence both of rhyme and of line-length is subject to just those corrections which I have noted as necessary to the understanding of the nature of the phrase. However, rhyme need not oceur at the close of every phrase; and it may sometimes occur where the phrase does not end, but where, from the pattem already established, the phrase might be expected to end. Similarly, a pause is sometimes introduced in such a way as to break up the logical phrase group, and for no other reason than that which causes the placing of an accent upon a syllable where normal specch habit would preelude its use, - namely, the desire to maintain any periodicity that has once beeome thoroughly established.

1 T. S. Omond: "The Limits of Verse-Length," The Academy, April 25,1908 , pp. $711-712$. 
"There is a striking difference between rhythmic movement from unit group to unit group within a period, and movement from period to period (i.e., from verse to verse of nonsense syllables). Each foot is simply the repetition of the movement cycle; all the tensions are maintained and each foot is an integral part of a larger act. At the close of the period (verse) the active tensions die out either because of the introduction of some unusual stimulus which causes the positive muscle-set to strike a heavy blow, and abruptly upset the balanced tensions, or because a pause of indefinite length ensues in which the tensions die out. This is the process which we call 'finality.'

"In the stanza there is evidently a different type of unity from that in the single verse. When we hear the first verse of the stanza, we do not know what the verse whole is, until the finality factor or the verse pause is reached, at its close. Then the verse has a certain cumulative effect, a synthetic effect which results from the echoes of the various movements and the total effect on the organism. The verse pause may vary within large limits, but after a few verses there is a definite scheme, or 'Gestaltsqualität,' which represents the verse unity. It is some sort of a memory image which functions as a cue to the motor process. This motor image, set of strains, or whatever it may be, is more than a mere standard by which we judge the present verse. The memory image fuses in some way with the living motor process. The preceding verse affects the character of the following verse. An irregularity, easily noted in the first verse, is obscured in the second, and not detected in the third verse, when the verses are identical."

Whether or not the stanza should be considered as a rhythmic unit of verse depends entirely upon the length of the stanza. If it be of such a length as to make it incapable of being held in consciousness as a unit, I should say most positively that it is not a rhythmic unit, no matter how closely it may be knit logically. Every rhythmic unit must be immediately perceived as a whole, the first

1 R. H. Stetson: "Rhythm and Rhyme," p. 459. 
of which has not passed out of consciousness before the end is reached. Again the personal equation comes into play. Where one subject can keep before himself two, three, or four phrases, another can easily retain in consciousness eight or ten. I should say, therefore, that the longer stanzaic forms and stanzas that run on are not rhythmic units at all, but merely convenient methods of writing phrasal groups so as to make their rhyme scheme readily apparent to the eye. For me personally the Italian sonnet and the Spenserian stanza do not form rhythmic units, because they fall apart long before I have come to the end, and I am compelled either to count on my fingers or to go back after having read them and make an analysis of their structure before I am able to say exactly what I have heard. In just this way long prose sentences fall apart before the close is reached; and only fragments, - a phrase, a clause, or a member - can be retained in consciousness at any one time as an immediate perception.

In a study of sentence-lengths with a view to deriving therefrom any additional knowledge as to the nature of

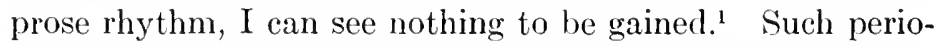
dicity as occurs comes only at the close of intervals of time too large to be detected except by very careful counting

1 The work done by the following men at the University of Nebraska, Lincoln, Nebraska, was of this nature:-

L. A. Sherman: "Some Observations upon the Sentence-Length in English Prose," University Studies, Vol. I., No. 2, Oetober, 188s, p. 119; and "On Certain Faets and Prineiples in the Development of Form in Literature," Ibid., Vol. I., No. 4, July, 1892, p. 337.

G. W. Gerwig: "On the Decrease of Predication and of Sentence Weight in English Prose," University Studies, Vol. II., No. 1, July, 1894, p. 17.

R. E. Moritz: "On the Variation and Funetional Relation of Certain Sentence Constants in Standard Literature," University Studies, Vol. III., No. 3, July, 1903, p. 229. 
plus additional computations. Rhythm is concerned with the apparent, the immediately perceived. The facts that have been brought out by the studies of prose style conducted at the University of Nebraska are interesting in many ways; but they add nothing to our knowledge of rhythm as characteristic of prose, verse, or music. For exactly the same reason the larger divisions of musical compositions cannot be considered rhythmic units. The several movements of a sonata or of a symphony are logically complete. Each is sufficient unto itself; but each is too long to be compassed by a single span of consciousness.

The tonal arts, then, are built up by the combination of silences with sounds of different tone-color, capable of being given desired time-lengths and degrees of intensity and of being employed at various pitches more or less standardized. For English prose and verse and for music the phenomena which make possible the measurement of rhythm are two, - the centroid and the pause. Neither one occurs with unfailing regularity; but both can be made to approach periodicity sufficiently to be accepted as periodic when attention is not centered solely upon the measurement of time-intervals. Prose makes no effort to secure from these periodicity of any kind. Still, certain types of emotional prose unconsciously fall into more or less pronounced periodic recurrence of centroids and of pauses. In verse and in music this periodicity is deliberately sought; and, when it is not attained to a degree which is accepted by the ear as exact, the pronouncement of judgment is both speedy and condemnatory. The periodicity of music is more nearly accurate, however, than that of verse, because in verse other considerations must give place to thought, while in music thought is sacrificed to regularity of form. Both verse and music have as their primary object the awakening of the emotions. Verse is compelled 
to sccure this awakening through an appeal to the intellect as well as to the senses. Pure music makes its appeal primarily to the senses. Therefore, when undistracted by the thought-content of the sounds, the ear is much stricter in enforcing its demands, though at no time is it overbearingly tyrannical. To say that the degree of periodicity attained by the recurring centroids and pauses is the distinguishing factor in the differentiation of prose from verse and of both from music would be to fall very far short of the truth. This degree of periodicity is a factor, and undeniably an indispensable factor; but, after all, it is only one factor. These two types of periodicity ought theoretically to be sufficient to establish rhythm. As a matter of fact, the rhythm of art is never felt to be rhythm unless a third factor is present along with these. There must be not only the consecutive occurrence of phenomena. To this must be added the perception of a succession of distinct, related patterns in time. 


\section{CHAPTER XV \\ THE CONTENT OF THE PHRASE}

BETwEen pauses come sounds which are either centroid or non-centroid, and which are capable of being given desired durations and of being arranged in desired successions. A group of sounds between two pauses I have already defined as the phrase. I have shown, too, that the pauses of verse and of vocal music occur with a fair degree of periodicity. Since this is the case, the length of each phrase must be sensibly equal to some other phrase. It is the formal content of the phrase which I now wish to examine. This must be made up of centroid and noncentroid sounds. We know that the centroid sounds occur at time-intervals which are felt, when not too closely inspected, to be of equal length. The question, therefore, arises: What relation is borne by the centroid to the noncentroid sounds?

Music is built upon the assumption that the time between centroids is occupied by sounds bearing to one another such ratios as are expressed by the series $1: 2: 4: 8: 16: 32: 64$, and that the number of these units between successive centroids is equal. When the sounds are actually played or sung, however, the theory does not hold with any degree of strictness; yet the successions are sufficiently regular for them to be felt as presenting patterns which are related both in absolute time-value and in the order of the arrangement of the sounds within the groups. Where the timevalues of the sounds are as definitely fixed as in music, 193 


\section{THE FOUNDATIONS AND NATURE OF VERSE}

there is less necessity for definiteness of arrangement as to the types of succession which shall occur within the time-intervals between centroids. Nevertheless, there is a constant tendency for the same type of arrangement to repeat itself, so much so, indeed, that music is usually felt as rhythmic group after rhythmic group. Where the patterns themselves are different, the whole is held together by the regularity of the recurring centroid and by the common relation borne to each other by the sounds within the successive centroid units. In music any number of rhythms may be carried forward simultaneously. In fact, aceording to Stetson,

"The essential character of musical rhythm, as contrasted with the rhythm of both simple sounds and of verse, is just this coördination of a number of rhythms which move side by side. This is the reason for the immense complexity and variety of musical rhythms. The processes check each other and furnish a basis for a precision and elaborateness of rhythmical movement in the individual parts which is quite impossible in a simple rhythm." 1

Although at least two theories of verse have posited mathematical exactness in the relation of the syllables within the centroid groups as fundamental, such a precision of timelengths between centroids or of the syllables within the intervals marked off by the recurrence of centroids is even less defensible than in music. However, when due allowance has been made for the inaccuracies of time-judgments, the time-lengths of the syllables do approach the time-lengths of notes, not as written but as played. Notwithstanding, of itself this approximation would not be sufficiently close to bind together either the centroid groups or the phrases if something further were not added. Here order of arrangement comes in to help establish a further

1 R. H. Stetson: "Rhythm and Rhyme," p. 465. 
feeling of relationship. Even though there may be no mathematical precision in the ratios of the syllables, some syllables are felt to be longer than others, and some are felt to be centroid and others non-centroid. By arranging successions of both longer and shorter and of both centroid and non-centroid syllables rhythmical patterns are formed. These successions of types when marked off by centroids give rise to a feeling of definite time-relationship among the syllables, which, even once established, makes possible the replacing of any syllable or syllables of the pattern by other syllables which are felt to have approximately the same time-value as the syllable or syllables replaced. ${ }^{1}$ As soon as any one type of arrangement ceases to prevail, the rhythm falls apart, because the time values of the syllables are not sufficiently exact to furnish the ear with a distinct pattern of tone. Each phrase, however, presents a particular rhythmic pattern which may or may not ever be exactly duplicated in the course of the poem; but, because the phrases are constructed upon a framework of a common periodicity, made evident by the recurring centroid syllable, and because a fairly uniform time-relationship, indispensably strengthened by a similarity of kind in the order of arrangement of the syllables, is maintained throughout by the syllables and the pauses, a feeling of artistic completeness and unity is realizable. One phrase of a poem can never be understood when considered alone. It is a part of a continuum. It fits in with all that has preceded and with all that is to follow; and it must be felt as vitally related to the whole. To conceive of each centroid group within the phrase as an independent unit, and of each phrase as a larger independent unit, is to commit the gravest of errors. Though the syllabic pattern may be this at one

1 Warner Brown, "Time in English Verse Rhythm" (p. 75), agrees with this conception. 
moment and that at the next, all rests upon a common basis of measured time.

Coleridge thought the distinguishing quality of verse to consist in the number of accents in the line. His confusion was doubtless the result of his failure to recognize that, although the line is usually coincident with the phrase, and although within a given poem the phrases normally contain the same number of centroid syllables, nevertheless, it is the tendency of corresponding phrases toward equality of time-length that makes possible their division by an approximately equal number of centroid syllables.

What difference does it make whether the phrase begins with a centroid or a non-centroid syllable, or whether it ends with a centroid or non-centroid syllable? What difference does it make whether it contains this number of syllables or that, or in what order the several types of syllables are arranged? The whole truth, as I see it, is to be found in the possibility of placing these numerous rhythmic groups together in such a manner as to form an organic whole; and this is possible only because they are all so constructed as to work into a general time scheme, measured by the periodic recurrence of centroids and made the more apparent by the fairly regular recurrence of the same type of syllabic succession. "The continuity of the rhythmic series," says Stetson," "whereby all the beats of a period seem to belong to a single whole is due to the continuity of muscular sensations involved and the continuous feeling of slight tension between the positive and negative muscle sets. Nowhere within the period does the feeling of strain die out." If the phrase succession happens to begin with a centroid syllable, it is quite probable that the syllables will be felt to succeed each other as centroid followed by non-centroid throughout the length of the phrase, 1 "Rhythm and Rhyme," p. 445, III. 
while the very next phrase, if begun with a non-centroid syllable, will probably be felt to have the rhythmic grouping non-centroid followed by centroid. The centroids themselves have not shifted their positions. The difference lies in the way in which the other syllable or syllables are felt to be grouped in regard to the centroids. Even though subjective factors may be the most potent in determining whether a syllable or syllables shall be felt as grouped with the preceding or with the following centroid, many objective factors do come into play; and the feeling of rhythm is the more definitely established as we proceed in a phrase, or a series of simple sound sensations. Until the cycle is perfectly adjusted, complete automatism cannot be possible. ${ }^{1}$

When sounds are robbed of their intellectual significance and are mechanically altered to suit the experimenter, it is perfectly possible to say what order of grouping the hearer will normally make; but, when, as in verse, no such simplicity of experimentation is possible, and when, in a great degree, thought-content is influencing both the length of time accorded each syllable and the amount of stress which each syllable is receiving, the matter becomes much less capable of predetermination, or even of determination at all. Many and unprofitable have been the hours I have spent in trying to determine with a number of friends whether a certain succession of syllables presented a series of trochees or of jambuses, of dactyls or anapæsts. As one read them, they were of a certain type; as another read them, the type was reversed. Of course, where the types are perfectly regular, no occasion for difference of opinion arises. But, alas! the most beautiful verse is rarely regular in type.

The unity is that of a single coördinated movement. This is nowhere more apparent than in nonsense syllables. But for the regularity of recurring centroids and for the 1 R. H. Stetson: "Rhythm and Rhyme," p. 445. 
general form, the different phrases would be no better than a jumble. ${ }^{1}$ It is in nonsense verse, as might be expected, that the rhythm of verse approaches the rhythm of musie most closely. For it is here that thought-content is at the minimum.

Exactly the same state of affairs in regard to rhythmie grouping prevails in music as in verse. One conductor will have his orchestra play a composition in such a manner as to bring out a rhythmic pattern in a particular way and another conductor will reverse the successions. Sometimes it is next to impossible to discover any rhythmie pattern at all, because melodic and harmonic factors are outweighing rhythmic considerations. In verse, however, this latter state of affairs ought never to arise. Verse has no fixed tonal framework. Therefore, unless the rhythm is well marked, the poem falls apart structurally.

The primary requisite of the unit groups is that they shall be alike, not equal. "Time is not mysteriously lost; the objective difference is not noticed, simply because there are no striking differences in the cycles to lead one to a time judgment.", 2

Seansion is nothing more than an attempt to present to the eye the rhythmic pattern of the poem. The only problem for the scanner ought to be : What is the best way of writing down the rhythm as it is heard? For, what the rhythm is heard as being, not what the rhythm presents to the eye when written down, is the matter of consequence. Counting on the fingers may aid in the writing out of a rhythm; but my experience has always been that the man who has to count on his fingers in order to follow the rhythmic structure of a poem is pretty sure to have but a mediocre susceptibility to rhythm in general.

1 R. H. Stetson: "Rhythm and Rhyme," p. $443 . \quad 2$ Ibid., p. 461. 


\section{CHAPTER XVI}

\section{THE RHYTHM OF PROSE}

What of the rhythm of prose? Having seen what constitutes rhythm in general and the rhythm of verse in particular, it should now be easier to understand the rhythm of prose. Exactly the same phenomena are presented as the material from which to construct prose as that presented for the construction of verse. The difference between prose and verse rests in the peculiar uses to which each form subjects this material. Grammatically and rhetorically but few distinctions can be drawn between verse and prose; and these are neither germain nor significant. What lines of demarcation can be set up must rest upon the difference in intention of the two forms. Verse sets out to secure regularity, to bind poet and hearer in a common emotional experience by an appeal to the almost universal susceptibility of men to the influence of measured time. Prose has no such intention. It does not set out to secure regularity. What regularity it attains comes as the result of human inability to escape from a certain degree of periodicity in all thought and in all action. As emotion increases, the tendency toward regularity of expression increases, until at a given moment of emotional excitement all regularity breaks down, and expression of any kind becomes impossible. Both thought and expression are for the moment paralyzed. As I have said before, the point at which prose passes into verse is impossible of determination. Therefore, the best that 
can be done is to examine the most highly artistic prose that is clearly prose and not verse, and therefrom try to formulate the difference between the two.

Undoubtedly the centroids of prose are equally as pronounced as the centroids of verse; and in many instances the recurrence of the centroids of prose is not much less regular than that of verse. The phrase-lengths of prose approach in regularity the phrase-lengths of verse. By actual measurements, the syllable-lengths of prose are not more irregular than the syllable-lengths of some verse. In examining the arrangement of syllables within the divisions from centroid to centroid almost any pattern that is found in verse can also be found in prose. But at this point the analogy ceases. The intention of the two being opposed, the means of securing their several ends must be different.

I have pointed out for verse that the unifying principle is found not only in felt time-relationship between any one unit and any other, but also among all the parts, so that they can become factors in the creation of an impression of totality and completeness, and that this feeling is due particularly to the repetition of types of syllabic arrangement. The prevalence of any one type is never sufficiently marked in prose to arouse a feeling of time-relationship in either the speaker or the hearer. One phrase, for instance, may present a certain type; but the very next phrase will present another type of such entirely different structure that the feeling of relationship is prevented from establishing itself. In prose the units are mosaic in structure. They are merely placed next to each other without regard to a unifying principle, without the slightest intention of creating the impression of temporal relationship. There is no striving for periodicity of recurring centroids or of periodicity of recurring pauses in order that both may aid in marking for the ear the arrangement of syllabic 
types in such succession as will arouse a feeling of temporal uniformity throughout the whole. The rhythmic units of prose are fragmentary, undeveloped, unrelated. To study the rhythm of prose is as unproductive of results as to study the tunes of speech. Both are ever varying, formless, and, therefore, incapable of analysis.

Many attempts have been made to establish for prose a rhythmic structure exactly analogous to that of verse. ${ }^{1}$ The analysis of prose would never have been undertaken, however, if there had been in the minds of the analysts anything approaching a true conception of the nature of rhythm in general or of verse rhythm in particular. All that Professor Saintsbury, for instance, has succeeded in showing is the utter futility and the utter fruitlessness of the task which he set himself. I do not see how any one can read "A History of Prose Rhythm" without gaining a higher appreciation of such beauties as prose undoubtedly possesses and a clearer knowledge of the stylistic changes which have gradually taken place through a great number of years. I closed the book with regret; but it was with regret that as great a mind as Professor Saintsbury's could hold so inadequate a conception of the nature of rhythm as he here displays, rather than regret that a useless search was ended; for Professor Saintsbury certainly has the rare

1 George Saintsbury: "History of Prose Rhythm" (Macmillan, 1912).

Albert C. Clark: "Prose Rhythm in English" (Clarendon Press).

K. Marbe: "Über d. Rhythmus d. Prosa," Giessen, 1904 (Oxford, 1913).

Abram Lipsky: "Rhythm as a Distinguishing Characteristic of Prose Style" (Science Press, New York, 1907).

Fred Newton Scott: "The Scansion of Prose Rhythm," Modern Lang. Notes, Dec., 1905; and "The Most Fundamental Differentia of Poetry and Prose," Modern Lang. Notes, June, 1904.

D. Winter: "Verse and Prose." 
faculty of entertaining most delightfully even where he fails to convince.

To the work of such men as those to whom I have been referring in the preceding paragraph, that of William Morrison Patterson ${ }^{1}$ is a most notable exception. His book did not come to hand until my own investigations had been closed and my manuscript was ready for press. It is, therefore, with peculiar pleasure that I find myself in almost entire agreement with his general attitude, especially as we drew in large measure from a common fund of psychological data. To this Dr. Patterson has added further experiments of his own, which, I am sorry to say, seem to me inconclusive in at least two particulars. How easy it might have been for him to test a far greater number of prose specimens! how easy to extend the length of those which he did test! (The longest contains only sixty-three words.) Beyond a doubt short passages of selected prose meet in every particular the same rhythmic requirements as are met by verse. My contention, however, is this: The vast body of prose is inappreciably rhythmical; and even the most rhythmical prose must after a few sentences either suffer a most disagreeable interruption of the forward swing to which it may return at intervals, or lose this swing altogether in a constantly changing movement. There is in it no such continuity of progress as characterizes verse. Otherwise how is prose to be distinguished from vers libre or verse from either?

To this Dr. Patterson would reply that the rhythmic unit is more clastic than I am willing to admit. Let me quote him at length:

"The truth of the matter is that the liberties allowed by the introduction of an elastic unit, and the endless possibilities of

1 "The Rhythm of Prose" (Columbia University Press, 1916). 
syncopation $^{1}$ and substitution, render quite easy to a musical observer the task of fitting a series of unitary impulses to any series of irregular sounds (provided the sounds do not come too close together to be discriminated or so far apart that they cannot easily be grasped as the boundaries of a continuous interval). Whatever is not explained by syncopation and substitution is easily explained by acceleration and retarding. We must add to all this the process of so-called 'subjective grouping,' both voluntary and involuntary, by means of which our perception of objective conditions, up to a certain degree, comes under the distorting influence of 'impressions.' Such illusions are fed by our enjoyment of the variegated effects of subjective organization. What needs to be remembered, then, is that for the individual, and consequently for psychology, these illusions are in themselves important 'facts' of conscious life.

"It is thus that we become aware of the phenomena heralded by Wundt's general statement about the possible rhythmic conception of all series of sounds, and exemplified in the data listed in Appendix III. There are individuals for whom a series of apparently irregular sounds can be easily organized subjectively into a satisfying rhythmic tune. There are also individuals for whom the task is difficult, if not impossible. Prose thus becomes

1 Syncopation is "the act, process, or result of inverting the rhythmic accent by beginning a tone or tones on an unaccented beat or pulse, and sustaining them into an accented one, so that the proper emphasis on the latter is more or less transferred back or anticipated." — "The Century Dictionary Cyclopedia." "Sound rhythm, of course, deals with sounds and silences; but concomitant with purely sound rhythm is motor rhythm, thought rhythm, etc. Concomitant sets of timeintervals, accordingly, when not coinciding, institute one form of syncopation. Another form occurs when there is interchange in the nature of the sensations or movements which mark off time-intervals. Finger-taps alternating with spoken syllables are an illustration." "The Rhythm of Prose," p. 92. Syncopation must not be confused with syncope, a term employed by Sievers in "Rhythmische-melodische Studien" (Heidelberg, 1912, p. 10), to mean the omission of an unaccented syllable in a foot, on account of which omission an accented syllable does duty for two. 


\section{THE FOUNDATIONS AND NATURE OF VERSE}

for some observers a sort of music, built upon elastic unitary pulses, sometimes grouped and always syncopating freely; but for others, it remains, and must always remain, an utter mystery, regarded either with indifference, or as tantalizing because of its constant suggestion of a rhythm never fully achieved except in spots - a so-called 'free' amorphous entity, identified merely by the chilling assurance that, at any rate, it is not verse.

"A new standard is thus established for passing judgment upon the rhythm of a sentence or paragraph. The marking of grammatical (dictionary) accent is by itself misleading, except for the purpose of detecting passages of metrical patchwork such as occur in the writings of Ingersoll, or unusually long stretches of 'iambies' such as have been fished out of Dickens and Ruskin. The reason such 'scanning' is misleading, is simply that a slow reading of some of our most unimpeachable prose turns it into just such iambic or trochaic drivel, while a rapid reading of some of the ridiculed passages introduces a varied swing that competes (in ease, spontaneity and appropriateness) with the very best. The stresspatterns of routine scanning have thus little more than suggestive value, when considered apart from the molding influences of tonecolor and dominating mood of thought. On the other hand, the stress-patterns of actual experience have great significance, and when combined with the corresponding time, pitch, quality and thought patterns, complete what we mean by the rhythm of language." 1

"From this point of view, typical prose is uttered language which, on a given occasion, produces a series of syllabic impressions, whose temporal arrangement is largely irregular, that is, haphazard, but which can be subjectively organized by an aggressive timer. A spontaneous or automatic process of syncopation between the syllabic sounds and the subjective unitary pulses secures satisfactory coördination, in the same way that a negro automatically improvises complicated syncopating melodies while he plies his hoe in the corn-field." 2

"Taking well-defined prose experience to be due to a predominance of syncopation in the relation between a timer's elastic

1 "The Rhythm of Prose," p. 12.

2 Ibid, p. 74. 
measuring pulses and the syllables in which we feel impressions of accent, and regarding verse experience as due to a predominance of coincidence in this relation, we first of all conceive the rhythm of either prose or verse in the form of a rhythmic tune, combining patterns of time, stress, and, to some extent, pitch. Patterns of tone-color are superimposed, as soon as we consider the actual sounds of the words, and patterns of subjective weight, as soon as we consider the words as vehicles of thought and feeling, in addition to their auditory impression." 1

"There are only two ways in which a series of measuring timeunits can be coördinated with a second series of sensations syncopation and coincidence. Either syncopation predominates, in which instance we feel the stimulus as prose, or coincidence predominates, and verse experience ensues. What room is there for a tertium quid? Nothing remains but the purely hypothetical case where syncopation and coincidence are exactly balanced in their occurrence, or else a mere confusion of mind in which temporal coördination practically ceases, that is, in which rhythm, so far as the timer is concerned, has been abrogated. . . . Accordingly, there exists no fundamental time-rhythm experience corresponding to a tertium quid between prose and regular verse. What actually happens in the hearing or utterance either of vers libre or of certain forms of so-called 'rhythmic prose' is that during one phrase or group of phrases the aggressive timer feels syncopating temporal experiences, during the next phrase or group he begins to feel coincidence of the accents with his subjective measuring pulses. The more vague impressions of the stresser are significant in the study of individual difference, but hardly illuminating with regard to the distinctive experience of rhythm because of his overly blurred sense of time-values.

"According to the results of our experiments, therefore, there is no psychological meaning to the claims for a third genre between regular prose and verse, except in the sense of a jumping back and forth from one side of the fence to the other. In spite of the fact, then, that many passages can be felt as either prose or verse, according to the utterance or the amount of 'suggestion' received

1 Ibid, p. 75. 
through visual arrangement, grammatical (dictionary) accent, artifices of tone-color, figures of speech, elevated diction, etc., nothing more than an unstable compound can be created out of the two typical forms of temporal experience." 1

"It must be recognized that whenever so-called vers libre goes beyond mere irregularity of length of line, and alternates successions of repeated stress-patterns with stretches where the grammatical accent is sufficiently irregular to suggest syncopating rhythmic responses, there results for the timer a patch work product, involving two processes which psychologically do not fuse." 2

Just here, it seems to me, lies the one weak point in Dr. Patterson's position. If prose is syncopated rhythm and verse coincident rhythm, then the two ought to fuse; and it ought to be possible to pass from one to the other without a feeling of break, just as is constantly happening in the developed themes of many of Beethoven's sonatas and in rag-time. Vers libre is, in the main, an amorphous prose, standing at the point where the undeveloped, uncoördinated rhythmic fragments of the latter tend to break into the full rhythmic swing of verse. In verse, as in music, syncopation is used with varying freedom; but, undoubtedly, as Dr. Patterson says, coincident rhythm prevails. By a sufficient amount of twisting and by a complete disregard of sense and of accepted habits of speech (although I do not know whether I should be considered an aggressive or a passive timer $^{3}$ ), I, too, find it possible to fit almost

1 “'The Rhythm of Prose," p. 77.

2 Ibid., p. 79.

3 The term aggressively rhythmic timer is applied to those who "not only attain a fair degree of reproductive precision in the tests, but evince a marked pleasure in rhythmie exercises and a marked tendency to organize upon a temporal subjective basis all of their eonscious life. Abundance and vividness of auditory amd motor imagery; unit accuracy; sense of swing and ability to syncopate, espeeially in complex tasks; pleasure in the effects of acceleration and syncopation; pleasure 
any sentence to marching or to any given tune; but I do not do this naturally. In fact, it goes against the grain. This, however, is of no great consequence. What my conception of rhythm leads me to emphasize is this: Verse utilizes natural habits of speech to establish and to maintain a continuous rhythmic flow; prose has no such intention; and, when by accident the speaker drifts into a rhythmically coördinated series of words, consciousness of what he is doing brings surprise to both speaker and hearer, and normally there is an immediate relapse into disjointed time-units. Of course, this is not true of highly oratorical, dithyrambic prose; for there one has to do with a transition product, of which type is vers libre, though for the most part the latter is more of an interspersing of snatches of verse with loose combinations of prose than is the former, which presents on occasion a gradual working of prose into a more and more regular rhythmic flow until it becomes a swelling and receding of speech impulses in no wise to be differentiated from verse.

Poetry may be read as prose. When thus read, it is prose, because the rhythmic effect is unsustained, uncoördinated. The intention being to produce prose, prose it is for both speaker and hearer. But prose cannot be read as poetry, no matter what linear arrangement it may receive or what may be the intention on the part of the

in unitary pulses as well as in groupings superimposed upon them; and, finally, strength of voluntary and involuntary 'subjective rhythm,' seem to be the conditions of this ability to organize, upon a time basis, any haphazard series." - Ibid., p. 94.

"For aggressively rhythmic states of mind and for these alone, it is true that 'no series of impressions exists that cannot in some way be conceived as rhythmic'; but the secret can be made clear to those with aggressive possibilities, by beating and humming syncopating rhythmic tunes, in which there is added to the haphazard series the properly elastic series of unitary pulses." - Ibid., p. 95 . 
reader. A few phrases may set up a rhythm and become so highly poetic, that, if taken out of the whole, they would be accepted as poetry; but, as a part of a body of prose, the rhythm must invariably break down very shortly, and the true nature of the form he revealed. In verse of a good quality, no matter whether written in lines or not, there is in the syllables the potentiality for being read in rhythmic patterns which are felt to be temporally related. Al that writing the words in lines can do is to indicate the intention of the author as to what attitude should be assumed toward his product and to make clearer in some instances the length of the phrases. If the author writes his words in lines of set lengths, he virtually says to the reader:

"This is poetry. Seek to read the words with a sustained tone and to bring out the centroids and the pauses as I here indicate them; otherwise the rhythmic patterns may not be apparent to the listener and his feeling of time-relationship may be left unaroused."

Similarly, by drawing vertical lines across the horizontal lines of written music, the composer says to the performer:

"Put your stress at this point, or my rhythmic pattern may elude you."

Both are conventions pure and simple. They do not mean that any division into units occurs at these places, or that the continuity of flow is in any way interrupted. They are just academic methods of writing the thing, the better to aid one man in conveying his conception and his intention to another. The hearer takes no note of bars or feet or lines. His impressions are of pauses interspersed among different kinds of sounds in such a way that the sounds become grouped, each group presenting a definite pattern and intensifying the feeling of general time-rela- 
tionship. For the ear there is no possibility of comparing the first group with the final group. As soon as the first is past, it can not be brought before consciousness again without repeating it, so that what remains of it in consciousness is only a general impression. Therefore, as long as a feeling of general equality is sustained, all that is necessary has been accomplished.

"If," as Dr. Warner Brown says of verse, "we take the ground that the grouping in rhythm is an effective experience and if we place it simply in the dimension of strain and relaxation it becomes at once clear why no regular time relations are necessary. The regularity becomes a matter of recurrence of strain at the end of a definite cycle. The muscles may take a longer or shorter time to accomplish their cycle and the strain may not come at equal intervals of time, but the swing is there, and from place to the next place is one definite mental state held together by the continuous circular process." 1

This swing, held together by the continuous circular process, is what I believe to be at times almost wholly lacking in ordinary prose, but to be partially developed in the prose of Walter Pater and in much of the so-called verse of Walt Whitman ${ }^{2}$ and of the makers of vers libre. Of course, any one constituted as is the aggressive timer may be able to get a well-defined rhythm from every experience of life; but, with the exception of those rarely gifted beings, I am confident that the subjective scheme which Wundt and Patterson posit as lying at the root of everything is in nowise as binding for prose as for verse. If it is found in prose at all, its presence is very, very much less obvious than in verse; and it is never consciously sought and maintained

1 "Time in English Verse Rhythm," p. 75.

${ }^{2}$ This should not be considered as derogatory of Whitman's best lyrics, some of which I consider to be verse of a very high order. 


\section{THE FOUNDATIONS AND NATURE OF VERSE}

as a structural necessity. The occasional introduction of a rhythmic ${ }^{1}$ passage into prose does give it dignity, beauty, flow; and all good prose does manifest a tendency toward rhythmic coördination. But this is quite different from saying that prose is syncopated verse.

${ }^{1}$ Saran, in spite of his pronouncement that rhythm is purely mental in origin ("Deutsche Verslehre," p. 128), holds that prose is seldom rhythmic, but predominantly rhythmless (Ibid., pp. 19-21).

Shipper ("History of English Versification," Clarendon Press, Oxford, 1910, p. $3, \S 4)$ says that the rhythmic order of prose is so loosely constructed as not to obtrude itself on the ear. 


\section{CHAPTER XVII}

\section{SCANSION}

As to what method should be used for the scanning of verse, I say without hesitation:- The same that is used for recording the rhythms of music. Of course, there is no such regularity of time-relations in verse as is expressed by these symbols. Neither is there this regularity in music itself. In both music and verse, however, there is the intention to measure off time-intervals of equal length and of similar structure. In the carrying out of this intention music is more successful than verse, because music is less occupied than verse with the expression of thought. Certainly our present methods of spelling are exceedingly defective; but we have been able to devise no better symbols for this purpose than those offered by the Roman alphabet. The same is true of musical notation. As long as it enables the musician to express his musical ideas with a fair degree of accuracy, he makes shift to get along with it. In applying it to expressing the rhythm of verse, there is this advantage, - The rhythm of verse can then be clapped off, and, in being clapped, is recognizable as the rhythm of the specimen of verse under examination. This process of reproducing the rhythms by clapping is certainly not possible from any system of scansion such as longs and shorts or accents and non-accents. It has the further advantage of making evident the continuity of verse and of showing the repetition of temporal patterns alike in kind as well as of approximately equal duration. In the 


\section{THE FOUNDATIONS AND NATURE OF VERSE}

scanning of songs from listening to their being sung, pitch relations are ignored; and only the temporal relationships of the tones are set down. These temporal relationships are not written, however, exactly as they are heard (for the imperfectness of musical notation makes this impossible), but as nearly approaching this as the assumption of theoretic temporal equality among the time-intervals will permit of.

That "all art is a compromise" must be taken into consideration by every true theory of art; and no theory of poetics which does not recognize this without wincing and without attempting to evade the issue can hope for so much as an approximation to truth. Admitting that there is no absolute equality of time-length to be found anywhere in either verse or music, I can still make equality of timelength one of my major premises with just the same degree of assurance as the painter posits the possibility of drawing a straight line. Just as the eye will accept as straight lines which only a casual inspection will convince any one are not straight, so, too, the ear will be satisfied with a surprising degree of departure from absolute exactness, provided the inequality be not introduced too abruptly or thrust too rudely upon the attention. 


\section{CHAPTER XVIII}

\section{SUMMARY}

Prose, verse and music, as tonal arts, are constructed of the same material, - namely, sounds and silences. Silence has but one dimension; and this is length. Sounds are characterized in four ways, - that is, by differences in pitch, intensity, tone-color, and duration. Each of the arts will use this material in accordance with the object which it has in view. The primary intention of prose is to convey thought. Both verse and music have in view the awakening of emotion. Verse strives to awaken this emotion through the intellect and through the senses. Music makes its appeal to the senses. Neither music nor verse nor prose stands apart in any such clear-cut difference of intention as I have stated here. One grades into the other. Since there come moments when the intention of prose is almost identical with the intention of certain types of verse and when the intention of verse overlaps the intention of music, at such times the mode of expression of the one art form is compelled to overlap the mode of expression of the other.

Prose and verse and music present a tonal structure and a rhythmic structure. To dissimilarity in these two particulars are attributable the formal differentiation of the one from the other. Upon identity in these rest the intrinsic qualities which cause them to be classified in common as tonal art.

Tonally, prose and verse are differentiated from music, in that music employs only those pitches which are capable 


\section{THE FOUNDATIONS AND NATURE OF VERSE}

of coördination into scales of one kind or another. The pitches of verse are more definite than those of prose; but even in verse the pitches are still utterly incapable of standardization, so that no person or no two persons speak the same passage twice in exactly the same way as regards either absolute pitch or as regards inflection. The various forms of rhyme are mere tonal embellishments, presenting no means whatsoever of differentiating prose from verse or either of these from music.

Rhythm is constituted by the consecutive occurrence of phenomena which are perceived as forming a succession of distinct, related patterns in time.

Prose, verse, and music have rhythm in common. Prose rhythm is undeveloped, fragmentary. Before it can be sufficiently well established to awaken a feeling of relationship as to the successive patterns, any given pattern breaks down; and the impression of continuity is at once destroyed. The rhythmic patterns of verse and of music, on the other hand, are presented to consciousness as related units in an unbroken temporal whole. Every sound and every silence is related to every other sound and every other silence by virtue of its being of such a length that it is felt to have a place in a measured temporal scheme. In music the sounds and the silences are really of much more definitely fixed lengths than in verse. Were it not for the fact that in the latter certain successions of syllables of the same general kind occur with sufficient frequency to create the impression of temporalness among them, the rhythm could not be carried forward with enough certainty to produce an impression of continuity and completeness.

Vowels are neither long nor short, high nor low. They are tone-colors of indefinite length. When combined with consonants to form syllables and words, the vowels then assume such time-lengths as the speaker wishes to give 
them. Vowels and syllables which habit of speech causes to be stressed usually receive greater time-value than unstressed vowels and syllables, though this is not invariably the case. The vowel sounds of different lengths, when interwoven with silences and when considered apart from the other characteristics of verse, are not sufficiently regular of themselves to establish a feeling of temporal relationship from which it would be possible to build up a rhythmic whole.

Centroid syllables (of which the rhyming syllable is a special class) and pauses are the phenomena which mark for the senses the time-divisions of verse. Neither between pauses nor between centroid syllables is there true equality of time-length. Nevertheless, they furnish types of recurrence of sufficient regularity to be accepted as periodic under the special conditions presented by verse. Rhyme, as a centroid syllable, furnishes a periodic tone-color at a moment when its appearance reënforces the rhythmic accent. In addition, it has the same function as that performed by the pause; namely, - It aids in grouping together the words that logically and rhythmically belong together.

Within the time-divisions marked off by the centroid syllables occur different kinds of syllables which come to be felt as temporally related because syllables of like kind are repeated in sufficiently definite successions to establish in the perceiver a feeling of progressive unity and completeness when divided by the pauses into groups of fairly definite length called phrases. Because the phrases are all fundamentally similar in structure and are built on the same temporal uniformity of recurring centroid syllables, they fit into the general swing of the poem and are felt to coalesce into complete unity of movement as regards the whole. 


\section{THE FOUNDATIONS AND NATURE OF VERSE}

The arrangement of verse into lines of fixed length is a purely arbitrary matter, having nothing to do with its structure, except in so far as the arrangement into lines sometimes aids in making the phrasing of the poem the more readily apparent to the eye of the reader. The differentiation of prose from verse lies deeper than a mere convention of writing. The difference in the two forms is fundamental; regardless of the manner in which the words are written. Sceking to attain different effects, they employ different means to that end. Prose avoids regularity; verse relies upon it. Verse demands an uninterrupted flow of rhythm; prose never allows the impression of rhythm to become more than momentary.

There is no organic difference, however, between the various so-called feet of verse. They represent merely the perceiver's method of grouping the syllables. If he feels the syllable to be grouped with the preceding centroid syllable, he will look upon the succession as a trochaic or an anapæstic movement. If he feels the syllable or syllables to be grouped with the succeeding centroid syllable, the succession will be for him iambic or dactylic. If the pauses come in such a way that he feels the syllables to belong one before the centroid and another after it, he conceives of it as an amphibracic movement. Any number of syllables or any order of arrangement that does not interfere with the regular onward swing can be introduced into a movement. As to what patterns can be thus introduced into any particular movement, it is impossible to formulate a single rule. Everything will depend upon the special conditions under which the individual syllable or syllables are introduced. All that scansion can do is to record the rhythmic patterns of verse, and thus aid in attaining an understanding of its structure. To undertake to deduce from these patterns the laws of rhythmic suc- 
cession is to chase the wind. The patterns of verse are almost as free as the rhythmic patterns of song; and surely no one would attempt to dictate in what order the tonelengths of song should follow one another.

The rhythm of verse is identical with the rhythm of such nusic as results from unaccompanied singing by a single voice. As soon as an accompaniment is introduced or several voices sing at once, the time-units of music are compelled to take on greater regularity in order that the various parts may hold together. In music a perfectly indefinite number of rhythins may be carried on simultaneously, provided they can be fitted into the same temporal divisions, and provided they follow the same tonal structure. The presence of a very strong accent makes it possible to carry forward simultaneously many rhythms which without it would most assuredly fall apart. The rhythms of verse must always be comparatively simple, because the centroids can never he given undue prominence or be made to occur with too great regularity without producing singsong, while, if some very clearly marked phenomenon such as an unusually pronounced centroid be lacking and the rhythm become in the least complicated, the ear fails to make the necessary correlation, the various units cease to be felt as belonging together; and the whole falls apart.

As far, then, as structure is concerned, verse is that. form of tonal art which makes use of syllables of different intensity, length, and tone-color, and of indefinite and varying pitches, when combined with periods of silence, to establish rhythmic patterns which are felt to maintain to one another temporal relations such that each successivepattern takes its place in a general time scheme, sensibly uniform throughout, and contributes toward an impression: of unity and completeness as regards the whole. 



\section{APPENDIX}

The followings books contain excellent bibliographies in their respective subjects:

I. Acoustics:

Helmholtz, Hermann von: "Sensations of Tone," translation by A. J. Ellis (London, 1885).

Miller, Dayton Clarence: "The Seience of Musical Sounds" (Macmillan, New York, 1916).

Rayleigh, Lord: "Theory of Sound," 2 vols. (London, 1894).

Winkelmann: "Handbuch der Physik" (Leipzig, 1909). Vol. II. is by F. Auerbach, and is called "Akustik." This volume contains the bibliography.

Zahm, J. A.: "Sound and Music" (Chicago, 1892). Out of print at present.

II. Anthropology:

Wallaschek, Richard: "Primitive Music" (Longmans, London, 1893).

III. Prosody:

Alden, Raymond Macdonald: "An Introduction to Poetry" (Henry Holt, New York, 1909).

Cowl, R. P.: "Theory of Poetry in England" (Macmillan, New York and London, 1914).

Gayley and Scott: "Methods and Materials of Literary Criticism" (Ginn and Co., Boston, 1901).

Omond, T. S.: "English Metrists (18th and 19th Centuries)" (Oxford University Press, London, 1907). 
IV. RнYтнм:

Patterson, Wm. Morrison: "The Rhythm of Prose" (Columbia University Press, New York, 1916).

Ruckmich, Christian A.: "The Rôle of Kinæsthesis in the Perception of Rhythm," American Journal of Psychology, XXIV., No. 4, 1913, pp. 508-519.

Weld, Harry Porter: "An Experimental Study of Musical Enjoyment," American Journal of Psychology, XXIII., April, 1912, pp. 300-308. This is an excellent, classified bibliography. 


\section{INDEX}

Aalst, T. A. van, 36

Accent, 63, 64, 100, 108, 110, 120, 122-129, 133-135, 137-139, $142,143,158,162,170$, $180,185,186,188,195$, 203-206, 211, 217

deferred, 139, 140

hovering, 139, 140

logical, 140, 141

metrical, 141

word, 140,141

wrenched, 141

"Accuracy of Voluntary Movement," 105

Acoustics, 219

"Aesthetische Einfühlung," 84

"Afferent Values in Articulate Sounds," 56

"Afro-American Folk Song," 4, 26

Agnew, P. G., 40

"Akustik," 40, 62, 219

Alden, R. M., 219

Alliteration, 53, 59, 160-165, 188

Ambrose, W. A., 3

Amphibrach, 173, 214, 216

Amplitude, 61

"Analysis of Complex Sound Waves," 39

Anapæst, 123, 177, 197

"Ancient Egyptians," 35

Andrian, F. von, 3, 67

Anglo-Saxon, 165, 188

Angell, 75

“Animal Sketches," 65

“Annabel Lee," 166
Anthropology, 219

"Application de la méthode graphique à l'étude de l'intensité de la voix," 62

"Art of Music," 23

Art, 213

capabilities of, 184

expressed in, 74

origin of, 65

temporal, 124

tonal, 191, 212, 213, 217

Assonance, 53, 59, 160-162

"Atmungs- und Pulssymt. rhythmischer Gefühle," 71

" A travers chants," 36

Auerbach, F., 40, 47, 219

Bach, Johann S., 25

Bacon, Francis, 134, 142

Baker, Theodor, 4, 24, 26, 35

Ballads, 4

Balz, Albert, 57

Bar, 168

Barton, 40

Beats, 21, 40, 135

Beat-tone, 22, 39, 40, 41

Beethoven, Ludwig von, 157, 206

"Beginnings of Pcetry," 4

"Beiträge zur Analyse der Empfindungen," 80,84

"Beiträge zur deutschen Metrik," 129,176

"Beiträge zur experimentellen Psychologie," 80 
"Beiträge zur Theorie der sinnlichen Aufmerksamkeit," 72

"Bells, The," 55, 113

Bélugnon, L., 74

Benussi, V., 71, 104, 178

Bergson, Henri, 81

Berlioz, Hector, 36

Bevier, Louis, 47

Billert, 4, 36

Binet, 75

Bingham, W. Van Dyke, 18, 29-34

Bolton, T., 72, 75, 104, 174, 176

"Boundaries of Music and Poetry," 3

Bourdon, P., 62

Breath, 135, 144 group, see phrase

Bridgman, Laura, 74

Brown, M. E. and A. W., 24

Brown, Warner, 101, 104, 107, 110, $111,113,116,117,129$, $133,142,152,179,195$, 209

Browning, Robert, 135, 143, 162

Brücke, 75, 114, 128

Burton, R. F., 36

Centroid, 125-130, 132, 135-137, $139,140,143,146,173$, $176,179,180,185,191-197$, $200,207,215,216$

Chanting, 4

Characteristic, 50

Child, F. J., 4

"Childe Harold," 142

"Chinese Music," 36

"Chinese Theory of Music," 36

Chopin, F., 91, 135, 157

"Christabel," 142
Clark, Albert C., 201

Cleghorn, A., 129

Coincidence, 205, 206

Coleridge, S. T., 142, 143, 195

Consciousness, 80

Consonance, 33, 53

Consonant, 48, 116, 160, 214

"Construction and Type of Shakespeare's Verse as seen in 'Othello,'" 158

"Contributions to a Psychological Theory of Music," 21

"Contribution to the Psychology of Time," 82, 123

Corry, Joseph, 66

Courtier, 75

"Creative Evolution," 81

Dactyl, 158, 173, 177, 197, 216

Dance, 65-67, 74, 76

Darwin, Charles, 23, 26, 65

Dearborn, W. F., 1

"Descent of Man," 23, 26, 65

"Deutsche Verslehre," 124, 210

Dickens, Charles, 204

Dietz, 72

Diphthong, 47

Dogiel, 75

Donders, 44

Donovan, J., 5

Drozinski, L., 71

Duration: $10,64,80,81,90,103$, $104-107,110,125,140$, $168-170,172,175,176$, 213

\section{Ebhardt, 75}

Edwards, P. H., 39

Eijkman, L. P. H., 10

"Elements of a Psychological Theory of Melody," 129 
"Elements of Experimental Phonetics," 48

Ellis, A. J., 53

"Embassy at Ava," 36

Emotion, sympathetic induction of, 5

"English and Scottish Popular Ballads," 4

"English Metrists," 125, 219

"English Poetry: Its Principles and Progress," 138, 165

Equivalence, 178

"Essai sur les principes de la métrique anglaise," 29, 53, $56,67,73,116-118,130,133$

"Essay on Death," 142

Ettlinger, 75, 104, 126

"Experimental Psychology," 72

"Experimental Study of Musical Enjoyment," 3, 5, 57, 71, 146,220

"Experimental Studies of Rhythm and Time," 105, 127, 157, $173,174,179$

"Experiments on the Time Relations of Poetical Meters," 82,115

Faber, Ernst, 36

Falkenstein, 4, 65

Fif th, 14, 17, 18, 22, 32

Fiske, John, 70

"Fluctuation of Attention," 88, 97

Folk-song, 4

Foot, 135, 136, 138, 140, 158, 189, 216

compensating, 137,165

Formant, 45

Foster, Henry, 66

Fourth, 14, 18

Frequency, 8
Frequency, see Pitch

"From Lyre to Muse," 5

Fundamental, 16, 39, 46

Gardner, W., 3

Gayley, C. M., 138, 165, 219

Generator, 41

"Genetic Aspects of Consonance and Dissonance," 6, 23

"Genetic Study of Rhythm," 164

Gerwig, G. W., 190

Gilman, B. I., 31

Gilver, Robert C., 54-56, 59, 173

Glottal catch, 10

"Good-bye Sweet Day," 135

Grassmann, H., 44

Grosse, Ernst, 84

"Grundlegung der Aesthetik," 29

"Grundzüge der Phonetik," 72

Guessfelt, 4, 65

Guest, Edwin, 63, 100, 133

Gummere, F. B., 4

Gurney, E., 72

Hall, 104

"Handbuch der Physik," 40, 219

Harmonic, see Partial

Harmony, 35, 59, 175

Hauptmann, 75

Haushegger, 75

Helmholtz, Hermann von, 23, 39, $40,44-47,49,219$

Hemistich, 165

Hermann, 45

Hewlett, C. W., 39

Hexachord, 14

Heyse, 56

"History of English Prosody," 178

"History of English Versification," 210 
"History of Prose Rhythm," 201

"History of Sumatra," 36

Holmes, 75

"Hopi Songs," 31

Hofbauer, 129

Hughlings-Jackson, 75

Huhn, Bruno, 156

Hurst, 75, 80, 114, 115

Hylan, J. P., 88, 97

Iamb, 168, 169, 173, 175-177, 197, 204,216

"Impromptu," 135

Ingersoll, R., 204

Instrument, 12, 17

Intensity, 10, 50, 56, Chap. X, 61$64,78,105,124-129,134$, $140,170,172,175,176,179$, 213,217

Intoning, 3

"Introduction to Poetry," 219

"Introduction to the Rhythmic and Metric of the Classical Languages," 72

"Isochronisme dans le vers français," 177

Jacobsthal, 4

James, William, 81, 84

"Japanische Musik," 4, 36

Jastrow, 104

Johnson, Chas. W. L., 14, 15, 174

Johnson, 72, 105

Jones, D., 10

Josselyn, 48

Kafka, 104

Keller, Helen, 74

Key-note, 14

Key-tone, 14
Koenig, Rudolph, 13, 40

Krehbiel, H. E., 4, 26

Külpe, 82

Ladd, 97

"Lake Regions of Central Africa," 36

Land, J. P. N., 18

Lander, Richard, 66

Landry, E., 124

Lange, 72

Language, $3,4,26-28$

Lanier, Sidney, 31, 114, 117

"Latest Travels of I. P.," 36

Law of the Return, 32, 59, 169

"Laws of Tone-color in the English Language," 55,56

"League of the Ho-dé-no-san-nee, or Iroquois," 24,26

"Leitfaden der Akustik," 44

Length, see Duration

"Lieder der Ballakula Indianer," 35

"Limits of Verse Length, The," 188

Lindig, 40

Line, 142, 165-167, 188, 195, 206, 208, 216

Lipps, Theodor, 29, 30, 84

Lipsky, Abram, 201

Livingston, David, 35

Lloyd, M. G., 40, 43, 46, 48

"Loango Expedition," 4, 65

Loudness, see Intensity

"Maassbestimmungen über die Reinheit consonanter Intervalle," 21

Macdougall, Robert, 69, 75, 98, 99, 103, 104, 123, 165

Mach, Ernst, 75, 80, 84 
"Manual of Psychology," 81

Marbe, K., 72, 201

Mares, 116

Marey, 111

Marsden, Wm., 36

Martius, 72, 105

Mayor, J. B., vi, vii

McDougall, Wm., 5

McKay, 75, 114, 115

Measure, 165, 168

"Measurement of Pitch Discrimination," 14

Melodic fragment, 30

Melodic trend, 32

"Melodik und Rhythmik Zueignung Goethes," 34

Melody, 24, 29, 30-35, 59, 141, 175,204

primitive, 31

"Melody of Speaking," 34

Mentz, 75

"Méthode graphique, La," 111

"Methods and Materials of Literary Criticism," 219

Metre, 165

Meumann, Ernst, 72, 75, 82, 83, $84,104,105,123,174,176$

Meyer, Max, 21, 29, 30, 31, 107, $111,128,129,176$

Miller, D. C., 8, 12, 15, 16, 22, 40, $47,50,51,61,62,219$

Miner, J. B., 104, 125

Minor, J., 75

"Missionary Travels and Researches in Southern Africa," 35

Miyake, 114, 129

Mode, major and minor, 20, 36

Modulation, 20

Moodie, John W. D., 36

Moore, H. T., 6, 23
Moore, T. V., 105

Morgan, C. L., 65

Morgan, Lewis H., 24, 26

Moritz, R. E., 190

"Most Fundamental Differentia of Poetry and Prose," 201

"Motor, Visual and Applied Rhythms," 125

Müller, Max, 83

Müller, Robert, 129

Münsterburg, Hugo, 73, 80, 83

Music, 6, 126, 127, 129, 133, 141, $142,146,158,160,162,163$, $167,172,175,181,184$, 186-188, 190, 191, 193, 194, 198, 206, 208, 211-214, 216

Chinese, 14, 36

development of, 36

distinguished from vocal utterance, 65

effects attainable by, 5

Egyptian, 35

Greek, 14, 35

origin of, $26-28,67-69,74$

Persian, 14

time-lengths in, 121 ; see Timelengths and Time

vocal, 4-6

"Music and Emotion," 57

"Music in Relation to the Intellect and the Emotions," 69

"Musical Instruments and their Homes," 24

"Musical Pitch and the Measurement of Intervals among the Ancient Greeks," 14, 15

"Musik des Griechischen Alterthumes, Die," 35

"Musikalische Bildung der Meistersänger," 4 
"Musikalische Gedächtnis bei Katalepsie, im Traum, in der Hypnose," 27

"Narrative of a Voyage to the South Atlantic Ocean," 66

"Native Races of the Pacific States of North America," 35

Negro sermonizing, 4

"New Psychology, The," 72, 105, 129

Noise, 8-10

Notation, musical, 119, 211, 212

Note, length of, 183, 194

"Notes on English Prosody," 10

Nichols, E. L., 21

Nichols, 84

"Observations upon the Windward Coast of Africa," 66

Octave, 14, 15, 17

Ohm, G. S., 15

Ohm's Law of Acoustics, 15, 39

Omond, T. S., 125, 188, 219

Onomatopæia, 53, 55-58

"On the Inheritance of Rhythm," 69

"On the Decrease of Predication and Sentence Weight in English Prose," 190

"On the Difference of Time and Rhythm in Music," 86,87

"On the Origin and Function of Music," 26, 65

"On the Time Sense," 72

"On the Variation and Functional Relation of Certain

Sentence Constants in Standard Literature," 190

Oratory, 3

Organ-pipe, 46
"Outlines of Cosmic Philosophy,' 70

"Outlines of Psychology," 72, 80, 82,123

Overtone, ssee Partial

"Overture to Tannhauser," 89

Pace, 72

Parry, Hubert H., 22

Partial, 16-18, 39, 42, 46, 54, 60

Pater, Walter, 209

Patterson, Wm. M., 202, 206, 220

Pause, 118, 121, 122, 132-134, $137-146,157,158,163-166$, $185,187-189,192,193,208$, 215

Pechuël-Loesche, 4, 65

Pentameter, iambic, 165

Periodicity, 70-72, 90-91, 96, 101, $124,137,141,146,181,185$, $186,188,191,192,200$

Pfeiffer, Ida Laura, 36

Phase, 39, 40, 107

"Philosophy of the Human Voice," 34

"Photographische Untersuchungen," 45

Phrase, 120, 121, 133, 144-146, 149-159, 162, 163, 166, 181, 187, 188, 190-194, 197, 198, $200,205,207,215,216$

"Physiologischen Grundlagen der neuhochdeutschen Verskunst, Die," 115, 128

"Physiologische Psychologie," 80 Pierce, 75

Pipping, 45

Pitch, 10, 12-14, 29, 35, 37, 41, $56,60,61,64,78,90,106$, 123-126, 134, 171, 180, 187, 204, 205, 213 
Poe, E. A., 55, 166

Poetry, see Verse

Poetry, tonal theory, 54

"Power of Sound," 72

Present, specious, 81

Price, Thomas R., 158, 159

"Primer of Phonetics," 107

"Primer of Psychology," 72

"Primitive Music," 4, 23, 25, 59, 67,219

"Principles of Psychology," 81

Proportion, theory of simple, 110, 119,120

Prose, 3, 4, 6, 67, 68, 74, 120, 126, $127,129,130,133,134$, 141-143, 146, 158, 160, 161, $165,167,176,184,188,190$, 191, 193, 199-209, 213, $214,216,217$

"Prose Rhythm in English," 201

Prosody, prosodic problem, v-ix Psychic compound, 85

"Psychologie der Zeitauffasung," 71, 104, 178

"Psychologisches Studien," 29

"Psychology: Descriptive and Explanatory," 97

"Psychology of Time," 84

"Psycho-physiological Effect of the Elements of Speech in Relation to Poetry," 54-56, 59,173

Punctuation, 167

Pyrrhic foot, 136, 138, 140

Quality, see Tone-color and Vowel quality

"Quantitative Study of Rhythm," $105,114,116,129,168,170$, $171,174,176,179$
Quantity, 110

"Quelques Expériences d'Acoustique," 40

Ratzel, Friedrich, 36

Rayleigh, Lord, 47, 219

Raymond, George L., 74

Reading, psychological process, 1-3

"Recherches sur l'histoire de la Gamme Arabe," 18

Recitative, 4

"Records of Captain Clapperton's Last Expedition to Africa," 66

Relationship, 22, 30, 32-34

"Researches in Experimental Phonetics," 46, 48, 125, 128

"Researches in Practice and Habit," 72, 105

"Researches on Rhythmic Action," 127

"Researches on the Rhythm of Speech," 72, 73, 99, 100, $104,105,107,110,121,126$, $127,135,177,181$

Resolution, 34

Resonance chamber, 12, 41

Resonator, 12, 41

Return, law of the, $32,59,161$

Révész, Geza, 23

Rhyme, 59, 143, 160-167, 188, 214,215

"Rhythm," 71, 125, 176

Rhythm, 24, 34, 35, 53, 59, 64, $67-73,75-77,86-89,90$, 92-101, 120, 123, 139, 157, 169-173, 179, 180, 184-192, 194, 197-211, 214-217, 219

"Rhythm and Harmony in Poetry and Music," 74 
"Rhythm and Rhyme," 114, 145, $155,157,158,162-164,173$, $176,186,188,194,196-198$

"Rhythm as a Distinguishing Characteristic of Prose Style," 201

Rhythmic sense, 73

"Rhythmische-melodische Studien," 203

"Rhythm of Prose," 202, 203, 206,220

Ribot, 75

Roblee, Louise, 56

"Rôle of Kinæsthetics in the Perception of Rhythm," 3, 88,220

"Rôle of Pitch in Rhythm," 126, 164, 171

Rousselot, 111

Ruckmich, C. A., 3, 88, 220

Rush, Dr., 34

Ruskin, John, 204

Saintsbury, George, 117, 138, 178, 201

Saran, F., 34, 124, 210

Sargent, 55

Scale, 214

diatonic, 19, 22

origin of, 24-26

pure, 15

tempered, 15, 19

Scansion, 138, 198, 204, 210-212, 216

"Scansion of Prose Rhythm," 201

Schmidt, 72

Schubert, Franz, 155

Schumann, F., 82, 105

"Schwankungen der Gesichtsempfindungen, Die," 72

"Science of English Verse," 31
"Science of Musical Sounds," 8, $12,16,22,40,47,49-51,61$, 219

Scott, F. N., 10, 201

Scott and Gayley, 219

Scott, John R., 34

Scripture, E. W., 45-48, 72, 75, $105,125,126,128,129$, $155,158,186$

Sears, 172

Seashore, C. E., 14

Second, 18, 23

"Sensations of Tone," 23, 39, 44, 219

Seventh, 18, 23

Shakespeare, Wm., 166

Shaw and Wrinch, 75, 82-85, 123, 172,174

Sherman, L. A., 190

Sherrington, 75

Shipper, 210

Sievers, 72, 75, 203

Silence, 103-105, 108, 120, 121, $183,184,186,191,213-215$, 217

Sixth, 18

Smith, 72, 75, 83, 105

"Social Psychology," 5

"Some Observations upon the Sentence-length in English Prose," 190

"Some Results of Modern Ethnology," 3, 67

Song,

bird, 24

origin of, 26

Sonnet, 190

Sound, 77, 103, 104, 106-108, 183, $186,191,213,214$ æsthetic value of, 5 medium of communication, 3 
musical, 8

of subdivision, 15

physiological effect of, 5

psychological effect of, 5,6

"Sound and Music," 22, 41, 219

Speech,

development of, $27,28,36$

sounds, 107

"Speech in Song," 53

"Speech Sounds: Their Nature and Causation," 49

Spencer, Herbert, 26, 65

"Spencerian stanza, 190

"Spencer's Lehre von dem Unerkennbaren," 84

Spondee, 135, 136, 140

Squire, 103, 164, 171

Stainer, Sir John, 69

Stanza, 142, 189, 190

Stave, 158

Stetson, R. H., 114, 128, 145, 155, $157,158,162-164,173,175$, $176,186,188,196-198$

Stevens, 72, 174

Storm, 47

Stout, G. F., 81

Street cries, 3

Stress, see Accent suspended or deferred, 138

"Strueture of Simple Rhythm Forms," 69, 98, 99, 105

"Studies from Yale Psychological Laboratory," 114

"Studies in Melody," 18, 29, 30-34

"Studies in Rhythm," 104

"Study in Reaction Time and Movement," 105

"Study of Metre, A," 125

Stumpf, Carl, 21, 35, 75

Substitution, 178

Sweet, 47, 107
Swindle, P. F., 69

Syllable, accent, 137

in phrase, 144, 200

in prose and verse, 184

length, $110,116,118,120$, $122,126,180,186,217$

nonsense, 196

relation of, 194-197, 200, 214

strong, 116, 215, 216

weak, 116

Symes, Michael, 36

Sympathetic induction of emotion, 58, 60, 63, 69

Syncopation, 203-207, 210

Syncope, 203

"System der Sprachwissenschaft," 56

"Technique of the Speaking Voice," 34

Tempo, 34, 90, 91, 175

Tension, 144

"Ten Years in South Africa," 36

Tetrachord, 14

"Text-book of Sound," 40

"Théorie du rhythme et le rhythme du français déclamé, La," 124

"Theory of Poetry in England," 219

"Theory of Sound," 47, 219

Third, 17, 18, 31, 32

Tichener, 72

Time, 34, 75-78, 80, 82, 84-89, 91-93, 95, 99-101, 106, 178-180, 195, 204, 205, 207, 215,217

"Time in English Verse Rhythm," 105, 107, 111, 129, 195, 199, 209 
Time-interval, $86,115,123,186$, $193,194,203$

Time-length, 117-119, 121, 124, 12s, 132-134, 158, 163, 181, $185,186,191,194,212,214$, 215

Timer, 204-206, 209

Time-sense, 83, 96-88

Time, unit of, $82-84,97$

Tolman, 55, 56

Tonality, 32,37

Tone, $8-10,15$

portamento, 13

relation of, 22

Tone-color, 10, 34, 38, 41, 59, $78,105,106,122,124,126$, $160,161,191,204-206,213$, $214,216,217$

Tone-quality, $38,52,53,64$

Tonic, 18, 22, 23, 32, 36

Transcience, immediate experience of, 80,81

"Traváni hlásek a slabik dle objectivné miry," 116

Triad, major, 22

Trochee, 158, 168-173, 175-177, 197, 204

Tune, speech, 31, 204, 207

"Uber das Ansteigen der Tonerregnung," 104

"Uber die Bedeutung der Aphasie für den musikalischen Ausdruck," 27

"Über die Musik der Nordamerikanischen Wilden," 4 , $24,26,35$

"Über d. Rhythmus d. Prosa," 201

"Une nouvelle Laura Bridgman," 74
Unit of Time, 82, 83, 91, 97

"Unscientific Methods in Musical Estheties," 29

"Untersuchungen über den Umfang des Bewusstseins," 72

"Untersuchungen zur Psychologie und Aesthetik des Rhythmus," 72, 176

Vance, T. F., 14

Vannah, Kate, 135

"Variations in Pitch Discrimination," 176

"Variations temporelles du rhythm, Les," 118

Verrier, Paul, 29, 53, 56, 67, 73, $100,116,117,118,130,133$

Vers libre, 202, 205-207, 209

Verse, $3,6,120,126,127,129,130$, $133,138,141,142,143$, $146,158,160-162,164,165$, $167,177,178,183,185-191$, 193, 198-202, 204-216 accent theory, 63, 100, 117 blank, 166 classical theory, 117 defined, 217 fixed-pitch theory, 44, 46 musical theory, 117 origin of, $66-68,74$

"Verse and Prose," 201

Vibration, 8

Viderot, 174

Viëtor, L., 10

Vocal cords, 12, 13

"Völkerkunde," 36

Vowel, 161, 215 accommodation theory, 45 characterized by, 44, 46-49, 51 defined, 52,53 fixed-pitch theory, 44, 46 
fixed-resonance theory, 45,47 49,50

high, 59, 60, 214

length, 42, 52-54, 107, 112, $116,124,134,215$

long, 54, 116, 214

low, $59,60,214$

medium, 60

pitch, 5,59

produced how, 46

quality or color, 42, 43, 59-61

relative-pitch theory, 46

short, 54, 116, 214

theories of, 44,117

"Vowel Alliteration in Modern Poetry," 10

Wagner, R., 58, 89

Walker, John, 34

Wallaschek, R., 4, 23, 25-28, 59, 67-69, 86-88, 219

Wallin, J. E. Wallace, 72, 73, $99,100,104,105,107,109$, $116,117,120,121,126,127$, $133,135-137,146,157$, $174,175,177,179-181,186$

Washburn, M. F., 56

Webster, A. G., 62

Weinmann, Fritz, 29, 30

"Weitere Untersuchungen ü.d. Wesen der Vocale," 45
Weld, H. P., 3, 5, 57, 71, 146, 220

Westphal, Rudolph, 35

Wheatstone, Sir Charles, 44, 45

Whitman, Walt, 209

Wilkinson, Sir John G., 35

Willis, 43-45

Winkelman, 40, 62, 218

Winter, D., 201

Wrinch, and Shaw, 75, 82-85, 123, 172,174

Woodrow, H., 105, 116, 126, 127, $129,164,168,171,174-176$, 179

Woodworth, R. S., 101, 105

Wundt, Wilhelm, 75, 80, 82, 123, $174,203,209$

Young, 138, 165

Zahm, 22, 41, 219

"Zur Frage der Schwankungen der Aufmerksamkeit," 72

"Zur Grundlegung der Tonpsychologie," 23

"Zur Klangfarbe der gesungenen Vocale," 45

"Zur Lehre von den Vokalklängen" 45

"Zur Struktur der Melodie," 29

"Zur Theorie der Melodie," 29 



\section{COLUMBIA UNIVERSITY PRESS}

Columbia University in the City of New York

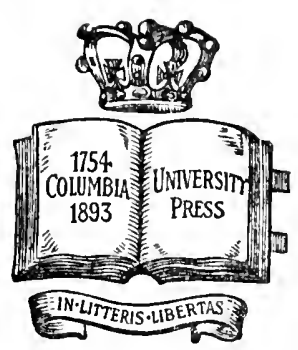

The Press was incorporated June 8, 1893, to promote the publication of the results of original research. It is a private corporation, related directly to Columbia University by the provisions that its Trustees shall be officers of the University and that the President of Columbia University shall be President of the Press.

The publications of the Columbia University Press include works on Biography, History, Economics, Education, Philosophy, Linguistics, and Literature, and the following series:

Columbia University Contributions to Anthropology.

Columbia University Biological Series.

Columbia University Studies in Cancer and Allied Subjects.

Columbia University Studies in Classical Philology.

Columbia University Studies in Comparative Literature.

Columbia University Studies in English.

Columbia University Geological Series.

Columbia University Germanic Studies.

Columbia University Indo-Iranian Series.

Columbia University Contributions to Oriental History and Philology.

Columbia University Oriental Studies.

Columbia University Studies in Romance Philology and Literature.

Records of Civilization: Sources and Studies.

Adams Lectures.

Julius Beer Lectures.

Blumenthal Lectures.
Carpentier Lectures.

Hewitt Lectures.

Jesup Lectures.

Catalogues will be sent free on application.

\section{LEMCKE \& BUECHNER, Agents 30-32 WEST 27th ST., NEW YORK}



. 

THE LIBRARY

UNIVERSITY OF CALIFORNIA

Santa Barbara

THIS BOOK IS DUE ON THE LAST DATE STAMPED BELOW.

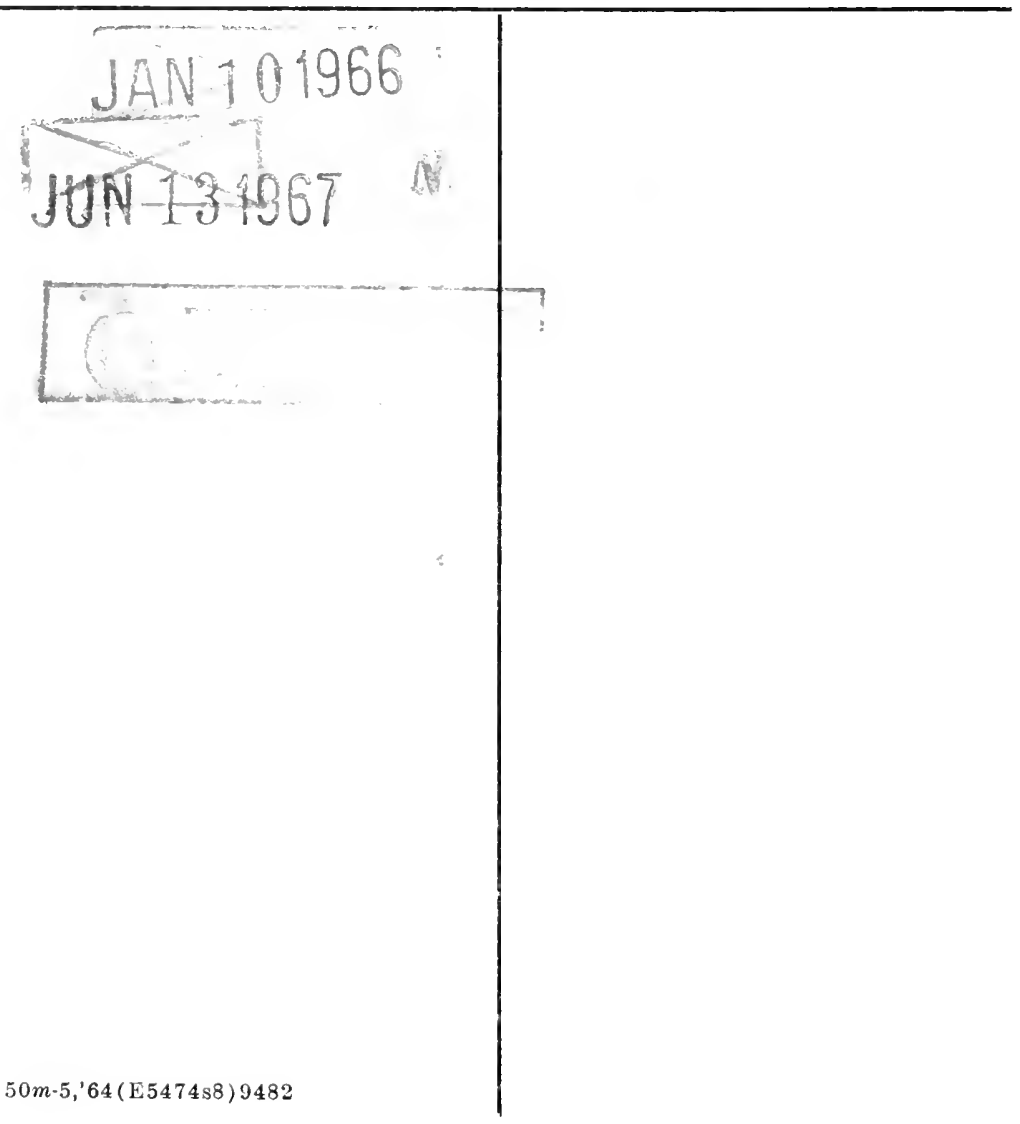




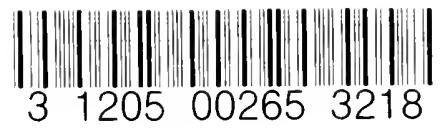

UC SOUTHERN REGIONAL LIBRARY FACILITY

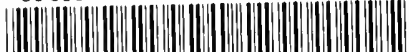

AA 0010648129 
